


\section{Academica Turistica}

Tourism \& Innovation Journal - Revija za turizem in inovativnost

YeAR 13, No. 2, DECEMBER 2O2O, ISSN 2335-4194

https://doi.org/10.26493/2335-4194.13_2

127 Virtual Reality in Tourism: Is it 'Real' Enough?

Marion Rauscher, Andreas Humpe, and Lars Brehm

139 The Effects of Destination Image on Tourist Satisfaction: The Case of Don-Wai

Floating Market in Nakhon Pathom, Thailand

Napaporn Janchai, Glenn Baxter, and Panarat Srisaeng

153 Is International Tourism Growth Supported by Increased Tourism Receipts?

Helena Nemec Rudež

157 Pillars of City Spatial Sensitivity and Their Integration into Sightseeing Routes

Melita Rozman Cafuta and Boštjan Brumen

167 Spiritual Intelligence and Business Environments

\section{Fadil Mušinović}

179 Professional and Organisational Commitment in the Hospitality Sector Marjetka Rangus, Srđan Milošević, Iva Škrbić, Bojana Radenković-Šošić,

Jože Hočevar, and Mladen Knežević

193 Utilization Analysis of Slovenian Hotel Websites

Mitja Petelin and Dejan Križaj

201 Travel Motivations as Criteria in the Wellness Tourism Market Segmentation Process Ana Težak Damijanić

215 Service Quality Measurement in Rural Tourism: Application of RURALQUAL Model Suzana Marković and Jelena Kljaić Šebrek

229 Abstracts in Slovene - Povzetki v slovenščini

235 Instructions for Authors

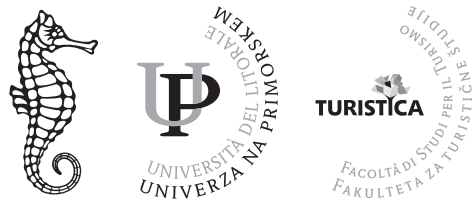

UNIVERSITY OF PRIMORSKA PRESS 
Executive Editor Marijana Sikošek

Editor-in-Chief Gorazd Sedmak

Associate Editors Metod Šuligoj, Emil Juvan, Helena Nemec Rudež, and Mitja Gorenak

Technical Editors Mariana Rodela and Peter Kopić

Production Editor Alen Ježovnik

\section{Editorial Board}

Tanja Armenski, University of Novi Sad, Serbia

Rodolfo Baggio, University di Bocconi, Italy

Štefan Bojnec, University of Primorska, Slovenia

Dimitrios Buhalis, Bournemouth University, UK

Alan Clarke, Pannonian University, Hungary

Frederic Dimanche, Ryerson University, Canada

Jesse Dixon, San Diego State University, us A

Johan Edelheim, Hokkaido University, Japan

Felicite Fairer-Wessels, University of Pretoria,

South Africa

Doris Gomezelj Omerzel, University of Primorska, Slovenia

Sotiris Hji-Avgoustis, Ball State University, USA

Jafar Jafari, University of Wisconsin-Stout, USA,

University of Algarve, Portugal

Sandra Jankovič, University of Rijeka, Croatia

Anna Karlsdóttir, University of Iceland, Iceland

Maja Konečnik Ruzzier, University of Ljubljana, Slovenia

Sonja Sibila Lebe, University of Maribor, Slovenia

Mara Manente, Cà Foscari University of Venice, Italy

Yoel Mansfeld, University of Haifa, Israel

Tanja Mihalič, University of Ljubljana, Slovenia

Matjaž Mulej, University of Maribor, Slovenia

Milena Peršič, University of Rijeka, Croatia

Jasna Potočnik Topler, University of Maribor, Slovenia

Caroline Ritchie, University of Welsh Institute, UK

Vinod Sasidharan, San Diego State University, USA

Regina Schlüter, National University of Quilmes, Argentina

Marianna Sigala, University of the Aegean, Greece

Cristina Roxana Tănăsescu, Lucian Blaga University,

Romania

Andreja Trdina, University of Maribor, Slovenia

John K. Walton, Ikerbasque, Instituto Valentín de

Foronda, University of the Basque Country, Spain
Suosheng Wang, Indiana University-Purdue

University Indianapolis, USA

Indexed in Scopus, Erih Plus, С А В Abstracts, CIRET, EBSCO, and EconPapers.

Published by University of Primorska Press

University of Primorska

Titov trg 4, SI-60oo Koper

E-mail: zalozba@upr.si

Web: http://www.hippocampus.si

Editorial Office Academica Turistica

Faculty of Tourism Studies - Turistica

Obala 11a, SI-6320 Portorož, Slovenia

E-mail: academica@turistica.si

Web: http://academica.turistica.si

Subscriptions The journal is distributed free of charge. For information about postage and packaging prices, please contact us at academica@turistica.si.

Copy Editor Terry Troy Jackson and Susan Cook Cover Design Mateja Oblak

Cover Photo Alen Ježovnik

Printed in Slovenia by Grafika 3000, Dob

Print Run 100 copies

Academica Turistica - Revija za turizem in inovativnost je znanstvena revija, namenjena mednarodni znanstveni in strokovni javnosti; izhaja $v$ angleščini s povzetki $v$ slovenščini. Izid publikacije je finančno podprla Agencija za raziskovalno dejavnost Republike Slovenije iz sredstev državnega proračuna iz naslova razpisa za sofinanciranje domačih znanstvenih periodičnih publikacij.

ISSN $1855-3303$ (printed)

ISSN 2335-4194 (online)

\section{(cc) BY-SA}




\title{
Virtual Reality in Tourism: Is it 'Real' Enough?
}

\author{
Marion Rauscher \\ Munich University of Applied Sciences, Germany \\ marion.rauscher@hm.edu \\ Andreas Humpe \\ Munich University of Applied Sciences, Germany \\ andreas.humpe@hm.edu

\section{Lars Brehm} \\ Munich University of Applied Sciences, Germany \\ lars.brehm@hm.edu
}

Virtual Reality Technology is increasingly becoming popular in the tourism sector. So far, the most researched application is the marketing of destinations. In contrast, the technology has also been mentioned as a means to limit or reduce the number of tourists at a specific sight or destination. In this respect VR is considered as a substitute for the actual trip. This paper addresses this issue by looking at the possibility to apply VR-technology to transfer the real-life experience into the digital world. In a qualitative research framework, visitor behaviour and experience are investigated when encountering V R sights in order to better understand items driving technology adoption. Structured content analysis is applied for data analysis where coding follows an adjusted Unified Theory of Acceptance and Use of Technology model. For interpretation purposes a pure qualitative framework was chosen. We find that enjoyment is an important driver for VR technology acceptance, whereas facilitating conditions and outcome expectations seem to be obstacles for it. Perceived usefulness is evaluated controversially. While the technology is not acknowledged as a substitute for a regular holiday trip, especially for travellers who take pleasure in active holidays or appreciate social interaction, it was recognised as an alternative for special occasions such as brief getaways from everyday life or short city trips. Overall, when appropriately implemented the technology might not only be useful to decrease visitor concentration in touristic hotspots or to decrease negative aspects associated with frequent travel but could further be applied to sites where visitors do not engage physically because sites are too distant, expensive, inhospitable, unsafe or fragile.

Keywords: virtual reality, tourism, travel substitute, technology adoption, U TAU T

(cc)BY-SA https://doi.org/10.26493/2335-4194.13.127-138

\section{Introduction}

Although virtual reality (vR) technology and research thereof has been around for more than 20 years, it has recently seen a renewed upsurge in academic inter- est due to advancements in technology (Williams \& Hobson, 1995). The most commonly used definition of Guttentag (2010, p. 638) describes the term 'virtual reality' as 'the use of computer-generated $3 \mathrm{D}$ environ- 
ment $[\ldots]$ that one can navigate and possibly interact with, resulting in a real-time simulation of one or more of the user's five senses.' Whereas the ability to move around and explore the virtual environment is labelled as a compulsory requirement, interaction is only facultative. According to this definition it is not straightforward to determine whether $360^{\circ}$ videos or even augmented reality (AR) is part of VR or not. While both applications represent, for the most part, a mere passive consumption, some navigation or limited interaction might nevertheless be possible. Apparently, lines are blurred and opinions differ in this regard. In fact, academia has been arguing about whether navigation is an optional component of VR or not (Yung \& KhooLattimore, 2019).

For the purpose of this paper, we follow the more flexible point of view (Gibson \& O'Rawe, 2018; Wiltshier \& Clarke, 2017) and consider VR as a computergenerated 3D environment where navigation and interaction are optional.

Irrespective of the technology or device used to create a VR experience, two main factors are necessary. The first one is physical immersion and the second one psychological presence (Disztinger et al., 2017; Tussyadiah et al., 2018). The more the v R user is detached from the real world the more physically immersed he is. In light of this and the elaborated definition, on the one end of the VR spectrum there are semi-immersive virtual environments where the user is still in contact with the reality around him such as $360^{\circ}$ videos followed by AR experiences. The other end of the spectrum is determined by fully immersive environments created, for example, by Head Mounted Display (HMD) devices, maybe accompanied by headphones and gloves or other supporting tools to create virtual tactile sensations. When smell or further haptic stimuli are added the sensation of immersion increases even more (Gutiérrez et al., 2008). Psychological presence is the subjective feeling of the user of physically being in the virtual environment rather than in the place where the body is located. This follows Wirth et al.s (2007) definition of spatial presence. An individual might reach a high psychological presence even in a physical semi-immersive environment while another may not. It has been found, though, that both concepts are somewhat related. Highly physical immersive technologies may lead to a high level of psychological presence. A lack of high immersion, on the other hand, does not necessarily lead to a low feeling of psychological presence. Subjective internal processes of an individual may indeed compensate for lacking external stimuli (Ijsselsteijn \& Riva, 2003).

Empirical analyses of V R applications in tourism are a fairly new research area. Since technological progress has only recently led to an acceptable level, such studies have not been on the rise until the last few years. Nevertheless, empirical research on the adoption of V R technology in a tourism context is still limited (tom Dieck et al., 2018). This acknowledges Hine's (2000) demand for more empirical research of user experience rather than mere prophecies of groundbreaking V R applications in tourism. Yung and KhooLattimore (2019) even observe that among those analyses that exist, many are still not based on theoretical concepts or frameworks which verifies Huang et al.s (2016) assessment, that more substantive and theorybased research on VR and its application is necessary.

This paper contributes to reducing this void by analysing V R user acceptance based on a qualitative empirical research approach. More precisely, participants in two semi-immersive VR tourism experiences in a CAVE Automated Virtual Environment were observed and questioned based on the Unified Theory of Acceptance and Use of Technology (UtAut). The aim is to better understand determinants for acceptance and adoption willingness of V R technology as a substitute for a real trip.

\section{VR Applications in Tourism}

Applications of VR in tourism have been discussed in various contexts. Suggested areas of use range from a planning and management instrument to better assess tourists' desires and needs through an entertainment tool, deployed for example within a theme park, to a means for educational purposes, for instance in a museum or at a historical site (Guttentag, 2010). The most frequently researched area is, however, the use of V R as a promotional tool. Several papers have already descriptively highlighted the marketing potential of the 
technology (Williams \& Hobson, 1995; Cheong, 1995; Williams, 2006; Guttentag, 2010; Griffin et al., 2017). The hypothesis has been tested empirically within diverse research settings. For example, one of the earlier studies questioned test persons after showing them $360^{\circ}$ videos steerable by a regular PC mouse (Lee \& Oh, 2007). Pantano and Servidio (2011) used what they called a pervasive environment which was represented by stereoscopic technology creating a $3 \mathrm{D}$ image on a screen. Both studies confirm the assumption that VR provides an efficient marketing tool for destinations. The reason is mainly attributable to the fact that $\mathrm{VR}$ can help reduce uncertainty associated with buying a touristic product. The 'try-before-you-buy' option helps the traveller to get a more realistic experience of what to expect. This way it can reduce travel anxiety (Lee \& Oh, 2007) or increase motivation to visit places that were somewhat unfamiliar to the individual (Pantano \& Servidio, 2011).

Empirical v r research in tourism gained ground with the introduction of so-called virtual worlds. The most prominent example is Second Life from Linden Lab. In this Internet-based 3D infrastructure users are able to develop and design the virtual environment and interact with each other via avatars. Related research focused on the question whether the virtual visit and associated interaction possibilities would positively contribute to destination marketing efforts (Guillet \& Penfold, 2013; Huang et al., 2012; Huang et al. 2013; Huang et al., 2016; Mascho \& Singh, 2013). The studies generally confirm the hypothesis, finding that users develop positive feelings and increased awareness towards the respective destination. This is in line with later analyses in alternate research settings. For example, Tussyadiah et al. (2018) conclude that the feeling of being in a virtual environment creates a positive sensation for the potential tourist, which leads to a stronger preference for the destination and ultimately a higher likelihood of visiting it. McFee et al. (2019) compare $360^{\circ}$ video information with a more immersive VR experience and find that involvement is a key aspect in image formation. Therefore, information transmission via immersive VR should be preferred over $360^{\circ}$ videos since it leads to a positive destination image which increases visit intention. Gibson and O'Rawe (2018) also observe a higher likelihood of visiting the 'real' destination after experiencing it in a virtual environment. Tussyadiah et al. (2017) measure spatial presence which was found to have a positive effect on post-VR attitude change toward the tourism destination.

All of the aforementioned studies centre on the question whether VR can help to create awareness of a destination and ultimately increase visitor numbers. Yet, the opposite objective can also be of interest. It might, for example, be sensible to restrict the number of visitors at vulnerable natural or cultural spots such as heavily visited heritage sites. Dewailly (1999) adopts the specific perspective of sustainability in this context. To put it in a broader perspective, VR might be a beneficial instrument to tackle problems associated with the current overtourism debate. The general idea behind it is, that by means of a virtual visit the site is still accessible to everybody while at the same time, the environment is not harmed. This rationale holds for all destinations that might be too distant, inhospitable or unsafe. It also holds for travellers themselves who might be unable to visit a destination (Guttentag, 2010). Hence, v r can serve as a substitute for the actual trip (Cheong, 1995; Sussmann \& Vanhegan, 2000) rather than a motivational factor for it. Wiltshier and Clarke (2017) point out the opportunities of virtual cultural tourism but also address some challenges for the future. The present study takes on this viewpoint as well and explores the necessary prerequisites for the tourist to accept a technology solution over a physical travel experience.

When investigating VR acceptance the sense of presence plays an important role (Slater et al., 1994; Hyun \& O’Keefe, 2012; Tussyadiah et al., 2018). Although not placed within a VR environment, empirical researches (Klein, 2003; Jacob et al., 2010) highlight the importance of media richness, i.e. number and quality of sensory stimuli, as well as interaction possibility on the attitude towards and acceptance of an envisioned product. VR-related studies support this outcome by confirming that a high level of presence can be achieved by addressing multiple senses (Dinh et al., 1999; Feng et al., 2016; Rodrigues Martins et al., 2017). Apart from the user's sensations, the 
aforementioned interaction possibility requires further thought. Guttentag (2010) argues that acceptance of the VR tourism substitute is influenced by the individual's perception of authenticity as well as travelling motivations. While the technology is able to closely reconstruct objects and sites, social interaction is restrained. However, an individual's motivation to travel to a specific destination can be a friends or family visit regardless of the touristic surroundings. Furthermore, many tourists like to meet and exchange with locals and delve into their lifestyle to experience authenticity. Even the trip itself is oftentimes perceived as a social occasion. People usually do not travel alone and individuals who do, enjoy the company of others. Those social interactions can influence the tourism experience as much as the destination itself. Thus, each tourist becomes a co-creator of value. This does not only apply to the producer-consumer relationship such that the consumer enhances or degrades the value provided by the tourism producer (Binkhorst \& Den Dekker, 2009; Grissemann \& Stokburger-Sauer, 2012). It also holds for the consumer-consumer relation, since travellers influence each other in their tourism experience (Rihova et al., 2015). Integrating a social element is therefore vital when investigating a VR tourism experience, even though the technology can only provide for this aspect to a limited extent at the current stage.

\section{Methodology}

\section{Research Design}

The present study deals with visitors to two VR tourism sites who were observed and later questioned with regard to their experiences and assessments. Participants in the researched group were 16 University students of a Tourism Management programme. All of them had already encountered full or semi-immersive virtual environments using VR HMD devices. For the purpose of this study they were sent into a CAVE Automatic Virtual Environment (Cruz-Neira et al., 1992) 3 metres in diameter. Shutter glasses had to be put on in order to create the $3 \mathrm{D}$ image but no VR HMD was necessary. Although this implies a lower physical immersion this semi-immersive research framework, similar to the one used by Pantano and Servidio (2011), was chosen in order to provide for a more interactive and social environment. More precisely, participants were sent into the CAVE in groups of 5-6 people, simulating a travelling group. As pointed out earlier, individuals may nevertheless develop feelings of psychological presence. The spatial area left room for motion in every direction enabling the group to change positions in order to show things to and talk with each other.

In the CAVE they were shown two different settings. The first one was a 3D reconstruction of Christ the Redeemer on Corcovado with a view down to Rio de Janeiro, Brazil. The participants were able to change perspective as well as zoom in and out of the picture with a handheld controller. This way involvement and interaction was intensified, which may also increase psychological presence for some individuals (Wirth et al., 2007). The second setting was a guided tour through the Syrian ruined city of Palmyra, a digital $360^{\circ}$ movie initiated by the TV station ZDF/Terra X and the Prussian Cultural Heritage Foundation showing the reconstructed site.

As Guttentag (2010) elaborates, the acceptance of VR as a substitute for the real destination is subjective. Not only is the tourist's individual perception of the substitute's authenticity of importance but also his or her travel motivations and constraints. It is therefore central to profoundly understand and question the VR user's behaviour, perception and sensation on an individual basis. In light of this, and due to the exploratory character of the research, a non-participative observation research framework of the groups in the CAVE was chosen as a first step. Two researchers were deployed to get a better view and align observations in order to limit observation errors. Results were subsequently backed and further elaborated. One week after the visit, semi-structured interviews took place with each participant, questioning them regarding their general travel motivations, their virtual travel experience and their technology adoption appraisal. Contrary to Sussmann and Vanhegan (2000), by actually sending sample groups into the $\mathrm{CAVE}$, individuals were able to more precisely verbalise their experience rather than answering what they think it would feel like. 


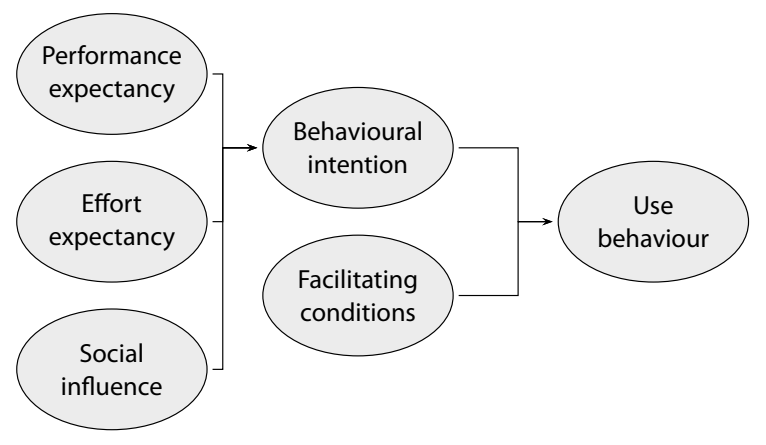

Figure 1 U TAU T Model (adapted from Venkatesh et al., 2003)

\section{Theoretical Background}

The Unified Theory of Acceptance and Use of Technology (UTAUT) model (Venkatesh et al., 2003) provided the underlying theoretical basis for observations and semi-structured interviews. UTAUT is an empirically validated evolution of the Technology Acceptance Model (там). там was introduced by Davis (1989) and applied in several tourism-related V R studies, partly with minor adaptions (Disztinger et al., 2017; Huang et al., 2016, 2013; Mascho \& Singh, 2013). UTAUT applications are not as widespread as some to be found in the VR-related segment of Augmented Reality. For example, Hein et al. (2018) investigate consumer assessment of opportunities and threats of smart glasses for society. Targeted towards the tourism industry is Paulo et al's (2018) research of influencing factors of mobile AR adoption in tourism. A specific case is studied by Kourouthanassis et al. (2015) who test a mobile A R travel guide in Corfu, Greece.

Variables impacting technology adoption according to UTAU T are performance expectancy, effort expectancy, social influence and facilitating conditions. The first three drive the intention to use the respective technology. Behavioural intention in turn, together with facilitating conditions, motivate technology use.

Additionally, U TAU T postulates that constructs are moderated by individual differences, i.e. gender, age and experience, as well as by the voluntariness to use the technology.

In the present research we adopted UTAUT categories to formulate and evaluate interview questions and observations. A few adjustments in accordance with the literature reviewed were made to fit the needs of the specific setting. First, Venkatesh et al.s (2003) study was tailored to the business environment as opposed to the present analysis. The item 'job-fit' was therefore omitted to describe performance expectancy. However, a more hedonic-related item was included to define performance expectancy in order to represent the interactive and social nature of the technology (tom Dieck et al., 2018). More specifically, the item 'perceived enjoyment' was supplemented similar to Disztinger et al. (2017), who follow Holsapple and Wu's (2007) proposition that VR is a hedonic rather than a utilitarian technology. Within the construct effort expectancy the item 'perceived ease of use' and 'ease of use' are very similar (Davis, 1989; Moore \& Benbasat, 1991; Venkatesh et al., 2003) and it is criticised that statements are therefore not clearly allocable to either one. Additionally, participants were not questioned a second time after applying the technology several times. Therefore, it was unlikely that they were able to clearly assess ease of use. In order to avoid distortions and ambiguities, both items were grouped together to 'perceived ease of use.' The item 'social factors' in the original UTAUT model refers to co-workers and supervisors who use the system, as well as to organisational support given to the individual. Again, this is not applicable for the present analysis. Consequently, the item was excluded. To sum up, constructs and tantamount items used are shown in Table 1 with respective anchoring statements from the interviews.

Due to the small sample size we did not control for gender. Neither was age and experience accounted for since all of the participants were in the same age group and had the same prior V R experience. Lastly, the purpose of the technology employment is solely for leisure activities and participation in the study was free of choice for the sample group. Therefore, voluntariness of use was also not applicable in the present setting.

Structured content analysis (Mayring, 2014) was used to analyse and interpret data obtained by the observations and interviews. Coding followed the previously described adjusted U TAU T constructs and items. 
Table 1 Adjusted Constructs and Anchoring Statements

\begin{tabular}{lll}
\hline Construct & Item & Anchoring Statement \\
\hline Performance expectancy & Perceived usefulness & I had read before, that it's an application to rebuild historical sites \\
& Extrinsic motivation & When I start my travel plans, there is some outside influence \\
& Relative advantage & A lot of things are missing - activities. This is why I travel \\
& Outcome Expectations & I am looking for recuperation. To be away from everyday life \\
& Enjoyment & I thought it was cool \\
\hline Effort expectancy & Perceived ease of use & I would say, using the controller seemed to be relatively easy \\
& Complexity & It wasn't complex, it was easy to operate \\
\hline Social influence & Social norm & I don't travel alone, but together with a friend or in a small group \\
& Image & Social Media is relevant for me when choosing a destination \\
\hline Facilitating conditions & Facilitating conditions & I didn't find it too impressive from a technical point of view \\
& Compatibility & I don't think it can be a substitute for real travel experiences \\
\hline
\end{tabular}

Table 2 Frequencies of Codings

\begin{tabular}{ll}
\hline Outcome expectations & 142 \\
Perceived usefulness & 80 \\
Relative advantage & 46 \\
Enjoyment & 52 \\
Extrinsic motivation & 31 \\
Perceived ease of use & 42 \\
Complexity & 12 \\
Social norm & 57 \\
Image & 2 \\
Facilitating conditions & 108 \\
Compatibility & 29 \\
\hline
\end{tabular}

The intention with this approach is not to measure impact on behavioural intention and use behaviour on a quantitative scale as this requires a large sample survey methodology. Rather, the aim is to get a deeper understanding of the relevant input parameters affecting technology acceptance and adoption in the outlined travel context.

\section{Results}

Frequencies of coded observation results and interviews are displayed in Table 2.

Within the construct performance expectancy, outcome expectations and perceived usefulness seem to be important elements for the participants. It was found that the assessment of outcome expectations strongly depends on the travel motive of the individual interviewee. While travellers with motives such as hiking, kite-surfing or two-week relax holidays were less likely to imagine $\mathrm{vR}$ travel as a substitute at the current stage, those with motives like short-term city breaks or sightseeing tours considered it more positively. Further investigations revealed that the first set of motives are linked to certain feelings, emotions and the search for authenticity in terms of getting into contact with the local community, which cannot properly be transported via VR. For example, one person primarily looking for recovery from a demanding working life mentioned: 'I actually want to feel emotions. [...] Simply, that it was a good time.' Another one pointed out that the feeling of actually being on Corcovado is different because 'you have gone or driven up. You've already taken the path. You know "ok I'm here" and have a certain feeling. I didn't get this feeling in the cave.' Regarding the search for authentic encounters with locals, one interviewee expressed: 'So if it is really about travelling and not about city trips, then the people and their hospitality are always the most important thing.' More generally, it was added that only authentic experiences are able to create a positive attitude in the tourist, which he or she can live off in the weeks and months to come. Even though the reasoning of many 
participants went in this direction, there were some exceptions, which imply a higher psychological presence: 'Nevertheless, I felt like I am walking through it [Palmyra]. You have to get involved, you have to tell yourself "ok, I'm really looking at this now." And not think of something else at the same time. You have to get involved and then you can empathize.'

Usefulness of the technology in the travel industry was saliently perceived to be very low. During the observations, only one group started to develop ideas for whom such a virtual travel would be suitable. Interestingly, during the interviews, after reference to potential alternative uses (e.g. travel option for physically disabled people) was made by the interviewer, almost all respondents revised their opinion and confirmed the suggested applications as being a relative advantage over the actual trip. Some even developed further ideas subsequently. For example, as a consequence of watching the Palmyra video, some stated the advantage of experiencing a destination that no longer exists. Few mentioned additionally, that there might be an advantage in the cultural tourism area, where VR technology could be used as an efficient educational tool. In some instances, a potential economic threat of VR travel for destinations and their service providers was voiced mainly due to loss of revenues caused by shrinking visitor numbers. Besides these special-purpose applications, many interviewees were able to imagine VR to be a substitute for a short getaway from everyday life, for example as a two-hour VR travel experience to relax after work. The time and monetary savings potential supports a possible relative advantage over a real trip in that respect: 'You have only little time and need a break, but you can't fly or drive anywhere at the moment because it takes too long. Then you might want to go to a V R studio for a city trip and come back more relaxed.' Or, as another one put it: 'I would consider it an experience. Maybe it can replace a short holiday. Like a visit to an amusement park.'

Enjoyment was a clear positive contributor to performance expectancy. In fact, all of the participants mentioned the 'fun-factor' and the pleasure that group members experienced during the activity. This was also observable during the surveillances and empha- sises the importance of hedonic elements when driving technology acceptance. It also hints towards the supposition that intrinsic motives play a much greater role among the participants than extrinsic ones. Especially when taking the circumstance into account that extrinsic motivation had no declared influence on using VR technology for travel purposes, even though it sometimes played a minor role in choosing a destination or holiday activity.

Both the observational as well as the interview analyses of effort expectancy indicate that participants perceived the ease of use as very positive and were comfortable in testing the equipment. Furthermore, they found it easy to operate the equipment and the complexity was rated low. However, some mentioned that the controller needed a little practice and thus the ease of use could be improved.

Social influence was rather negatively evaluated mainly because social norms play an important role for traveling. Almost none of the partakers travel alone and meeting locals is relevant for most of them. In fact, in several cases it seemed like social norm was almost perceived as a facilitating condition, because the respective interviewees referred to the two items within the same text passages. Within this context, it was striking that no one regarded experiencing the VR sites in a group as beneficial, which was originally intended by the researchers. Obviously the social element does not seem to be superficially present. In contrast to this, observations pointed towards the fact that it nevertheless is a valuable component because participants started conversations as well as shared impressions and encounters with each other after they familiarised themselves with the technology. Furthermore, although social media and recommendations of friends or family members are important when deciding which destination to visit, according to the interview statements this external input does not seem to be relevant for technology adoption. Thus, image does not present a stimulus in the present study. Taken together with extrinsic motivation, outside factors in general do not appear to have any importance for the respondents in their assessment of the technology.

Facilitating conditions were rated rather negatively as most partakers mentioned technical shortcomings, 
specifically directed towards visual elements. Moreover, some demanded additional stimuli of senses like temperature, wind, sound or smell to make the v R experience more real. However, the latter was often mentioned only after indicated by the interviewer. Finally, evaluation of compatibility can be related to the somewhat negative appraisal already discussed in connection with relative advantage.

\section{Discussion}

In our qualitative study we were not able to define a commutated tendency for items describing the construct performance expectancy and consequently for behavioural intention. While some declared that they felt to be in an artificial space [...] because there is no impact from the environment around, others acknowledged that 'the destination does not exist any longer, so V R is better than nothing.' Apparently, the absence of deeper emotions, which was criticised by many interviewees, as well as lacking social encounters with locals, seem to be a major obstacle for technology acceptance. Likewise, Mura et al. (2017) found that virtual tourism in its current form is being regarded as not authentic enough and thus not viable as a replacement for corporeal tourism. 'The journey itself is irreplaceable,' as one respondent aptly expressed. Our research revealed, however, that more granular reflections are indeed necessary in this respect.

To begin with, the assessment of outcome expectations seems to depend on how strongly the individual is able to get involved in the VR experience. This supports the proposition that a person can feel psychological presence even though physical immersion is rather low as Ijsselsteijn \& Riva (2003) suggested. Also, answers relating to outcome expectations were connected to travel motives of the participants. In this regard, most participants proactively perceived the technology as useful and advantageous for short getaways or sightseeing tours. This points at least weakly towards the findings of Disztinger et al. (2017), who report perceived usefulness or relative advantage to have a positive effect on the intention to use VR technology. In addition, after advocated by the interviewer, respondents stated that although the VR experience cannot replace the real visit, it might be a useful appli- cation for special purposes. This applies in particular to individuals who are not able to physically travel or to destinations that are simply not visitable anymore such as Palmyra, which is in line with Sussmann and Vanhegan's (2000) results. Summing up, the type of travel and specific motivation appear to be crucial for technology acceptance. If technology adoption wants to be achieved, the content of the VR offer therefore should reflect these customer needs. This conclusion is further backed by studies researching the application of A R in a cultural context (Dueholm \& Smed, 2014; Leue et al., 2015), which state that the suitable quality of content emerged as one of the biggest requirements.

Reinforcing Disztinger et al.s (2017) findings, perceived enjoyment gave a positive impulse for all participants. Hedonic benefits are, thus, an input parameter that should not be neglected when promoting V R travel technology acceptance.

Moreover, participants' statements gave no indication of the existence of any extrinsic motivators for technology adoption. This might be due to the fact that the usage of VR technology in the given context is leisure-related and purely voluntary. Additionally, interviewees were students who might not yet be able to assess the professional benefits of the technology at the time of the inquiry. Or, as a third explanation, the application itself might still be too new which means that an external motive and image has yet to develop.

In terms of effort expectancy we find that perceived ease of use was high among the respondents. The operation of the technique in a CAVE setting is no noteworthy hurdle. When arguing in line with quantitative studies (tom Dieck et al., 2018) this would shape attitude and behavioural intention of VR technology in a positive way.

Generally speaking, social interaction is a strong motivation for many tourists according to Guttentag (2010). Our study supports this viewpoint and reveals the limitations of V R technology to achieve this motivational aspect. Although participants experienced the VR application in the CAVE in small groups, no perceived social interaction was voiced even though observations conveyed a somewhat different picture. Apparently, the setting could not provide the profound social interaction that the partakers expect. 
Finally, facilitating conditions were negatively perceived mainly due to technical issues. It seems that technical aspects are still one of the most important aspects driving VR technology adoption. Especially, the perceived low quality of the visual element was one of the most frequent items mentioned to hinder technology acceptance. However, these shortcomings might change in the future with more advanced VR technology and eventually more social interaction possibilities in VR applications. Even now, perceived usefulness might be assessed more positively with more cutting edge vR equipment, which then offers technically viable substitutes for short getways or short-term sightseeing tours. Interestingly, moving pictures (Palmyra) were evaluated better than the 3D (Christ the Redeemer) experience. On the one hand, this might be due to the fact that more information is transferred via the Palmyra tour which underlines the educational aspect of v R technology. On the other hand, it could have to do with the controller handling of the still image of Corcovado since some partakers experienced motion sickness while zooming through it.

Contrasting, the absence of the naturally changing environment, such as cloud or sunlight movement, was not perceived as a disturbing factor. This is an interesting finding since Chen et al. (2015) describe the creation of dynamic geographic environments as one of the most difficult issues in moving away from a scientific setting to real virtual world research. To put it in other words, in order to generate a satisfactory tourism experience, it might not be necessary to reflect the real world in its entirety. The same might hold for other sensory stimuli. Although some participants wished for more, it did not seem to impair the experience to a significant extent because the absence was not criticised for the most part. Possibly, some participants were missing something but were not able to identify or articulate what it is. In this case, lack of additional inducements other than visual or auditive would be subconscious deficiencies that limit the VR experience. Psychological presence might, thus, be a more latent existing impression rather than that it can be proactively expressed by the users. Customer segmentation according to their sensory preferences could consequently be feasible (Agapito et al., 2014) when applying VR travel substitutes.

\section{Conclusion}

The findings of our study contribute to tourism-related VR literature by offering a more profound and differentiated understanding of items influencing technology acceptance and use intention. Generalisation, however, is difficult due to some limitations. First of all, our approach is purely qualitative. While participants' statements and comments give first indications towards the willingness to accept and use the technology as a travel substitute, they are nevertheless subjective individual opinions. As such they can only provide the basis for a more detailed comprehensive analysis. Future research should therefore test our findings in a quantitative model to derive robust results in terms of behavioural intention and use behaviour as dependent variables within the UTAU T model.

The second limitation builds on this aspect, as our sample is relatively small with 16 participants and not representative because only students of a Tourism Management bachelor degree programme were questioned. They were mainly female students of the same age group (between 20 and 25 years). Furthermore, all participants had similar previous experience with VR technology and the time frame for observations was fairly short. Again, future research should verify our findings with larger and more representative samples within an extended time frame.

Finally, outcome expectations and facilitating conditions have been evaluated rather negatively. One might get different outcomes with more high-end VR technology currently and in the future, since VR technology is evolving rapidly.

Despite the limitations our research offers room for further research questions. The researchers of the present study assumed a CAVE environment to provide for interaction possibilities. It was found, however, that not all participants acknowledged this aspect and results are likely to change in other V R environments. It would therefore be feasible to, for example, focus on more immersive VR settings or even compare findings within different VR environments. In this context, participants' preferences for settings are 
of interest as well. Moreover, in our research, the partakers participated voluntarily in the study. In terms of commercialisation, the willingness to pay for a V R experience as well as the marginal price are further questions worth noting. Customer segmentation may gain additional importance in this regard. Lastly, the content of the VR experience was not part of the discussion in the present analysis. Participants were not able to choose the type or subject of the experience. As discussed and supported by our research results, personal travel motivations and interests play an important role in the evaluation of the experience and ultimately technology acceptance. Prospective studies could therefore look more deeply into the question of stakeholders' content preferences.

\section{References}

Agapito, D., Valle, P., \& Mendes, J. (2014). The sensory dimension of tourist experiences: Capturing meaningful sensory-informed themes in Southwest Portugal. Tourism Management, 42, 224-237.

Binkhorst, E., \& Den Dekker, T. (2009). Agenda for cocreation tourism experience research. Journal of Hospitality Marketing \& Management, 18(2/3), 311-327.

Chen, M., Lin, H., Kolditz, O., \& Chen, C. (2015). Developing dynamic virtual geographic environments (VGES) for geographic research. Environmental Earth Sciences, 74(10), 6975-6980.

Cheong, R. (1995). The virtual threat to travel and tourism. Tourism Management, 16(6), 417-422.

Cruz-Neira, C., Sandin, D. J., DeFanti, T. A., Kenyon, R. V., \& Hart, J. C. (1992). The CAvE: Audio visual experience automatic virtual environment. Communications of the ACM, 35(6), 64-72.

Davis, F. D. (1989). Perceived usefulness, perceived ease of use, and user acceptance of information technology. MIS Quarterly, 13(3), 319-339.

Dewailly, J. (1999). Sustainable tourist space: From reality to virtual reality? Tourism Geographies, 1(1), 41-55.

Dinh, H. Q., Walker, N., Hodges, L. F., Song, C., \& Kobayashi, A. (1999). Evaluating the importance of multi-sensory input on memory and the sense of presence in virtual environments. In Proceedings of the 1999 IEEE Virtual Reality (pp. 222-228). IEEE.

Disztinger, P., Schlögl, S., \& Groth, A. (2017). Technology acceptance of virtual reality for travel planning. In R. Schegg \& B. Stangl (Eds.), Information and Communication Technologies in Tourism 2017 (pp. 255-268). Springer.
Dueholm, J., \& Smed, K. M. (2014). Heritage authenticities: A case study of authenticity perceptions at a Danish heritage site. Journal of Heritage Tourism, 9(4), 285-298.

Feng, M., Dey, A., \& Lindeman, R. (2016). An initial exploration of a multi-sensory design space: Tactile support for walking in immersive virtual environments. Proceedings of IEEE 3D User Interfaces (pp. 95-104). IE EE.

Gibson, A., \& O'Rawe, M. (2018). Virtual reality as a travel promotional tool: Insights from a consumer travel fair. In T. Jung \& M. C. tom Dieck (Eds.), Augmented Reality and Virtual Reality (pp. 93-107). Springer.

Griffin, T., Giberson, J., Lee, S. H., Guttentag, D., Kandaurova, M., Sergueeva, K., \& Dimanche, F. (2017, June). Virtual reality and implications for destination marketing. Paper presented at the International Conference of the Travel and Tourism Research Association, Quebec City, Canada

Grissemann, U. S., \& Stokburger-Sauer, N. E. (2012). Customer co-creation of travel services: The role of company support and customer satisfaction with the co-creation performance. Tourism Management, 33(6), 1483-1492.

Guillet, B. D., \& Penfold, P. (2013). Conducting immersive research in second life: A hotel co-branding case study. International Journal of Hospitality \& Tourism Administration, 14(1), 23-49.

Gutiérrez, M. A., Vexo, F., \& Thalmann, D. (2008). Stepping into virtual reality. Springer.

Guttentag, D. A. (2010). Virtual reality: Applications and implications for tourism. Tourism Management, 31(5), 637651.

Hein, D. W. E., Jodoin, J. L., Rauschnabel, P. A., \& Ivens, B. S. (2018). Are Wearables good or bad for society? An exploration of societal benefits, risks, and consequences of augmented reality smart glasses. In Wearable technologies: concepts, methodologies, tools, and applications (pp. 1313-1337). I I Global.

Hine, C. (200o). Virtual ethnography. Sage.

Holsapple, C. W., \& Wu, J. (2007). User acceptance of virtual worlds: The Hedonic framework. SIGMIS Database, 38(4), 86-89.

Huang, Y. C., Backman, S. J., \& Backman, K. F. (2012). Exploring the impacts of involvement and flow experiences in Second Life on people's travel intentions. Journal of Hospitality and Tourism Technology, 3(1), 4-23.

Huang, Y. C., Backman, K. F., Backman, S. J., \& Chang, L. L. (2016). Exploring the implications of virtual reality technology in tourism marketing: An integrated research framework. International Journal of Tourism Research, $18(2), 116-128$. 
Huang, Y. C., Backman, S. J., Backman, K., \& Moore, D. (2013). Exploring user acceptance of 3D virtual worlds in travel and tourism marketing. Tourism Management, 36(1), 490-501.

Hyun, M. Y., \& O'Keefe, R. M. (2012). Virtual destination image: Testing a telepresence model. Journal of Business Research, 65(1), 29-35.

Ijsselsteijn, W., \& Riva, G. (2003). Being there: The experience of presence in mediated environments. In G. Riva, F. Davide, \& W. A. Ijsselsteijn (Eds.), Being there: Concepts, effects and measurement of user presence in synthetic environments (pp. 3-16). Ios Press.

Jacob, C., Guéguen, N., \& Petr, C. (2010). Media richness and internet exploration. International Journal of Tourism Research, 12(3), 303-305.

Klein, L. R. (2003). Creating virtual product experiences: The role of telepresence. Journal of Interactive Marketing, 17(1), 41-55.

Kourouthanassis, P., Boletsis, C., Bardaki, C., \& Chasanidou, D. (2015). Tourists responses to mobile augmented reality travel guides: The role of emotions on adoption behavior. Pervasive and Mobile Computing, 18(1), 71-87.

Lee, O., \& Oh, J.-E. (2007). The impact of virtual reality functions of a hotel website on travel anxiety. CyberPsychology \& Behavior, 10(4), 584-586.

Leue, M. C., Jung, T., \& tom Dieck, D. (2015). Google glass augmented reality: Generic learning outcomes for art galleries. In I. Tussyadiah \& A. Inversini (Eds.), Information and communication technologies in tourism 2015 (pp. 463-476). Springer.

Mascho, E., \& Singh, N. (2013). Virtual tourism: Use of 'second life' for destination marketing. Anatolia, 25(1), 140143.

Mayring, P. (2014). Qualitative content analysis: Theoretical foundation, basic procedures and software solution. Beltz.

McFee, A., Mayrhofer, T., Baràtovà, A., Neuhofer, B., Rainoldi, M., \& Egger, R. (2019). The effects of virtual reality on destination image formation. In J. Pesonen \& J. Neidhardt (Eds.), Information and communication technologies in tourism 2019 (pp. 107-119). Springer.

Moore, G. C., \& Benbasat, I. (1991). Development of an instrument to measure the perceptions of adopting an information technology innovation. Information Systems Research, 2(3), 192-222.

Mura, P., Tavakoli, R., \& Pahlevan Sharif, S. (2017). 'Authentic but not too much:' Exploring perceptions of authenticity of virtual tourism. Information Technology \& Tourism, 17(2), 145-159.

Pantano, E., \& Servidio, R. (2011). An exploratory study of the role of pervasive environments for promotion of tourism destinations. Journal of Hospitality and Tourism Technology, 2(1), 50-65.

Paulo, M. M., Rita, P., Oliveira, T., \& Moro, S. (2018). Understanding mobile augmented reality adoption in a consumer context. Journal of Hospitality and Tourism Technology, 9(2), 142-157.

Rihova, I., Buhalis, D., Moital, M., \& Gouthro, M.-B. (2015). Conceptualising customer-to-customer value co-creation in tourism. International Journal of Tourism Research, 17(4), 356-363.

Rodrigues Martins, J. L. B., Gonçalves, R., Branco, F., \& Barbosa, L. (2017). A multisensory virtual experience model for thematic tourism: A Port wine tourism application proposal. Journal of Destination Marketing \& Management, 6(2), 103-109.

Slater, M., Usoh, M., \& Steed, A. (1994). Depth of presence in virtual environments. Presence: Teleoperators and Virtual Environments, 3(2), 130-144.

Sussmann, S., \& Vanhegan, H. (2000). Virtual reality and the tourism product substitution or complement? In Proceedings of the Eighth European Conference on Information Systems (pp. 1077-1083). ECIS.

tom Dieck, D., tom Dieck, M. C., Jung, T., \& Moorhouse, N. (2018). Tourists' virtual reality adoption: An exploratory study from Lake District National Park. Leisure Studies, $37(4), 371-383$.

Tussyadiah, I. P., Wang, D., \& Jia, C. (2017). Virtual reality and attitudes toward tourism destinations. In R. Schegg \& B. Stangl (Eds.), Information and communication technologies in tourism 2017 (pp. 229-239). Springer.

Tussyadiah, I. P., Wang, D., Jung, T. H., \& tom Dieck, M. C. (2018). Virtual reality, presence, and attitude change: Empirical evidence from tourism. Tourism Management, $66,140-154$.

Venkatesh, V., Morris, M., Davis, G. B., \& Davis, F. D. (2003). User acceptance of information technology: Toward a unified view. MIS Quarterly, 27(3), 425-478.

Williams, A. (2006). Tourism and hospitality marketing: Fantasy, feeling and fun. International Journal of Contemporary Hospitality Management, 18(6), 482-495.

Williams, P., \& Hobson, J. P. (1995). Virtual reality and tourism: Fact or fantasy? Tourism Management, 16(6), 423-427.

Wiltshier, P., \& Clarke, A. (2017). Virtual cultural tourism: Six pillars of VCT using co-creation, value exchange and exchange value. Tourism and Hospitality Research, 17(4), $372-383$.

Wirth, W., Hartmann, T., Böcking, S., Vorderer, P., Klimmt, 
C., Schramm, H., Saari, T., Laarni, J., Ravaja, N., Gouveia, F. R., Biocca, F., Sacau, A., Jäncke, L., Baumgartner, T., \& Jäncke, P. (2007). A process model of the formation of spatial presence experiences. Media Psychology, 9, 493525 .
Yung, R., \& Khoo-Lattimore, C. (2019). New realities: A systematic literature review on virtual reality and augmented reality in tourism research. Current Issues in Tourism, 22(17), 2056-2081. 


\title{
The Effects of Destination Image on Tourist Satisfaction: The Case of Don-Wai Floating Market in Nakhon Pathom, Thailand
}

\author{
Napaporn Janchai \\ Suranaree University of Technology, Thailand \\ napaporn_jan@sut.ac.th \\ Glenn Baxter \\ Suan Dusit University, Thailand \\ g_glennbax@dusit.ac.th \\ Panarat Srisaeng \\ Suan Dusit University, Thailand \\ panarat_sri@dusit.ac.th
}

The aim of this study was to analyse the effects of a Floating Market's destination image on tourist satisfaction. A closed-question questionnaire was prepared drawing from the attributes that influence tourist destination satisfaction in the literature. The sample in the study consisted of 200 tourists who visited Nakhon Pathom's Don Wai Floating Market in January 2018. Multiple regression analyses were applied to empirically test the study's four hypotheses. The results found that the uniqueness of nature, uniqueness of history, and uniqueness of tourist products are the most critical factors affecting the tourists' satisfaction at the 95 percent significance level. However, the uniqueness of architecture factor did not have a significant effect on tourist satisfaction. The study for the first time established an empirical relationship between the uniqueness of nature, uniqueness of history, and uniqueness of tourist products of a floating market and tourist satisfaction with a Floating Market as a tourist destination. These insights may help other Floating Markets to better understand the factors that influence tourist satisfaction with such facilities.

Keywords: destination image, floating market, tourism management, tourist satisfaction, Thailand

(cc)BY-SA https://doi.org/10.26493/2335-4194.13.139-151

\section{Introduction}

Cultural tourism plays a significant role in economic, social and cultural aspects in terms of a source of income for local communities and a source of cultural learning and recreation for tourists, as well as a source of cultural conservation and community development (Boniface, 2012; Prideaux et al., 2008; Richards, 2010). Moreover, cultural tourism also encourages involve- ment and pride within the community. Local people can learn and increase awareness toward the value of culture as a heritage and an essential resource for tourism (Tourism Collaborative Commerce, 2015).

Floating markets are an essential resource of cultural tourism in Thailand that reflect the traditional ways of life and local culture of the Thai people who are connected to the river and canal. Rivers and canals 
were used for subsistence, consumption, agriculture, and transportation (Tourism Authority of Thailand, 2009). A floating market is a meeting place around a river site where both buyers and sellers gather to trade in a variety of consumer goods, principally cooked and raw food items, and household utensils (Din, 2008). In Thailand, canals were also used for trading various goods by boat or floating houseboat. Floating markets were widespread in the Ayutthaya period until the Ratanakosin era, especially, canals with many households living (Tourism Authority of Thailand, 2009). At present, there are over 30 floating markets in Thailand, mainly located in various provinces in the central region such as Bangkok, the capital city of Thailand, and nearby provinces, Nakhon Pathom, Samut Songkram, and Ratchaburi provinces. Some of them are in the east, the northeast, and the south of the country (Tourism Authority of Thailand, 2009). This study focused on the floating market at Wat Don Wai, which is located quite close to Wat Rai Khing, in Nakhon Pathom province. The floating market has become very popular for both Thai and foreign tourists. The floating market is located on Nakhon Chai Si River, Nakhon Pathom province, and is around $30 \mathrm{~km}$ from Bangkok.

The image of a destination is an essential component of tourist attractions (Bowen \& Clarke, 2009). The destination image is based on the perceptions of tourists as an individual or a group concerning the destination (Ksouri et al., 2015). There is a substantial volume of research that has concluded that destination image has a positive effect not only on tourists' satisfaction but also on destination loyalty (Chi \& Qu, 2008; Chiu et al., 2016; Martins, 2015; Puh, 2014; Rajesh, 2013; Shafiee et al., 2016). Ksouri et al. (2015) have suggested that the image can be used to add value to attract new visitors and retain loyal ones. Additionally, the destination image can be a strategic tool to attract different types of tourists. Iordanova and Stylidis (2019) note that direct destination experience plays a vital role in forming destination image.

The significance of the destination image emphasises the need to study destination image from various perspectives. In addition, various research has been conducted focusing on the importance of the image of a tourist destination (Garay, 2019; Guzman-Parra et al., 2016; Ksouri et al., 2015; Kim et al., 2019); the impact of tourist harassment on destination image (Alrawadieh et al., 2019); the relationship between the tourist imagery, the destination image and the brand image (Martins, 2015); the relationship between tourist destination image and consumer behaviour (Kim, 2018; Melo et al., 2017); and the impact of country image and destination image on tourists' travel intention (Chaulangain et al., 2019; Zhang et al., 2018). However, studies identifying what characteristics of destination image have a positive effect on tourists' satisfaction are quite limited. Understanding these characteristics may lead to the development of a tourist destination, especially a key destination like a floating market, to enhance the satisfaction of tourists and their intention to visit and revisit the destination, and recommendation to others.

Therefore, the aim of the study is to analyse the level of perceived image and satisfaction of tourists in the case of Nakhon Pathom's Don-Wai Floating Market and analyse the effects of the Floating Market's destination image, which characteristics of destination image influence tourist satisfaction, and to quantify the degree of influence of each characteristic on tourist satisfaction.

\section{Literature Review}

\section{Destination Image}

From a tourism perspective, the image potential customers have of a tourist destination is a very significant issue. Indeed, images play an essential role in destination choice matters (Sonnleitner, 2011). As tourism services are intangible (Dwyer et al., 2010), images are said to become even more important than reality. The concepts of destination image and destination marketing and branding have a very close inter-relationship. The ultimate aim of any destination is to influence possible tourists' travel-related decision making and choice through marketing activities (Sonnleitner, 2011).

Destination image is an essential factor contributing to perceived value, satisfaction and tourist loyalty (Chankingthong, 2014; Hsu et al., 2008; Kakai \& Panchakachornsak, 2011; Kunrattanaporn, 2013; Pike, 
2008; Tsai, 2015; Sangla-or \& Kornpetpranee, 2015; Sukphol, 2014). The image of a tourist destination is an incentive for tourists to visit a place (Chaulagain et al., 2019; Murphy \& Murphy, 2004).

According to Melo et al. (2017), although many scholars have developed concepts of the tourist destination, its concept is still complicated and subjective, and no consensus has been reached on its definition, formation, and measurement. These conceptualisations are dependent on the factor of time and place. Ksouri et al. (2015) state that the measure of the destination image is a complex phenomenon; since the multiplicity of attributes and inferences characterises the destination image, its creation and evolution depend on several factors.

The concept of image was initially applied in the area of tourism in the early 1970 s by Hunt (1971). He conceptualises destination image as the set of impressions that are perceived by a group or an individual about a place where they do not live. Since then, destination image has been widely discussed in the tourism literature (Beerli \& Martin, 2004; Govers et al., 2007; Melo et al., 2017; Perpiña et al., 2017; Zhang et al., 2014). According to Al-Azri and Morrison (2006), the destination image is a perception of tourists regarding a tourist destination based on a combination of their beliefs, feelings, impression, ideas, and knowledge that people attach to a given place. Perception about a destination may be derived from various sources of information (Cavlak \& Cop, 2019; Pike, 2008) and their own experience. This perception can be formed before, during, and after visiting a place (Ioradanova \& Stylisdis, 2019). This study focuses on the perception of tourists on destination image during or after visiting the destination (Nakhonpathom's Don Wai Floating Market). In addition, the destination image is a combination of both cognitive and affective images (Birdir et al., 2018; Lin et al., 2007). The cognitive image involves knowledge about the destination, while the affective image concerns the feelings and emotions of people about the destination.

Hsu et al. (2008) observe that destination image is what tourists imagine or receive information about what they perceive that the tourist attractions look like. Meanwhile, the tourist destination is trying to create a different image from other destinations and build awareness of the image of the tourist destination. The image of a tourist destination can be communicated in several ways: the name of the tourist destination or brand, logo, and visible media such as photos and animations.

As Pike (2008) notes, in general, the image of the tourist attraction is based on the characteristics of tourist attractions or elements of tourism which are unique, both the concrete and abstract nature of the tourist attraction. According to Qu et al. (2011), uniqueness is an important reason for tourists to choose their destinations. Creating a unique destination image is in the focus for marketing the destination. Unique and distinctive characteristics have been used to differentiate tourist destinations among similar destinations, to build the destination image in target tourists' minds, and to increase their attention to the destinations. Formation of positive image is based on strong, favourable and unique associations that tourists hold. These associations help tourists distinguish the destination from others. Various studies confirm that destination uniqueness has a significant effect on tourists' behavioural intentions to visit the destination (Chen et al., 2007; Chunashvili, 2019; Ramkissoon et al., 2011).

However, the unique nature of the destination may not be a competitive image. If the uniqueness cannot meet the needs of the tourists, the image of the destination can be divided into two types: organic image and induced image. The organic image of a tourist destination is the tourist's impressions of a destination without them physically visiting the place (Ispas et al., 2016). The tourist's organic image of a destination is developed through their everyday assimilation of information, which come from a diversity of sources, which include school history lessons, word of mouth, social media posts, mass media, and actual visitation (Pike, 2016). The image of a tourist attraction is closely correlated with perceived value, satisfaction, and the loyalty of tourists. The image of a tourist attraction is also influenced by the relationship between attitudes about travel experience and future travel behaviour which consists of cognition, affect, and connotation (Hsu et al., 2008; Khunrattanaporn, 2013; Pike, 2008). 


\section{Tourist Satisfaction}

Satisfaction has been theoretically delineated as the tourist's emotional state which has developed at the post-visitation stage, that is, where the tourist has experienced the visit to their desired destination (Horávth, 2013; Um et al., 2006; Walters \& Li, 2017). Satisfaction is the expression of overall pleasure perceived by the tourist following their trip or visit (Chen \& Tsai, 2007; Thiumsak \& Ruangkanjanases, 2016). Satisfaction is categorised as an affective attitude to a product or service or a brand and is an important predictor of frequent purchase behaviour, or loyalty by a customer to products and services that are functionally substitutable (Olson, 2006). There is a wide body of literature that concludes that customer satisfaction influences consumer loyalty to a product and service. Furthermore, satisfaction has been shown to have a positive correlation to post-purchase behaviour, especially in the process of repurchase in the future by a consumer (Thiumsak \& Ruangkanjanases, 2016).

Satisfaction is an essential goal of business and tourism (Cooper \& Hall, 2008). Customer satisfaction is a measure of how a firm's total product performs in relation to a set of customer requirements (Hill et al., 2003). If things meet or exceed a consumer's expectations, it will result in satisfaction. On the other hand, if something diminishes or does not meet the individual's expectation, then this will result in customer dissatisfaction (Kotler \& Keller, 2012).

In addition, satisfaction is an essential factor directly affecting tourist loyalty (Alegre \& Cladera, 2007; Dasgupta, 2011; Kakai \& Panchakachornsak, 2011; Lertwannawit \& Gulid, 2004; Meechinda et al., 2008; Quintal, 2010; Sukphol, 2011; Tsai, 2015; Wongkangwan, 2013; Wang et al., 2009). According to Maignan et al. (1999), customer loyalty is the non-random tendency displayed by many of a firm's customers to keep purchasing products from the same firm over time and to associate positive images with the firm's products and services. Satisfaction also creates a bond with the product or company (Kotler \& Keller, 2012). Cooper and Hall (2008) have observed that customer satisfaction can result in a profound relationship.

However, each tourist's satisfaction rating is different. Some people are easily satisfied, while some peo- ple often feel uncomfortable or often unhappy (Kotler \& Keller, 2012). Cooper and Hall (2008) have stated that the factors that affect satisfaction are the need of the tourist, price and value that are recognised, expectations and past experiences, the credibility of tourism resources and related businesses, quality of both physical and service environment, and staff and the people involved are friendly and taking care of tourists. The study undertaken by Quintal (2010) found that satisfaction with tourist attractions, and the quality and value of the tourist attraction has a positive influence on the return of tourists.

Parasakul (2012) observes that satisfaction consists of a variety of dimensions. Each dimension is individual in nature. Therefore, tourist satisfaction with tourism activities is diversified satisfaction. Satisfaction includes satisfying the various dimensions of the tourism experience, for example, satisfaction with the natural environment (scenery, beauty, cleanliness, unspoiled), or satisfaction with the services. Satisfaction in each dimension must be analysed separately. This analysis will reveal what the tourists are satisfied with and what aspects they are not satisfied with because, in one trip, tourists may not be satisfied or dissatisfied with everything. In summary, the satisfaction of tourists from their tourism experience will affect their loyalty to a tourist destination in the future. If tourists are satisfied with the tourism experience, they will return to visit the place and recommend it to others.

\section{Research Methodologies}

Research Instrument

A survey using close-ended questions (Mayo, 2014; Smith, 2017) to gather data on the predictors and criterion variable, as well as on specific demographic characteristics underpinned the research undertaken in this study. Closed-end questions are typically used in confirmatory research, that is, when the researcher(s) want to empirically examine specific hypotheses (Johnson \& Christensen, 2008).

The questionnaire was developed based on previous research focusing on tourist satisfaction and tourism destination image (Bui \& Le, 2016; Chiu et al., 2016; Moon \& Han, 2019). The self-administered questionnaire was used to assess the Thai people's 
perceived image and respondent's satisfaction with Nakhon Pathom's Don-Wai Floating Market. The questionnaire was written in Thai. The questionnaire comprised five main sections: demographic information, the tourist's views towards the image of the Floating Market, the tourist's perceived value of visiting the Floating Market, the tourist's opinion on destination image attributes, the tourist's satisfaction with the Floating Market, and the level of tourist loyalty to the Floating Market.

In this study, the tourist satisfaction attributes were in the categories of the images of the uniqueness of nature, the uniqueness of the Floating Market's history, the uniqueness of the Floating Market's architecture, and the uniqueness of the Floating Market's products offering. All four categories had single questions, except for the Floating Market's products offering, which had two questions.

The respondents were asked to indicate their level of satisfaction on a 5-point Likert scale, a more reliable tourist satisfaction assessment, which ranged from (1) strongly disagree to (5) strongly agree (Ángeles Oviedo-Garcíaa et al., 2019; Bui \& Le, 2016; Chiu et al., 2016; Huanga \& Crottsb, 2020; Moon \& Han, 2019). The demographic characteristics of the respondents were measured using nominal and ordinal scales.

\section{Pilot Study}

Following the recommendations of Cargan (2007), Johanson and Brooks (2010), and Ruel et al. (2016), a pilot study to test the efficacy of the survey instrument was conducted. Pilot studies are often recommended so that the researcher(s) can address a variety of issues. These include preliminary scale or instrument development. Specific concerns such as item difficulty, item discrimination, internal consistency, response rates, and parameter estimation in general are all viewed as being highly relevant for undertaking a pilot study (Johanson \& Brooks, 2010). The pilot study consisted of 30 Thai citizens. A convenience sampling approach (Battaglia, 2008; Gravetter \& Forzano, 2012) was used to conduct the pilot study. Following the conclusion of the pilot, several minor changes were made to the survey instrument to address the feedback from the pilot study participants.

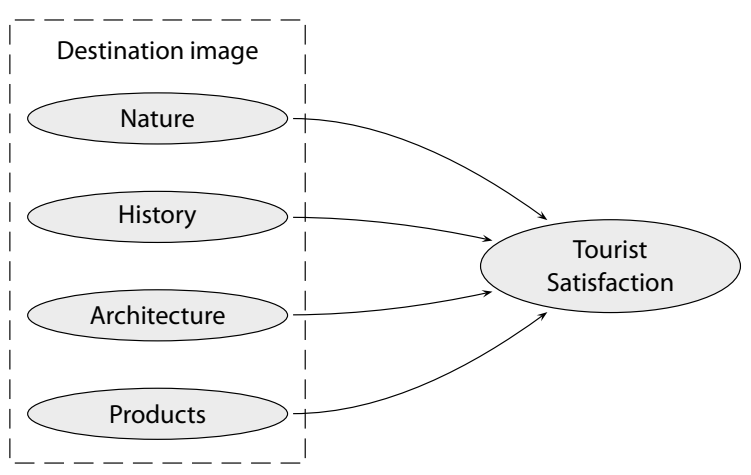

Figure 1 Proposed Research Framework

\section{Research Framework}

The tourism destination image of Nakhon Pathom's Don Wai Floating Market was identified based on past studies (Ahmad et al., 2014; Chittangwattana, 2005; Jankingthong, 2013; Inkson \& Minnaert, 2012; Kanwel et al., 2019). Four independent variables, that is, the image of tourism destination in the aspect of nature, the image of tourism destination in the aspect of history, the image of tourism destination in the aspect of architecture and the image of tourism destination in the aspect of products were considered to affect tourist satisfaction. The research framework is shown in Figure 1.

\section{Data Collection and Study Sampling}

The target population of this study were the Thai people who visited Nakhon Pathom's Don Wai Floating Market during January 2018. The questionnaire survey was conducted in both the morning and the evening. The convenience sampling method was used to collect data (Lertputtarak, 2012). Field editing was also conducted at the market to check for the completeness of the questionnaire (Gunturo \& Hui, 2013).

The sample in this study comprised 200 Thai visitors travelling to Nakhon Pathom's Don Wai Floating Market during January 2018. Blair and Blair (2015) and Read (2011) have suggested that 200 is an ideal sample size for a survey.

\section{Data Analysis}

To analyse the gathered data, this study utilised both descriptive and inferential statistics. The demographic 
variables were analysed using frequency and percentage. The mean score and standard deviation analysed each independent variable. Multiple regression analysis was used to analyse the relationship between the tourism destination image (independent variables) and the tourist satisfaction dependent variable.

\section{Hypothesis Development}

The destination image consists of three main elements: the image of organisation, the image of products and services, and the image of attractions (Jankingthomg, 2013). According to Chittangwattana (2005), the destination image can be divided into 5 elements. They are physical, cultural and historical, economic, construction or built environment, and flora and fauna. Historical sites now feature strongly as sites for tourist visitation (Austin, 2002). Belton (n.d.) states that key elements of a destination consist of 5 As: Access, Accommodation, Attractions, Activities, and Amenities. In the tourism industry, a tourist's decision to travel is influenced by both push and pull factors (Dann, 1977). Push and pull factors distinguish between the reasons why individuals participate in tourism, and the reasons why they travel to a particular destination. Push factors are the personal drivers that encourage a tourist to travel, for example a need to escape the daily routine, a need to spend quality time with family, or the demand for adventure. And Pull factors are the elements that attract a tourist to a specific destination in order to satisfy the push factors. Pull factors could be natural environment, festival, tradition, tourism activities, and attractions (Inkson \& Minnaert, 2012).

In the case of Nakhon Pathom's Don-Wai Floating Market, the present study examined four elements of the destination image that represent the uniqueness and identity of the floating markets and have a strong link to tourist demand. The uniqueness of nature, the uniqueness of history, the uniqueness of architecture of a tourism destination, and the product's uniqueness offered by a tourism destination were selected to determine how these attributes will affect a tourist's satisfaction with the tourist attraction. The following hypotheses were empirically tested in this study.

$\mathrm{H} 1$ The image of the uniqueness of nature as a tourism destination will affect tourists' satisfaction.
$\mathrm{H} 2$ The image of the uniqueness of history at a tourism destination will affect tourists' satisfaction.

H3 The image of the uniqueness of architecture of a tourism destination will affect tourists' satisfaction.

H4 The image of the product's uniqueness offered by a tourism destination will affect tourists' satisfaction.

\section{Findings}

\section{Don-Wai Floating Market: A Brief Overview}

The Don-Wai Floating Market is located near Wat Don Wai, Sam Pran District, Nakhon Pathom Province. The market is around 32 kilometres west of Bangkok. The market is mainly patronised by the Thai people, but tourists also visit the market as well. Food, cooking utensils, cosmetics and furniture is sold at the market. There are food stalls and restaurants, with the restaurants primarily being located on the river (Liedtke, 2012).

\section{Demographic Profile of the Respondents}

Table 1 (p. 145) presents the demographic profile of the respondents. Out of the 200 participants, the majority were female $(57 \%)$, and $43 \%$ were male. Most of the age group were respondents with an age of 31-40 years (31.5\%). This was followed with respondents with an age between $21-30$ years old (23.5\%). The majority of respondents (58\%) held a Bachelor's degree. Thirtyone percent of the respondents were government officers, followed by students ( $21 \%)$. Most of the respondents $(28 \%)$ had income in the range of $15,000-25,000$ Thai Baht.

Most of the visitors (44\%) lived in Bangkok and most respondents (47.5\%) had visited the Don Wai Floating Market more than three times. Nineteen per cent of the respondents had visited the Floating Market on three occasions. A further eighteen and a half per cent had visited the market on two occasions, whilst $15 \%$ of the respondents were making their first visit to the Floating Market.

Most of the respondents resided in Bangkok (44.5\%) and Nakhonpathom (24\%). The smallest number of respondents lived in the Southern Region (2\%). 
Table 1 Demographic Characteristics of the Study's Respondents

\begin{tabular}{|c|c|c|c|}
\hline Item & Category & $f$ & $f \%$ \\
\hline \multirow[t]{2}{*}{ Gender } & Male & 86 & 43.0 \\
\hline & Female & 114 & 57.0 \\
\hline \multirow[t]{6}{*}{ Age group } & Less than 21 & 26 & 13.0 \\
\hline & $21-30$ & 47 & 23.5 \\
\hline & $31-40$ & 63 & 31.5 \\
\hline & $41-50$ & 31 & 15.5 \\
\hline & $51-60$ & 25 & 12.5 \\
\hline & $>60$ & 8 & 4.0 \\
\hline \multirow[t]{3}{*}{ Education } & High school or lower & 63 & 31.5 \\
\hline & Bachelor degree & 116 & 58.0 \\
\hline & Postgraduate or higher & 21 & 10.5 \\
\hline \multirow[t]{6}{*}{ Occupation } & Student & 42 & 21.0 \\
\hline & Housewife & 32 & 16.0 \\
\hline & Employee & 31 & $15 \cdot 5$ \\
\hline & Government officer & 62 & 31.0 \\
\hline & Private business owner & 25 & 12.5 \\
\hline & Others & 8 & 4.0 \\
\hline \multirow{6}{*}{$\begin{array}{l}\text { Income/ } \\
\text { Month } \\
\text { (тнв) }\end{array}$} & Less than 15,000 & 56 & 28.0 \\
\hline & $15,000-25,000$ & 66 & 33.0 \\
\hline & $25,001-35,000$ & 54 & 27.0 \\
\hline & $35,001-45,000$ & 11 & $5 \cdot 5$ \\
\hline & $45,001-55,000$ & 4 & 2.0 \\
\hline & $>55,000$ & 9 & 4.5 \\
\hline
\end{tabular}

Continued in the next column

\section{Descriptive Statistics}

As mentioned earlier, destination image attributes of Nakhon Pathom's Don Wai Floating Market were composed of nature, history, architecture and products. The respondents were asked to express their opinion toward the destination image attributes of the Don Wai Floating Market. The mean and standard deviation (SD) scores for the destination image are presented in Table 2. The uniqueness of nature has the highest mean score (3.81), followed by the uniqueness of products (3.78), the unique nature of history (3.47) and the uniqueness of the architecture (3.44).

Tourists were also required to rate their satisfaction
Table 1 Continued from the previous column

\begin{tabular}{llrr}
\hline Item & Category & $f$ & $f \%$ \\
\hline Respondents' & Nakhonpathom & 48 & 24.0 \\
hometown & Bangkok & 89 & 44.5 \\
& Central Region & 28 & 14.0 \\
& Northern Region & 4 & 2.0 \\
& Eastern Region & 11 & 5.5 \\
& Western Region & 4 & 2.0 \\
& Northeastern Region & 12 & 6.0 \\
& Southern Region & 4 & 2.0 \\
\hline Past & First Time visit & 30 & 15.0 \\
Experience & Second Time visit & 37 & 18.5 \\
& Third time visit & 38 & 19.0 \\
& Over three times visit & 95 & 47.5 \\
\hline
\end{tabular}

Table 2 Tourists' Opinion toward the Destination Image Attributes

\begin{tabular}{lrrr}
\hline Destination image attributes & Mean & SD & Rank \\
\hline The uniqueness of nature & 3.81 & 0.792 & 1 \\
The uniqueness of history & 3.47 & 0.961 & 3 \\
The uniqueness of architecture & 3.44 & 0.954 & 4 \\
The uniqueness of products & 3.78 & 0.847 & 2 \\
\hline
\end{tabular}

Table 3 Tourists' Satisfaction on Visiting Don Wai Floating Market

\begin{tabular}{lrrr}
\hline Tourists' satisfaction & Mean & SD & Rank \\
\hline I really enjoyed the visit & 4.02 & 0.630 & 1 \\
I have gained great experience & 4.00 & 0.723 & 2 \\
Visiting was better than expected & 3.90 & 0.753 & 3 \\
\hline
\end{tabular}

on visiting Nakhon Pathom's Don Wai Floating Market. The results are presented in Table 3. It was found that the tourists who enjoyed their visit to Don Wai Floating Market has the highest mean score of 4.02, followed by the tourists who gained a great experience (4.00) and the visit was better than expected (3.90).

\section{Hypothesis Testing}

The data that was obtained from the 200 respondents through the questionnaire was used to analyse and explore how the impacts of the uniqueness of nature, history, building architecture and tourism products at a 
Table 4 Multiple Regression Results between Destination Image and Satisfaction

\begin{tabular}{lrrr}
\hline Tourism Destination Image & $\beta$ & $t$ & $p$ \\
\hline Nature & 0.345 & 4.658 & $0.000^{*}$ \\
History & 0.231 & 3.344 & $0.001^{*}$ \\
Architecture & 0.075 & 1.383 & 0.168 \\
Products & 0.200 & 2.983 & $0.003^{*}$ \\
\hline
\end{tabular}

Notes $R^{2}=0.467$, adjusted $R^{2}=0.456, F=42.638$, sig. $=$ o.000. ${ }^{\star} p<0.05$.

tourist destination affect tourists' satisfaction. In predicting the relationship between the factors and tourist satisfaction with the tourist destination, multiple regression analysis was used to test the four hypotheses.

\section{Regression Analysis}

As previously noted, multiple regression was performed to test the research's hypotheses and to quantify the effects of the tourism destination image, including the four factors nature, history, architecture, and products on the tourists' satisfaction. The four factors or the independent variables were regressed with the dependent variable, the tourist satisfaction. The multiple regression results are shown in Table 4. According to the regression analysis, the $F$ value is 42.638 ( sig. $=0.000$ ), and the significance test of the regression equation shows that there is a linear correlation between three independent variables nature, history, and products, and the dependent variable. All independent variables, except the image of the uniqueness of the tourism destination's architecture, were significant in the model at a significance level of 0.05 (95\%). The Adjusted $R^{2}$ value is 0.456 , indicating that the closeness of the relationship between tourism destination image attribution and the satisfaction degree is $45.60 \%$.

The results found that all independent variables have a positive relationship with tourist satisfaction. The image of the uniqueness of nature of a tourism destination was $\beta=0.345, p=0.000$. The image of the uniqueness of history of a tourism destination was $\beta$ $=0.231, p=0.001$. The image of the product's uniqueness offered by a tourism destination was $\beta=0.200, p$ $=0.003$. However, the image of the uniqueness of architecture of a tourism destination was $\beta=0.075, p=$

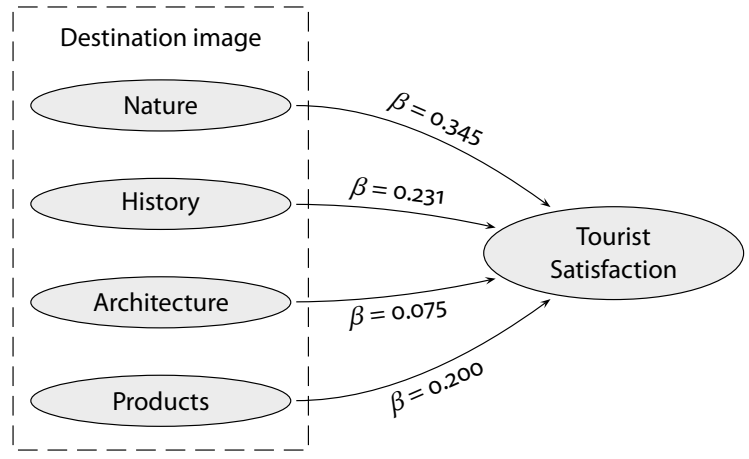

Figure 2 The Effects of Destination Image of Don Wai Floating Market on Tourist Satisfaction

0.168; these statistical results suggest that uniqueness of a tourist destination's architecture was insignificant to the tourists' satisfaction with the Don Wai Floating Market. Thus, hypotheses $\mathrm{H} 1, \mathrm{H} 2$ and $\mathrm{H} 4$ were supported whilst $\mathrm{H} 3$ was not accepted. The image of the uniqueness of nature of a tourism destination was the most important predictor of tourist satisfaction $t=$ 4.658, while the second and the third most essential predictors are the image of uniqueness of the history of a tourism destination $t=3.344$, and the image of the product's uniqueness offered by a tourism destination $t=2.983$. The effects of the destination image of Don Wai Floating Market on tourist satisfaction is depicted in Figure 2.

\section{Discussion}

As previously noted, the elements of a tourist destination in general consist of 5 As: Access, Accommodation, Attractions, Activities, and Amenities (Belton, n.d.). Chittangwattana (2005) argues that the destination image can be divided into five elements; they are physical, cultural and historical, economic, construction or built environment, and flora and fauna. According to a study by Jankingthong (2013), the image of Thailand can be measured in three elements: the image of organisation, the image of products and services, and the image of attractions. In terms of floating markets, influential elements of a destination image on tourist satisfaction include the uniqueness of nature, the uniqueness of history and the uniqueness of products provided by the floating market. 
The finding of the uniqueness of nature is a key component of a tourist destination image which strongly influences tourist decision making, similar to various previous studies which show that natural environment is a major attraction for tourists (Belton, n.d.; Chittangwattana, 2005; Jankingthong, 2013). The uniqueness of history which adds more value to a destination is now a feature as sites for tourist visitation (Austin, 2002). Finally, the uniqueness of products is also significant for tourists to choose the destination (Jankingthong, 2013). The three elements of a destination image of a floating market may be pull factors to attract tourists to the destination and an influence on satisfaction of tourists and intention to revisit the destination.

In the tourism literature, the role of behavioural intention is viewed as being the most powerful force for the sustainability of tourism products including tourist destinations (Ahmad et al., 2014). Behavioural intention shows how frequent visitors decide to revisit the destination at some point in the future (George \& George, 2004). Tourists' satisfaction plays a vital role, being the primary precursor of post-purchase behavioural intentions (Kanwel et al., 2019). This is because it positively develops the insight of tourists towards the service, brand, or product. Furthermore, it may also heighten the conscious attempt of tourists to return to the destination again in the future (Oliver, 1980).

\section{Conclusions and Implication}

This research aimed to analyse the effects of the destination image of Nakhon Pathom's Don Wai Floating Market on tourist satisfaction. The sample in this study consisted of 200 tourists who visited Don Wai Floating Market in January 2018. Data was collected and analysed using multiple regression analysis. Four aspects of tourism destination image were identified, which included the image of uniqueness of nature of a tourism destination, the image of the uniqueness of history of a tourism destination, the image of the uniqueness of architecture of a tourism destination, and the image of the product's uniqueness offered by a tourism destination.

It was found that the destination image had a sig- nificant effect on tourist satisfaction. The most important factor affecting tourists' satisfaction was the image of the unique nature of Don Wai Floating Market as a tourism destination, while the second and the third most essential predictors are the image of the uniqueness of history of the Don Wai Floating Market as a tourism destination, and finally the image of the product's uniqueness offered at the Don Wai Floating Market. However, the image of the uniqueness of the Don Wai Floating Market architecture was not significant to the study's regression model, and thus, this hypothesis was not proven.

Destination image becomes a critical factor for the success or failure of tourism management (Lopes, 2011). The image of tourist destination involves cognitive and affective conditions of tourists (Birdir et al., 2018; Lin et al., 2007) which may then contribute to a negative or positive image of the tourist destination (Jankingthong, 2013). If the organic image cannot meet the tourist demand, induced image should be built or developed to satisfy tourists. This study provides insights into the influence of destination image on tourist satisfaction in the case of a Floating Market. Tourism managers and marketing executives may adapt and apply this insight from the present study to build or develop the image of a tourist destination in the right dimensions since the image of a tourist attraction is closely correlated with perceived value, satisfaction, and the loyalty of tourists (Hsu et al., 2008; Khunrattanaporn, 2013; Pike, 2008).

\section{Suggestions for Further Study}

A limitation of the present study was that the sample was based on Thai citizens. Future research could explore the effects of destination image of a Floating Market on international tourists and further test the effect of destination image on tourist loyalty. The survey undertaken in the present study was conducted during Thailand's high tourism season. Thus, a suggestion for a future study would be to replicate the survey during the non-peak season of tourism. In addition, investigation of model variability should be added by studying a group of tourists who visited the floating market for the first time and a group of tourists who visited the floating market many times. 


\section{References}

Ahmad, M. A., Jamaluddin, M. R., Alias, M. A., \& Abd Jalil, A. Q. (2014). Destination attractiveness of a theme park: A case study in Malaysia. In N. Sumarjan,Z. Mohd Salehuddin Mohd, R. Salleh Mohd, M. Zurinawati, H. Mohd Hafiz Mohd, B. Mohd Faeez Saiful, Z. Artinah, S. Bakhtiar, M. Hafiz, \& M. Hanafiah (Eds.), Hospitality and tourism: Synergizing creativity and innovation in research (pp. 153-157). CRC Press.

Al-Azri, H. I., \& Morrison, A. M. (2006). Measurement of Oman's destination image in the us. Tourism Recreation Research, 31(2), 85-89.

Alegre, J., \& Cladera, M. (2009). Analysing the effect of satisfaction and previous visits on tourist intentions to return. European Journal of Marketing, 43(5/6), 670-685.

Alrawadieh, Z., Alrawadieh, Z., \& Kozak, M. (2019). Exploring the impact of tourist harassment on destination image, tourist expenditure, and destination loyalty. Tourism Management, 73, 13-20.

Ángeles Oviedo-Garcíaa, M., Vega-Vázquezb, M., Castellanos-Verdugob, M., \& Orgaz-Agüerac, F. (2019). Tourism in protected areas and the impact of servicescape on tourist satisfaction, key in sustainability. Journal of Destination Marketing \& Management, 12, 74-83.

Austin, N. K. (2002). Managing heritage attractions: Marketing challenges at sensitive historical sites. International Journal of Tourism Research, 4(6), 447-457.

Battaglia, M. (2008) Convenience sampling. In P. J. Lavrakas (Ed.), Encyclopedia of survey research methods (pp. 148149). Sage.

Beerli, A., \& Martin, J. D. (2004). Factors influencing destination image. Annals of Tourism Research, 31(3), 657-681.

Belton, V. (N.d). Key Elements of a Destination, Part 5: Amenities. https://stampdestinations.com/insights/keyelements-destination-amenities/

Birdir, S. S., Dalgic, A., \& Birdir, K. (2018). Destination marketing and destination image. In D. Gursoy \& C. G. Chi (Eds.), The Routledge handbook of destination marketing (pp. 71-81). Routledge.

Blair, E., \& Blair, J. (2015). Applied survey sampling. Sage.

Boniface, P. (2012). Managing quality cultural tourism. Routledge.

Bowen, D., \& Clarke, J. (2009). Contemporary Tourist Behaviour: Yourself And Others As Tourists. CA B I.

Bui, H. T., \& Le, T. A. (2016). Tourist satisfaction and destination image of Vietnam's Ha Long Bay. Asia Pacific Journal of Tourism Research, 21(7), 795-810.

Cargan, L. (2007). Doing social research. Rowman and Littlefield.
Cavlak, N., \& Cop, R. (2019). Perceived destination image: The case of Gallipoli. In M. A. Camilleri (Ed.), Strategic perspectives in destination marketing (pp. 240-265). IG I Global.

Chankingthon, V. (2014). Theory of planned behavior and tourist loyalty. Silpakorn University Journal, 34(2), 131146.

Chaulagain, S., Wiitala, J., \& Fu, X. (2019). The impact of country image and destination image on us Tourists' travel intention. Journal of Destination Marketing of Management, 12, 1-11.

Chen, C., \& Tsai, D. (2007). How destination image and evaluative factors affect behavioural intentions. Tourism Management, 28(4), 1115-1122.

Chen, X., Wasti, S. A., \& Triandis, H. C. (2007). When does group norm or group identity predict cooperation in a public goods dilemma? The moderating effects of idiocentrism and allocentrism. International Journal of Intercultural Relations, 31(2), 259-276.

Chi, C. G., \& Qu, H. (2008). Examining the structural relationships of destination image, tourist satisfaction and destination loyalty: An integrated approach. Tourism Management, 29(4), 624-636.

Chittangwattana, B. (2005). Tourism industry. Press and Design.

Chiu, W., Zeng, S., \& Cheng, P. (2016). The influence of destination image and tourist satisfaction on tourist loyalty. International Journal of Culture, Tourism and Hospitality Research, 10(2), 223-234.

Chunashvili, N. (2019). Which factors influence tourists to choose Northern Norway as a travel destination? Factors influencing behavioral intentions of tourists [Unpublished $\mathrm{PhD}$ dissertation]. Nord University, Bod?.

Cooper, C., \& Hall, C. M. (2008). Contemporary tourism: An international approach. Elsevier.

Dann, G. (1977). Anomie, ego-enhancement and tourism. Annals of Tourism Research, 4(4), 184-194.

Dasgupta, D. (2011). Tourism marketing. Dorling Kindersley India.

Din, K. (2008). Floating market. In M. Lück (Ed.), The encyclopedia of tourism and recreation in marine environments (p. 178). САВ I.

Dwyer, L., Forsyth, P., \& Dwyer, W. (2010). Tourism economics and policy. Channel View Publications.

Garay, L. (2019). \#Visitspain: Breaking down affective and cognitive attributes in the social media construction of the tourist destination image. Tourism Management Perspectives, 32, 10056o. https://doi.org/10.1016/j.tmp.2019 .100560 
George, P. B., \& George, P. B. (2004). Past visits and the intention to revisit a destination: Place attachment as the mediator and novelty seeking as the moderator. The Journal of Tourism Studies, 15(2), 51-66.

Govers, R., Go, F. M., \& Kumar, K. (2007). Promoting tourism destination image. Journal of Travel Research, 46(1), 15-23.

Gravetter, F. J., \& Forzano, L. B. (2012). Research methods for the behavioral sciences (4th ed.). Wadsworth.

Gunturo, B., \& Hui, T. K. (2013). Travel satisfaction and revisit intention of Chinese visitors: The case of Singapore. In J. S. Chen (Ed.), Advances in hospitality and leisure (pp. 29-47). Emerald.

Guzman-Parra, V. F., Roberto Vila-Oblitas, J., \& Javier Maqueda-Lafuente, F. (2016). Exploring the effects of cognitive destination image attributes on tourist satisfaction and destination loyalty: A case study of Málaga, Spain. Tourism \& Management Studies, 12(1), 67-73.

Hill, N., Brierley, J., \& MacDougall, R. (2003). How to measure customer satisfaction. Gower.

Horávth, Z. (2013). Cultural value perception in the memorable tourism experience. In M. Smith \& G. Richards (Eds.), The Routledge handbook of cultural tourism (pp. 375-381). Routledge.

Hsu, L. K., Graham, B., Michael, J. G., \& Sam, H. (2008). Tourism marketing: An Asia Pacific perspective. Wiley.

Huanga, S., \& Crottsb, J. (2020). Relationships between Hofstede's cultural dimensions and tourist satisfaction: A cross-country cross-sample examination. Tourism Management, 72, 232-241.

Hunt, J. D. (1971). Image: A factor in tourism [Unpublished PhD dissertation]. Colorado State University, Fort Collins, co.

Inkson, C., \& Minnaert, L. (2012). Tourism Management: An introduction. Sage.

Iordanova, E., \& Stylidis, D. (2019). International and domestic tourist 'a priori' and 'in situ' image differences and the impact of direct destination experience on destination image: The case of Linz, Austria. Current Issues in Tourism, 22(8), 982-1005.

Ispas, A., Constantin, C., and Candrea, A. N. (2016). Cultural tourism and museum marketing: Contributing to the development of Alba Julia's image. In A. M. Nedelea, M. Korstanje \& B. George (Eds.), Strategic tools and methods for promoting hospitality and tourism services (pp. 26-48).

Jankingthong, W. (2013). Destination Image in Thailand. Journal of Silpakorn University, 34(1), 31-50.

Johanson, G. A., and Brooks, G. P. (2010). Initial scale devel- opment: Sample size for pilot studies. Educational and Psychological Measurement, 70(3), 394-400.

Johnson, R. B., \& Christensen, L. (2008). Educational research: Quantitative, qualitative, and mixed approaches. Sage.

Kakai, V., \& Panchakachornsak, V (2011). Tourist destination loyalty model for Pattaya City. Journal Anthropology and Social Science, 19(31), 123-140.

Kanwel, S., Lingqiang, Z., Asif, M., Hwang, J., Hussain, A., \& Jameel, A. (2019). The influence of destination image on tourist loyalty and intention to visit: Testing a multiple mediation approach. Sustainability, 11(22), 6401. https://doi.org/10.3390/su11226401

Khunrattanaporn, T. (2013). The influences of marketing mix and the image of cultural tourism products on the loyalty of foreign tourists studying Thai culture [Unpublished $\mathrm{PhD}$ dissertation]. Ramkhamhaeng University, Bangkok.

Kim, J. H. (2018). The impact of memorable tourism experiences on loyalty behaviors: The mediating effects of destination image and satisfaction. Journal of Travel Research, 57(7), 856-870.

Kim, S., Lehto, X., \& Kandampully, J. (2019). The role of familiarity in consumer destination image formation. Tourism Review, 74(4), 885-901.

Kotler, P., \& Keller, K. L. (2012). Marketing management. Pearson Prentice Hall.

Ksouri, R., Ayoun, S., Storai, C., \& Abdellatif, T. (2015). The importance of the image of a destination in the choice and intention of revisiting: The case of Island of Djerba. SSRN Electronic Journal, 7(7), 1-24.

Lertputtarak, S. (2012). The relationship between destination image, food image, and revisiting Pattaya, Thailand. International Journal of Business and Management, 7(5), 111-121.

Liedtke, M. (2012). Bangkok travel guide: Bangkok \& the surrounding area. Lovely-Thailand.com.

Lin, C., Morais B. D., Kerstetter, L. D., \& Hou, J. (2007). Examining the role of cognitive and affective image in predicting choice across natural, developed, and themepark destinations. Journal of Travel Research, 46(2), 1-11.

Lertwannawit, A., \& Gulid, N. (2014). A structural relationship between domestic tourist satisfaction, trust, switching barriers and retention. International Business \& Economics Research Journal, 13(6), 1375-1382.

Lopes, S. D. F. (2011). Destination image origin, developments and implications. PASos Revista DeTurismo $y$ Patrimonio Cultural, 9(2), 305-315.

Maignan, I., Ferrell, O. C., \& Tomas M. Hult, G. (1999). Cor- 
porate citizenship: Cultural antecedents and business benefits. Journal of the Academy of Marketing Science, 27(4), 455-469.

Martins, M. (2015). The tourist imagery, the destination image and the brand image. Journal of Tourism and Hospitality Management, 3(2), 1-14.

Mayo, F. B. (2014). Planning an applied research project in hospitality, tourism, and sports. Wiley.

Meechinda, P., Sereerat, S., \& Kulis, N. (2008). Loyalty of Thai and international tourists to tourist destinations in Chaing Mai and Phuket. The Thailand Research Fund.

Melo, H., Moniz, A., Silva, F., \& Batista, M. (2017). Tourist destination image and consumer behavior: The case of the Azores. Journal of Spatial and Organizational Dynamics, 5(2), 73-82.

Moon, H., \& Han, H. (2019). Tourist experience quality and loyalty to an island destination: the moderating impact of destination image. Journal of Travel \& Tourism Marketing, 36(1), 43-59.

Murphy, P. E., \& Murphy, A. E. (2004). Strategic management for tourism communities: Bridging the gaps. Channel View Publications.

Oliver, R. L. (1980). A cognitive model of the antecedents and consequences of satisfaction decisions. Journal of Marketing Research, 17(4), 460-469.

Olson, S. O. (2006). Issues in exploring consumer attitudes and choice of seafood. In F. Asche (Ed.), Primary industries facing global markets: The supply chains and markets for Norwegian food and forest products (pp. 292-324). Universitetsforlaget As.

Parasakul, L. (2012). Tourist behavior. Chulalongkorn University.

Perpiña, L., Camprubí, R., \& Prats, L. (2017). Destination image versus risk perception. Journal of Hospitality \& Tourism Research, 43(1), 3-19.

Pike, S. (2008). Destination marketing: An integrated marketing communication approach. Elsevier.

Pike, S. (2016). Destination marketing essentials (2nd ed.). Routledge.

Prideaux, B., Timothy, J. D., \& Chon, K. (2008). Cultural and heritage tourism in Asia and the Pacific. Routledge.

Puh, B. (2014). Destination image and tourism satisfaction: The case of a Mediterranean destination. Mediterranean Journal of Social Sciences, 5(13), 538-544.

Qu, H., \& Kim, L. H., \& Im, H. H. (2011). A model of destination branding: Integrating the concepts of the branding and destination image. Tourism Management, 32(3), 465-476.

Quintal, V. A. (2010). Factors influencing tourists' revisit in- tentions. Asia Pacific Journal of Marketing and Logistics, 22(4), 554-578.

Rajesh, R. (2013). Impact of tourist perceptions, destination image and tourist satisfaction on destination loyalty: A conceptual model. Revista de Turismo y Patrimonio Cultural, 11(3), 67-78.

Ramkissoon, H., Uysal, M., \& Brown, K. (2011). Relationship between destination image and behavioral intentions of tourists to consume cultural attractions. Journal of Hospitality Marketing \& Management, 20(5), 575-595.

Read, N. (2011). Attitude research is science education. In I. M. Saleh \& M. Swe Khine (Eds.), Attitude research in science education: Classic and contemporary measurements (pp. 3-44). Information Age Publishing.

Richards, G. (2010). Creative tourism and local development. In R. Wurzburger, T. Angelson, A. Pattakos, \& S. Pratt (Eds.), Creative tourism: A global convention how to provide unique creative experience for travelers worldwide (pp. 78-9o). Sunstone Press.

Ruel, E. E., Wagner iı., W. E., \& Gillespie, B. J. (2016). The practice of survey research: Theory and applications. Sage.

Sangla-or, C., \& Kornpetprani, S. (2015). A causal relations model of destination loyalty in the Eastern Region for the Thai Tourists. Research Methodology and Cognitive Science, 12(2), 23-33.

Shafiee, M. M., Tabaeeian, A. A., \& Tavakoli, H. (2016, April). The effect of destination image on tourist satisfaction, intention to revisit and wом: An empirical research in Foursquare Social Media. Paper presented at the 1oth International Conference on E-Commerce with focus on e-Tourism, Isfahan, Iran.

Smith, S. L. J. (2017). Practical tourism research (2nd ed.). CABI.

Sonnleitner, K. (2011). Destination image and its effects on tourism marketing and branding. Lambert.

Sukpol, S. (2011). Study of the components affecting loyalty in cultural tourism, Khao Kred, Nonthaburi Province [Unpublished master thesis]. Ramkamhang University, Bangkok, Thailand.

Thiumsak, T., \& Ruangkanjanases, A. (2016). Factors influencing international visitors to revisit Bangkok, Thailand. Journal of Economics, Business and Management, 4(3), 220-230.

Tourism Authority of Thailand. (2009). A handbook for travelling 15 markets and 16 floating markets.

Tourism Collaborative Commerce. (2015). Tourism e-commerce.

Tsai, C. (2015). The relationships among destination image, perceived quality, emotional place attachment, tourist 
satisfaction, and post-visiting behavior intentions. Marketing Review, 12(4), 455-479.

Um, S., Chon, K., \& Ro, H. Y. (2006). Antecedents of revisit intention. Annals of Tourism Research, 33(4), 1141-1158.

Walters, G., \& Li, S. (2017). The role and influence of emotions on tourist behavior. In S. K. Dixit (Ed.), The Routledge handbook of consumer behaviour in hospitality and tourism (pp. 46-54). Routledge.

Wang, X., Zhang, J., Gu, C., \& Zhen, F. (2009). Examining antecedents and consequences of tourist satisfaction: A structural modelling approach. Tsinghua Science and Technology, 14(3), 397-406.
Wongkangwan, A. (2013). Factors and loyalty of international tourists to tourist attraction in Bangkok. Journal of Research and Development, 5(1), 85-99.

Zhang, H., Fu, X., Cai, L. A., \& Lu, L. (2014). Destination image and tourist loyalty: A meta-analysis. Tourism Management, 40, 213-223.

Zhang, J., Wu, B., Morrison, A. M., Tseng, C., \& Chen, Y. C. (2018). How country image affects tourists' destination evaluations: A moderated mediation approach. Journal of Hospitality and Tourism Research, 42(6), 904-930. 



\title{
Is International Tourism Growth Supported by Increased Tourism Receipts?
}

\author{
Helena Nemec Rudež \\ University of Primorska, Faculty of Tourism Studies - Turistica, Slovenia \\ helena.nemec@fts.upr.si
}

Tourism demand growth during the period between 2000 and 2016 in 25 European countries is calculated using different tourism indicators. It is shown that the number of tourist arrivals and aggregate tourism receipts increase during the period. Tourism receipts per arrival at current prices show a slight increase in the majority of selected countries, while tourism receipts per arrival at constant prices more or less stagnate, ranging from $-2 \%$ to $+2 \%$, and even exhibit sharper decrease in some countries of Southern and Eastern Europe. It can be concluded that tourism growth is predominantly fueled by the increasing number of tourist arrivals and not by receipts per tourist arrival.

Keywords: international tourism, demand growth, European countries

(cc)BY-SA https://doi.org/10.26493/2335-4194.13.153-156

\section{Introduction}

There are plenty of data reports highlighting the remarkable growth of tourism demand worldwide and discussing the challenges and issues related to tourism expansion. Since there is plenty of literature in the field of tourism demand (for instance, Dogru et al., 2017; Peng et al., 2014; Song et al., 2012) and the tourism industry is one of the most important industries nowadays, generating an important share of GDP and export in many countries, the concept of tourism demand growth should be understood properly. There are various indicators used to measure it in the literature (for instance, Crouch, 1994; Lim, 1997; Li et al., 2005; Song et al., 2010), finding that the number of tourist arrivals is the most-used indicator of tourism demand in academic papers, followed by tourism receipts; on the other hand, the average length of stay and the number of overnight stays are rarely used. Indeed, from the suppliers' viewpoint, the number of tourist arrivals is relevant for transport suppliers and tourist attractions, while the number of overnight stays is obviously more relevant for accommodation facilities. As tourism receipts are important for the country's economy, tourist receipts per arrival give additional information on tourists' spending during their stay and price level.

Sheldon (1993 in Song et al., 2010) and GarciaFerrer and Queralt (1997 in Song et al., 2010) highlighted the difference between the growth in international tourist arrivals and the growth in international tourism receipts. Looking at quantitative tourism indicators (World Tourism Organization, 2018), fluctuations in their values are expressed in short-term periods, while steady long-term growth is observed. The increase in physical indicators (number of arrivals and overnight stays) that is higher than the increase in tourism receipts in the long-run period underlies orientation of tourism demand towards low cost products (such as budget accommodations and low-cost travel) along with the boost of sharing economy providers, promotion sales and sharp competition causing the prices to drop.

There arises a question why tourism demand is increasing - is the reason only in the higher number of 
tourist arrivals or do tourists really spend more? In times when academics, managers and tourism planners are discussing tourism growth at length, the paper attempts to assess the quantitative changes in tourism growth in 25 selected countries across Europe which still has the highest share of international tourists in the world.

\section{Methodology and Data Sources}

The research deals with 25 selected European countries during the 17-year period between 2000 and 2016 in order to research average annual growth rates of tourism indicators. For this reason the following annual data for the 25 European countries were gathered separately: (a) the number of international arrivals, (b) international tourism receipts for travel items (in USD, current prices) (see http://dataworldbank.org) and, (c) GDP deflator $(2010=100)$ for USD (see http://www .imf.org), in order to get changes in tourism export at constant prices. Based on these data, the following indicators were used for further analysis for each country:

- The number of international arrivals;

- Tourism export (at current prices) ${ }^{1}$ represented by international tourism receipts for travel items (in USD, current prices);

- Tourism export per international arrival (at current prices) which is calculated by dividing tourism export (in USD, current prices) by the number of international arrivals;

- Tourism export per international arrival (at constant prices) which is calculated by dividing tourism export (in USD, constant prices) ${ }^{2}$ by the number of international arrivals.

Sixteen annual growth rate coefficients $\left(r_{i}\right.$; where $i$ stands for $2,3, \ldots, 17)$ were calculated for each of the four indicators for each country as follows:

${ }^{1}$ Data for international arrivals for Denmark between 2000 and 2004 are adapted using average annual growth rate between 2005 and 2016.

${ }^{2}$ Tourism export at constant prices in USD (TEreal) is calculated using tourism export at current prices in USD (TEnominal) and USD GDP deflator $(2010=100)$ as follows: $\mathrm{TE}_{\text {real }}=\mathrm{TE}_{\text {nominal }} /(\mathrm{USD}$ GDP deflator/100).

$$
r_{i}=\frac{\text { value in year } n}{\text { value in year } n-1},
$$

where $n$ represents $2,3, \ldots, 17$.

Based on sixteen annual growth rate coefficients $\left(r_{i}\right)$, the average annual growth rate coefficient $(r)$ was compounded for each of the four indicators for 25 countries separately. The following equation was used:

$$
r=\sqrt[16]{r_{2} \times r_{3} \times \cdots \times r_{17}}
$$

\section{Findings}

Looking at Table 1, the number of international tourist arrivals has increased the most in Iceland (11.8\%) during the period between 2000 and 2016 whereas in Poland it has remained more or less at the same level. Thus, average annual growth rate was positive in all 25 countries. Besides Poland, very low average annual growth rate in the number of tourist arrivals is found in mature destinations, like France (0.4\%) and Belgium (0.9\%). Higher growth rate, around $1 \%$ on average, is detected in Western countries, like Denmark (1.1\%) and Italy (1.5\%). In contrast, average annual growth rate of international tourist arrivals is higher in Turkey (7.5\%) and in some Eastern European countries that represent emerging markets, like Estonia (6.1\%), Latvia (8.2\%) and Slovenia (6.6\%). Since these are countries with lower purchasing power along with lower price levels compared to the Western European countries, we can assume that price competitiveness of Turkey and Eastern European countries might have played a vital role in attracting tourists.

Receipts of foreign tourists are measured by tourism export. The average annual growth rates of tourism export by selected country are shown in Table 1 . The lowest growth rate of tourism receipts is found in a mature destination - France (1.6\%). The highest ones were found in Iceland (15.9\%) and two Eastern European countries. In addition, compared to the growth rate of international tourist arrivals, international tourism receipts have grown faster in the majority of countries researched (with the exception of Slovenia, Hungary, Greece and Turkey).

Besides aggregate measures, the tourism demand per arrival gives better information about an average tourist's consumption behaviour. International 
Table 1 Average Annual Growth Rate Coefficients of International Tourist Arrivals, Tourism Export at Current Prices, Tourism Export per Arrival at Current and Constant Prices in Selected European Countries during the Period between 2000-2016

\begin{tabular}{lrrrr}
\hline Country & $(1)$ & $(2)$ & $(3)$ & $(4)$ \\
\hline Austria & 1.0283 & 1.0424 & 1.0137 & 0.9945 \\
Belgium & 1.0092 & 1.0360 & 1.0265 & 1.0071 \\
Czech Republic & 1.0427 & 1.0481 & 1.0052 & 0.9862 \\
Denmark & 1.0107 & 1.0416 & 1.0305 & 1.0111 \\
Estonia & 1.0610 & 1.0697 & 1.0081 & 0.9891 \\
Finland & 1.0219 & 1.0420 & 1.0197 & 1.0004 \\
France & 1.0042 & 1.0164 & 1.0122 & 0.9930 \\
Germany & 1.0400 & 1.0447 & 1.0045 & 0.9855 \\
Greece & 1.0407 & 1.0297 & 0.9894 & 0.9707 \\
Hungary & 1.0364 & 1.0265 & 0.9905 & 0.9717 \\
Iceland & 1.1175 & 1.1591 & 1.0373 & 1.0177 \\
Ireland & 1.0265 & 1.0439 & 1.0169 & 0.9977 \\
Italy & 1.0151 & 1.0243 & 1.0090 & 0.9900 \\
Latvia & 1.0819 & 1.1254 & 1.0402 & 1.0206 \\
Luxembourg & 1.0134 & 1.0564 & 1.0425 & 1.0228 \\
Netherlands & 1.0291 & 1.0427 & 1.0132 & 0.9941 \\
Norway & 1.0416 & 1.0602 & 1.0178 & 0.9986 \\
Poland & 1.0003 & 1.0421 & 1.0418 & 1.0221 \\
Portugal & 1.0444 & 1.0636 & 1.0183 & 0.9991 \\
Slovakia & 1.0418 & 1.1225 & 1.0775 & 1.0571 \\
Slovenia & 1.0660 & 1.0596 & 0.9940 & 0.9752 \\
Spain & 1.0307 & 1.0454 & 1.0142 & 0.9950 \\
Sweden & 1.0364 & 1.0735 & 1.0358 & 1.0162 \\
Turkey & 1.0746 & 1.0577 & 0.9843 & 0.9657 \\
\hline K & 1.0275 & 1.0411 & 1.0132 & 0.9941 \\
\hline
\end{tabular}

Notes Column headings are as follows: (1) average annual growth rate coefficient of international tourist arrivals, (2) average annual growth rate coefficient of tourism export (current prices), (3) average annual growth rate coefficient of tourism export per international arrival (current prices), (4) average annual growth rate coefficient of tourism export per international arrival (constant prices $2010=100$ ).

tourism receipts per arrival (at current prices) perform a positive but modest average annual growth rate in 21 out of 25 countries during the period between 2000 and 2016. The highest one is perceived in Slovakia with an average annual increase of $7.8 \%$, followed by Luxemburg, Poland and Latvia with an increase between $4.0 \%$ and $4.3 \%$. In Slovenia, Turkey, Greece and Hungary average annual growth rate of international tourism receipts per arrival is less than 1 , confirming that receipts per arrival have been decreasing in four out of 25 countries during this period.

By removing the impact of price changes, international tourism receipts per arrival at constant prices reveal real changes in tourism receipts per arrival over time. It has ranged between $2 \%$ to $+2 \%$ in the majority of 25 countries. Further, Greece, Hungary and Slovenia were confronted with a negative average annual growth rate of international tourism receipts per arrival at constant prices between $-2 \%$ and $-3 \%$, whereas Luxemburg, Latvia and Poland have reached the one between $+2 \%$ and $+2.3 \%$. The strongest negative growth rate in receipts per tourist arrival in real terms was found in Turkey (below 3\%) and the highest positive one in Slovakia (above $5 \%$ ).

\section{Concluding Remarks}

International tourism growth is fueled by the increasing number of foreign tourist arrivals as well as by international tourism receipts, but tourism receipts per arrival more or less stagnate. However, there are differences between countries. The highest difference between the average annual growth rate of the number of tourist arrivals and the average annual growth rate of tourism receipts at constant prices is found in Turkey, followed by Iceland and Slovenia. On the other hand, Poland, Slovakia and Luxemburg have had an even slightly higher average annual rate of tourism receipts at constant prices than that of tourist arrivals; both average annual growth rates are also practically equal in Denmark.

It can be derived from this that some countries have not succeeded in attracting tourists who spend more money during their stay, probably due to the increased level of competition. In other words, the increased number of international tourist arrivals related to mass tourism is not reflected in substantive additional receipts per tourist. It can be explained in two ways. Firstly, low-cost business models (such as 
low-cost airlines, budget accommodation) and fierce competition among traditional suppliers as well as the sharing economy suppliers (in the field of accommodation, dining, travel guiding, transport) lead to a price decrease and, in turn, a decline in international tourism receipts per arrival. Secondly, the decreasing average length of overnight stays in line with the trend of travelling more times a year for a shorter period of time has probably had an impact on the growth rate of international tourism receipts per tourist arrival.

Further research could identify the reasons why the growth rate of international tourist arrivals outpaces the growth rate of international tourism receipts per tourist in real terms, how is it related to pricing strategies and what, consequently, are the perceptions and attitudes of residents towards tourists. Additional research could be extended to the overnight stays' growth rate in order to give additional knowledge about how international tourism receipts per overnight stay change.

The limitation of the study is that the growth of international tourism receipts is calculated per arrival as a unit and not per overnight stay, giving somewhat different results, especially for countries with a longer average period of stay. An additional limitation is that only international tourism is analysed. Moreover, it is worth noting that tourism export data use USD, enabling some exchange rate distortions in time series due to exchange rate fluctuations. The analysis is oriented towards demand in the European region where tourism demand is growing slower than in other regions, so the findings cannot be generalised worldwide.

\section{References}

Crouch, G. I. (1994). The study of international tourism demand: A survey of practice. Journal of Travel Research, 32(4), 41-55.

Dogru, T., Sirakaya-Turk, E., \& Crouch, G. I. (2017). Remodeling international tourism demand: Old theory and new evidence. Tourism Management, 60, 47-55.

Garcia-Ferrer, A., \& Queralt, R. A. (1997). A note on forecasting international tourism demand in Spain. International Journal of Forecasting, 13(4), 539-549.

Li, G., Song, H., \& Witt, S., F. (2005). Recent developments in econometric modeling and forecasting. Journal of Travel Research, 44(1), 82-99.

Lim, C. (1997). Review of international tourism demand. Annals of Tourism Research, 24(4), 835-849.

Peng, B., Song, H., \& Crouch, G. I. (2014). A meta-analysis of international demand forecasting and implications for practice. Tourism Management, 45(1), 181-193.

Sheldon, P. J. (1993). Forecasting tourism: Expenditures versus arrivals. Journal of Travel Research, 32(1), 13-20.

Song, H., Dwyer, L., Li, G., \& Cao, Z. (2012). Tourism economics research: A review and assessment. Annals of Tourism Research, 39(3), 1653-1682.

Song, H., Li, G., Witt, S. H., \& Fei, B. (2010). Tourism demand modeling and forecast: How should demand be measured? Tourism Economics, 16(1), 63-81.

World Tourism Organization. (2018). UNWTO Tourism Highlights. 


\title{
Pillars of City Spatial Sensitivity and Their Integration into Sightseeing Routes
}

\author{
Melita Rozman Cafuta \\ University of Maribor, Faculty of Civil Engineering, Transportation Engineering and \\ Architecture, Slovenia \\ melita.rozman-cafuta@um.si
}

\section{Boštjan Brumen}

University of Maribor, Faculty of Tourism, Slovenia

bostjan.brumen@um.si

Worldwide, many cities have appropriate and necessary conditions for the development of urban tourism. Some locations, although considered important for local tourist destinations as part of a standard repertoire, do not comply with modern standards. For tourism organisations, it is very important to plan the best possible sightseeing routes with the best sightseeing locations. Using the intuitive approach only, is not enough in the modern tourism industry. The focus of the presented research is an innovative approach to identify the most prosperous urban places that should be included in urban tourist offers. Empirical research was conducted, based on the analytical method of mental mapping. For the research location, Maribor city (Slovenia, EU) has been chosen. A sample of 200 respondents was taken. They were asked to draw a city map twice, once for the daytime city and once for the nighttime city. Graphical results obtained reflect a subjective mental spatial idea of individual thinking mode. Some locations in the city seem to be particularly important and visible. They were named 'Pillars of Spatial Sensitivity' or, pss locations. Ps locations are extremely suitable to be integrated in a tourist offer as building blocks of sightseeing routes. When processing the research results, 34 Pss locations were more or less frequently detected in Maribor city. 32 of them had different appearance frequency between day and night. Based on these results, it is possible to conclude that modified spatial circumstances affect the perception and utilisation of urban space. The research results make it obvious that spatial sensitivity of tourists depends on time. It is possible to design sightseeing routes adapted to the time component.

Keywords: urban tourism, pillars of spatial sensitivity, mental map, sightseeing location

(cc)BY-SA https://doi.org/10.26493/2335-4194.13.157-166

\section{Introduction}

Urban tourism is 'a complex phenomenon, which is heavily involved in the local, regional and national environment' (Rangus et al., 2017, p. 167). Nowadays, it is rapidly expanding because people visit foreign cities for many different reasons as long-stay or short-stay tourists (Ashworth \& Page, 2011). Planning appropriate sightseeing routes has become a challenging task for tourist guides as well as for individuals visiting unfamiliar urban destinations. The whole city represents 
the physical place in which the tourist's desire is accomplished. Today, most cities aim to promote themselves as tourist destinations to increase their competitiveness, while tourism is seldom studied as an intrusive activity because of its indisputable positive economic effects (Fistola et al., 2019).

Visits to museums, galleries, and religious and archaeological sites are a usual part of the tourist's routine in urban destinations. Points of Interests should be narrowed down, and aligned with personal interests and trip constraints (Gavalas et al., 2016). However, field studies have revealed that tourists seek to maximize the time spent wandering around an urban space, engaging all their body senses while 'on the move' (Larsen, 2001; Shoval \& Isaacson, 2007). They appreciate observing everyday life activities and discovering different scenic values as much as they care about the cultural and architectural elements of a historical district.

Tourists today have become increasingly dependent on mobile city guides or tourist guide companies to locate tourist services and retrieve informative content (opening hours, entrance fees, etc.) about nearby points of interest. The main aim is planning the best possible sightseeing routes with the best sightseeing points. Ad hoc spatial decisions are no longer acceptable. The human dimension in the form of scenic route planning environmental perception sensitivity is not included.

Previous research on tour planning problems is broadly divided into several directions. Some studies are devoted to solving the mathematical programming problems. Other studies are devoted to dynamically planning an optimal itinerary which is related to designing intelligent tour planning systems (Hasuike et al., 2014). There is also research on various tour planning problems such as the tourist trip design problem (Souffriau et al., 2008), and the tour planning problem in a multimodal and time-scheduled urban public transport network (Zografos \& Androutsopoulos, 2008). However, existing mathematical models for sightseeing do not include subjective perception values of sightseeing places. Mental mapping is a useful method for revealing how visitors spatially perceive tourism destinations. However, studies of this kind are under-researched in the tourism field (Younghee Lee et al., 2018).

The focus of the presented research is to reveal urban places with a great perception value and to identify the most favourable areas that should be integrated into sightseeing routes. To ensure tourists' well-being and high environmental perception sensitivity are priorities. We assumed that, if some places trigger positive emotions for dwellers, they have the same positive impact on tourists. Although public preferences on environment are shaped by many different factors, such as age, gender, social and economic status, etc., there are also some common preferences on urban types, especially for people with similar educational background and environmental viewpoints.

Today's standard repertoire of sightseeing locations may not comply with modern standards. Therefore, it is essential to seek new locations to keep sightseeing routes attractive. Locations with high environmental perception sensitivity should be included. What is seen and what is remembered? After a while, tourists do not perceive every architectural and environmental detail. But they perceive well-being as a combination of environmental settings, people and service at the location. Tourists' spatial sensitivity changes over time. Do the appropriate sightseeing locations change too? In this context, the following is crucial: (a) to identify locations that have high spatial sensitivity and (b) to know when these locations can be integrated into sightseeing routes.

The research concentrates on a scientific approach based on an analytical method of mental mapping as an assessment tool. There is a tendency to answer all raised questions using the following hypothesis:

$\mathrm{H} 1$ Spatial sensitivity of tourists depends on time.

$\mathrm{H} 2$ Based on the value of spatial sensitivity, it is possible to design sightseeing routes adapted to the time component.

\section{Tourists' Cognitive Experience of the City and Spatial Sensitivity}

The structure of the city is not permanent. It changes over time. Urban development is guided by social progress and technological capabilities (Rozman Ca- 
futa \& Brumen, 2016). The city of tomorrow strikes a balance among social, environmental and economic needs (Rozman Cafuta, 2015). Urban tourism can contribute substantial economic benefits to certain city areas with a large and varied economic base. These gain the most from tourism but are the least dependent upon it (Ashworth \& Page, 2011). The challenge comes with lesser-known parts of the city with a low level of tourist infrastructure. How to seek for opportunities in such areas, especially if the economic base is weak? How to define potential places that are appropriate to be developed and integrated into sightseeing routes?

Generally, the environment should create a good personal feeling. To ensure satisfied tourists, environmental circumstances should be adjusted. To establish interaction between the urban environment and its users (tourists), it is necessary to understand how they perceive their surroundings. Spatial circumstances are not only material reality, but are also mental structures that result in subjective perception. Spatial sensitivity is always subjective because it relies on individual response. It is dependent upon the individual's gender, age, time, experience, and culture (Rozman Cafuta, 2015). Visual perception dominates over hearing, smell, taste, and touch. Eyesight provides the largest amount of information to explain what happens around us. We are supplied with a large amount of information such as: distance, colours, shapes, textures, and contrasts (Gregory, 1998).

Environment defines a cognitive image of a specific location, like any human performance that includes physical and mental links between an observed location and its surroundings (Canter, 1977). Using information obtained by different authors, a triangular scheme was created using a method of inductive conclusion in order to determine what influences tourists' spatial sensitivity (Figure 1). Tourists' spatial sensation depends on factors such as psychological, sociological, and aesthetic-functional. All of them are equal and connected. Tourists respond and act in accordance with them.

The scheme represents the most important factors and their indicators that must be taken into account when planning and arranging sightseeing routes, such as: sense of safety, orientation ability, path and loca-

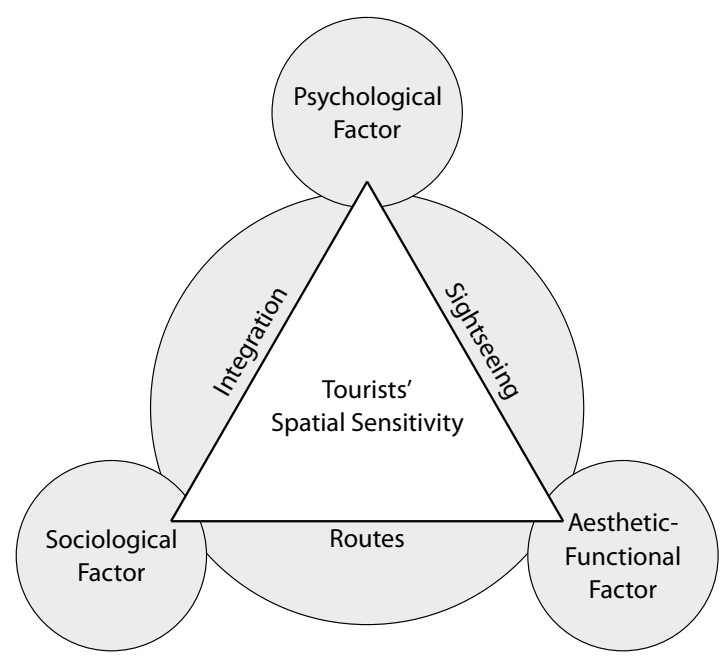

Figure 1 The Triangular Scheme of Tourists' Spatial Sensitivity Factors and Indicators

tion selection, way of movement, visual preferences and general place arrangement. The quality of service depends on it. Therefore, it is justified to explore how the time component and physical surroundings affect tourists' environmental sensation.

\section{Spatial Analysis by the Mental Mapping Method}

As already mentioned, environmental sensation is a complex process. Spatial sensitivity means recognising, collecting and organising received information. Through this procedure it is possible to be aware of our relative spatial position in relation to existing limitations. According to Canter (1977), the concept of space is based on individual cognitive experience and designated by the composite conceptual system. We are informed about a place through 'what behaviour is associated with, or is anticipated to be housed in it, what physical parameters of the settings are, and the description, or conceptions, which people hold of their behaviour in that physical environment' (p. 159). A place is set with a specific physical location and activities taking place in it. It is humans' cognitive experience of the material world and offers a concrete visual metaphor. The message of space ultimately depends on individual interpretation decomposing and recomposing its cryptic meanings (Šerman, 1997). 

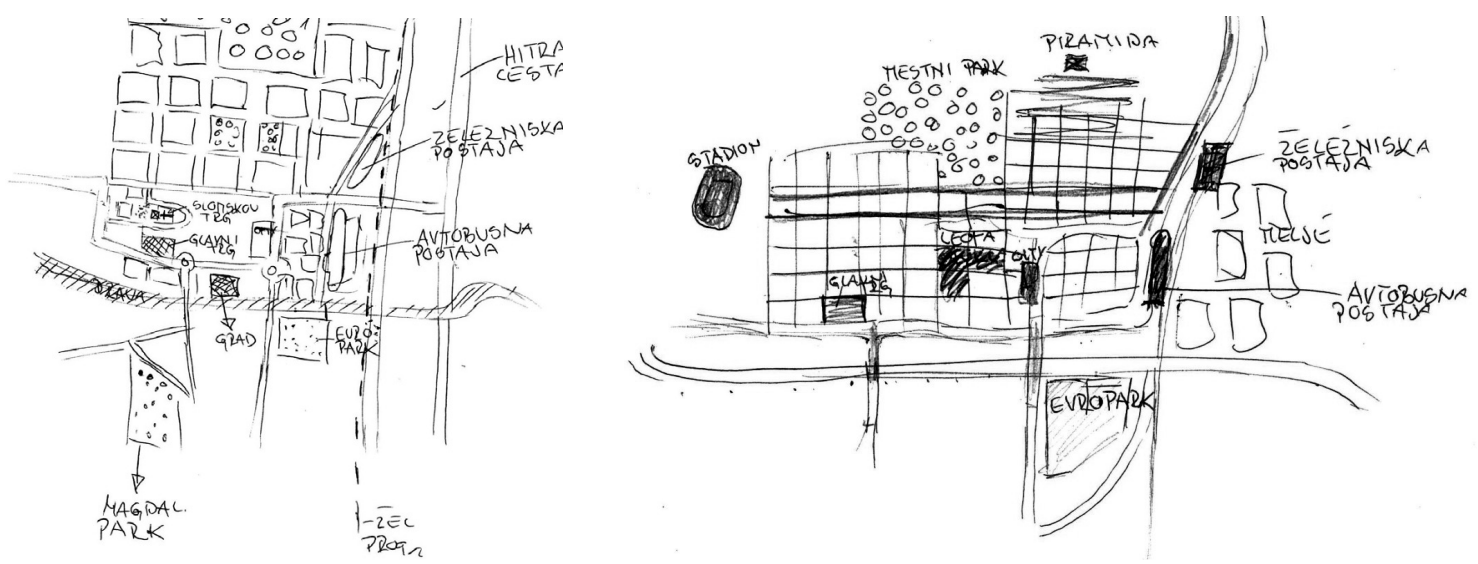

Figure 2 Mental Map of Maribor City (Slovenia, Europe); First During the Daytime and Second During the Nighttime (Graphical Output of Test Person)

In the sixties and seventies, urban theorists began studying the relationship between the reality and the idea of the space (Evans 1980; Liben et al., 1981; Lynch, 1960). Lynch's (1960) and Golledge's (1978) early studies have shown that our space perception can be articulated, evaluated and categorised. Tolman (1984) was the first who introduced the idea of cognitive mapping. Later, Downs and Stea (1973) upgraded his behavioural approach as a process composed of psychological transformations strings by which an individual acquires, codes, stores, recalls, and decodes information about the relative location and its attributes.

Today, cognitive mapping is the mental structuring process leading to the formation of a cognitive map. A cognitive map is a set of mental images. Environmental sensing enables identification of objects or areas, and determination of the distance between various points or patterns. Spatial visualization enables everyday movement, route planning, understanding the route descriptions and map reading. In more general terms, a cognitive map may be defined as an overall mental image or representation of the space and layout of a setting' (Arthur \& Passini, 1992).

Cognitive maps are a spatial representation of the outside world that is kept within the mind, until an actual manifestation (a drawing) of this perceived knowledge is generated, and a mental map is put down on paper. Cognitive mapping is the implicit, mental mapping the explicit, part of the process. Mental mapping has developed over the years. Today it has theoretical and practical potential to understand human environmental exchange. It comprises a subjective awareness of the surroundings and provides an insight into an individual's spatial sensitivity.

\section{Case Study: Maribor City}

In the presented research we upgraded the alreadyknown mental mapping method. In the previous practices, residents draw a map, from memory, of their city or some other research area. This allows the researcher to get a sense of which parts of the city are more substantial or imaginable. Tourists quickly developed cognitive images that are influenced by experience and the time spent in the area (Walmsley \& Jenkins, 1992). Similar use of mental maps is also applied in the presented research in order to identify specific points of interest that are sufficiently perceived and have enough potential to be included in sightseeing routes. Locations with high values of spatial sensitivity are generally the gathering sites of tourist spots. The research focus relied on a spatial impression of the city. It was attempted to give sensible form to the moods, feelings, and rhythms of functional life.

The conducted experiment was based on a sample of 200 respondents, 100 men and 100 women. All participants were students at the University of Maribor in Slovenia. The respondents can be equated as longterm tourists (they do not live at the research loca- 
Table 1 Occurrence Frequency of Pss Locations on Mental Maps

\begin{tabular}{|c|c|c|c|c|c|c|}
\hline \multirow[t]{2}{*}{ Pss location } & \multicolumn{2}{|c|}{ Day } & \multicolumn{2}{|c|}{ Night } & \multirow[t]{2}{*}{$\chi^{2}$} & \multirow[t]{2}{*}{$p$} \\
\hline & $f$ & $f \%$ & $f$ & $f \%$ & & \\
\hline River Drava & 160 & 80.0 & 147 & 73.5 & 33.269 & 0.000 \\
\hline Gosposka Street & 24 & 12.0 & 14 & 7.0 & 20.585 & 0.000 \\
\hline Poštna Street & 25 & 12.5 & 17 & 8.5 & 4.858 & 0.000 \\
\hline Koroška Street & 26 & 13.0 & 19 & 9.5 & 10.552 & 0.001 \\
\hline L. Štukelj Square & 41 & 20.5 & 52 & 26.0 & 24.281 & 0.000 \\
\hline Castle Square & 26 & 13.0 & 19 & 9.5 & 21.926 & 0.000 \\
\hline Main Square & 84 & 42.0 & 84 & 42.0 & 29.528 & 0.000 \\
\hline $\begin{array}{l}\text { A. M. Slomšek } \\
\text { Square }\end{array}$ & 85 & 42.5 & 73 & 36.5 & 35.223 & 0.000 \\
\hline Lent, Old City & 58 & 29.0 & 42 & 21.0 & 14.115 & 0.000 \\
\hline City Park & 58 & 29.0 & 17 & 8.5 & 15.607 & 0.000 \\
\hline $\begin{array}{l}\text { Ski slope Mari- } \\
\text { borsko Pohorje }\end{array}$ & 29 & 14.5 & 19 & 9.5 & 8.573 & 0.014 \\
\hline Hills & 54 & 27.0 & 35 & 17.5 & 27.674 & 0.000 \\
\hline Footbridge & 47 & 23.5 & 37 & 18.5 & 37.747 & 0.000 \\
\hline Old Bridge & 133 & 66.5 & 115 & 57.5 & 42.553 & 0.000 \\
\hline Main Bridge & 92 & 46.0 & 84 & 42.0 & 34.253 & 0.000 \\
\hline Koroška Bridge & 68 & 34.0 & 56 & 28.0 & 35.651 & 0.000 \\
\hline University & 70 & 35.0 & 52 & 26.0 & 32.241 & 0.000 \\
\hline Town Hall & 25 & 12.5 & 16 & 8.0 & 5.590 & 0.018 \\
\hline Main Post Office & 15 & 7.5 & 8 & 4.0 & 10.811 & 0.001 \\
\hline Town Market & 12 & 6.0 & 5 & 2.5 & 10.551 & 0.001 \\
\hline Football Stadium & 55 & 27.5 & 37 & 18.5 & 19.491 & 0.000 \\
\hline $\begin{array}{l}\text { Shopping Centre } \\
\text { Europark }\end{array}$ & 87 & 43.5 & 87 & 43.5 & $44 \cdot 380$ & 0.000 \\
\hline
\end{tabular}

Continued in the next column

tion, they come and go like visitors) or dwellers (while studying, they live at the research location). For the research location Maribor city has been chosen. Maribor is a vibrant, and the second largest, Slovenian city. It is a centre of the Styrian region and a semi-important tourist destination with medieval historical value.

The experiment was based on a memorised drawing of a city map and elements within it during different time sequences. Respondents were asked to imagine the city and put down a map of it. They were encouraged to create two drawings, once for the day-
Table 1 Continued from the previous column

\begin{tabular}{lrrrrrrrr}
\hline \multirow{2}{*}{ Pss location } & \multicolumn{2}{c}{ Day } & & \multicolumn{2}{l}{ Night } & \multirow{2}{*}{$\chi^{2}$} & $p$ \\
\cline { 2 - 3 } & $f$ & $f \%$ & & $f$ & $f \%$ & & \\
\hline Medical Faculty & 29 & 14.5 & 23 & 11.5 & 2.814 & 0.092 \\
Shopping Centre & 25 & 12.5 & 25 & 12.5 & 14.426 & 0.000 \\
City & & & & & & \\
Hall Stuk & 26 & 13.0 & 29 & 14.5 & 37.319 & 0.000 \\
Main Rail Station & 45 & 22.5 & 27 & 13.5 & 34.918 & 0.000 \\
Medical Centre & 51 & 25.5 & 34 & 17.0 & 49.742 & 0.000 \\
Movie Theatre & 50 & 25.0 & 54 & 27.0 & 28.446 & 0.000 \\
Kolosej & & & & & & \\
Student Hostel & 20 & 10.0 & 12 & 6.0 & 7.723 & 0.000 \\
Monument NOB & 21 & 10.0 & 8 & 4.0 & 6.464 & 0.011 \\
Plague Monument & 20 & 10.0 & 26 & 13.0 & 14.324 & 0.000 \\
Engineering Facul- & 50 & 25.0 & 22 & 11.0 & 15.322 & 0.000 \\
ties & & & & & & \\
Franciscan Church & 28 & 14.0 & 17 & 8.5 & 16.730 & 0.000 \\
Theatre & 25 & 12.5 & 26 & 13.0 & 9.120 & 0.003 \\
\hline
\end{tabular}

time city and once for the nighttime city. They had 10 minutes to complete each drawing (20 minutes altogether).

\section{Results and Discussions}

The obtained drawings were analysed according to the included or excluded elements. Spatial sensitivity is the respondents' mental image reflection. Already, every element that appears on a respondent's map is a spatial sensitivity carrier. When graphical outputs were analysed, 36 elements, more or less frequently detected, were exposed, such as: streets, squares, parks, morphological features, architectural attractions, and urban furniture. All exposed elements appear at least 10 times or more during daytime; the detected frequency is at least $5 \%$ or more (Table 1 ). The results show that the responders noticed most of the locations lying in the city centre, but only a few points in the wider surroundings. Such location distribution confirms the assumption that locations in the city centre are very noticeable and have a high value of spatial sensitivity. It is not surprising that most of the sightseeing routes already take place in the city centre. However, expanding the sightseeing routes on selected locations 
in the wider surroundings should also be considered.

In the second phase, obtained graphical data were statistically processed and analysed using the SPSS Windows computer program. Methods of descriptive statistics (frequency and numerical analysis, the arithmetic mean of the difference between the mean, and standard deviation) and inferential statistics ( $t$-test for dependent samples, and Pearson's correlation coefficient $r$ ) were used. The results in Table 1 show that almost all listed locations have different occurrence frequency. All exposed locations have specific characteristics that differentiate them from their surroundings. Their common qualities are good visibility, good accessibility, transportation network involvement, high usage frequency, high quality of spatial arrangement, higher property and rental values, etc. These are spatial qualities that are strictly necessary for tourist locations. In the presented research such locations are named Pillars of Spatial Sensitivity (pss locations). Pss locations have high spatial sensitivity value. They are spatial identity carriers and they stay in tourists' minds for a long time. Occurrence frequency is a criterion of importance.

During the day the most often noticed locations are the River Drava (160 times), Old Bridge (133 times), Main Bridge (92 times), A. M. Slomšek Square (92 times), Shopping Centre Europark (87 times), Main Square ( 84 times) and so on. During the night the most often noticed locations are the River Drava (147 times), Old Bridge (115 times), Shopping Centre Europark (87 times), Main Square (84 times), Main Bridge (84 times), and A. M. Slomšek Square (73 times). It can be concluded that some locations are in the group of the most often noticed ones in nearly everyone's mind, regardless of the time period. Such locations are suitable to be a part of sightseeing routes.

Locations are less noticeable at night except for the following locations: 7 (Leon Štukelj Square), 22 (Theatre), 30 (Hall Štuk), 31 (Main Bus station), 34 (Movie Theatre Kolosej), and 38 (Plague Monument). The results of the $\chi^{2}$-test confirm that spatial sensitivity depends on time. In the majority of cases we reach a statistically characteristic difference in the incidence of elements between day and night at the statistically significant level $p<0.05$. Hypothesis one is con- firmed. Spatial sensitivity of tourists depends on time.

If we want to plan the best possible sightseeing routes, it is necessary to identify the specific locations that make the observed city distinctive. Locations with a high noticed frequency should be part of a sightseeing route. Obviously, they trigger positive emotions. Locations with a low noticed frequency should be excluded. The emotions could be negative or simply not strong enough. Sometimes a location is suitable just for a specific time sequence. Generally, there are the following possible scenarios:

1. The location has high spatial sensitivity value. Noticed frequency is high regardless of time sequence. The location should be included in sightseeing routes.

2. The location has low spatial sensitivity value. Noticed frequency is low regardless of time sequence. The location should be excluded from sightseeing routes or it should undergo a complete architectural renovation of the location to be more functional.

3. The location has variable spatial sensitivity value. Noticed frequency is low or high depending on the time sequence. The location should be included in sightseeing routes only at a certain time.

By presenting possible scenarios hypothesis two is also confirmed. Based on the value of spatial sensitivity, it is possible to design sightseeing routes adapted to the time component. Application in practice is shown in three cases in Maribor City.

\section{Example 1: Location Gosposka Street}

(Variable Spatial Sensitivity Value)

Gosposka Street is one of the oldest streets, shaped in the 17 th century. Today it is a part of a wider pedestrian zone and well-known market street. Buildings' ground floors are occupied by shops or services, while upper floors are residential flats. The street is well accessible from various directions. At night, buildings' verticals are not visible. Illuminated shop windows are accentuated. General street brightness is uneven.

The location belongs to the standard repertoire of most existing sightseeing routes. It has high noticed 

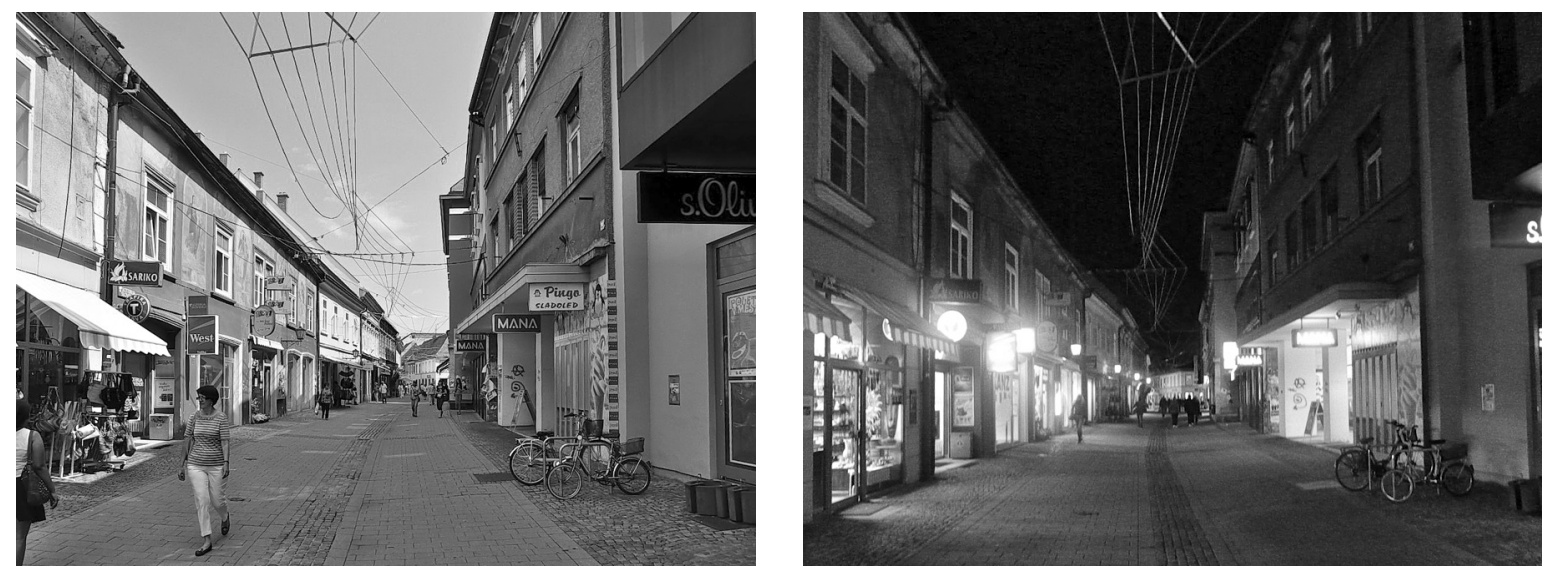

Figure 3 Gosposka Street During Daytime (left) and Gosposka Street During Nighttime (right)
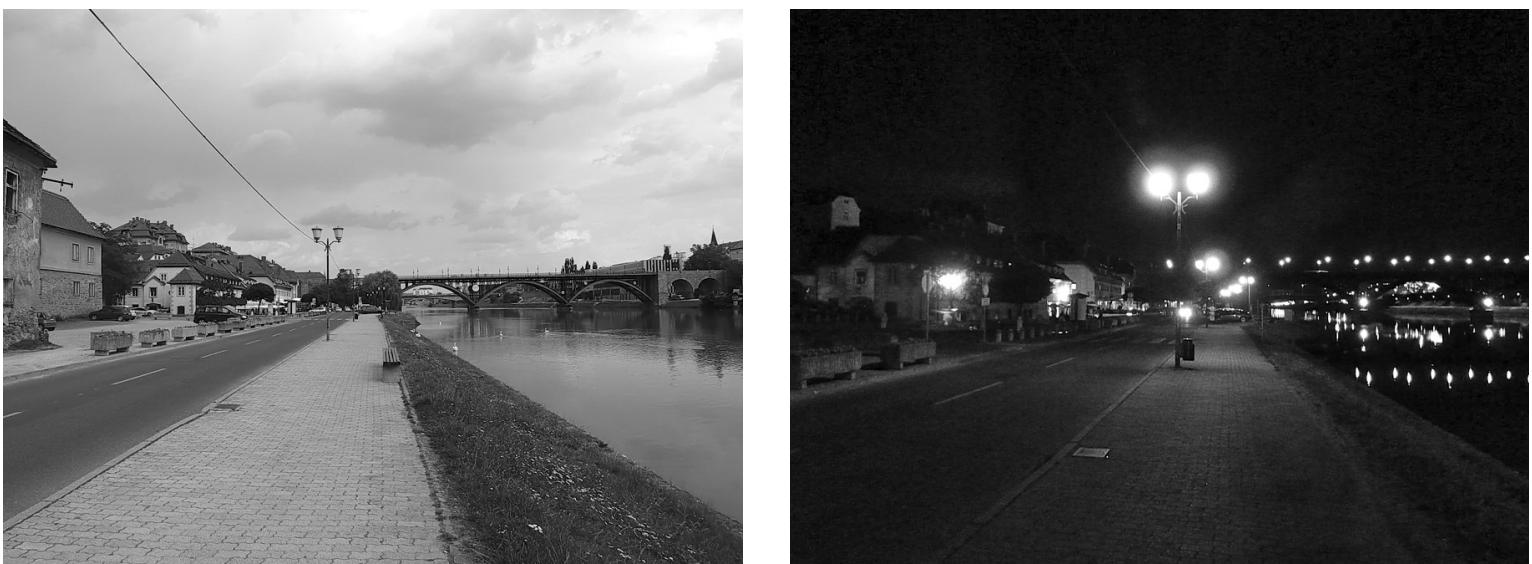

Figure 4 Old City Lent During Daytime (left) and Old City Lent During Nighttime (right)

frequency at daytime, so it seems to be very appropriate for daytime routes. But the location is not appropriate for organising nighttime sightseeing routes. Noticed frequency is low. Shops are closed and the environment seems not to be inviting enough.

\section{Example 2: Location Old City Lent}

(Low Spatial Sensitivity Value)

It is situated on the edge of the medieval city next to the river bank. The place is occupied by local streets and a sidewalk. Buildings are various typologies and ages. There are bars on ground floors and flats on upper floors. Illumination of the location is not sufficient; some parts are completely dark. The lights are placed on the sidewalk. The traffic area is minimally lighted. Lack of illumination at night makes walking freely more difficult. There are also several lights mounted on the buildings' walls. It is not sufficient because the open space remains in darkness.

The location belongs to the standard repertoire of most existing sightseeing routes. But the research results categorise the location as less attractive for inclusion in sightseeing routes because noticed frequency for day and night is low. The logical consequences would be to replace the location with another one. In this case such a recommendation is not the best 

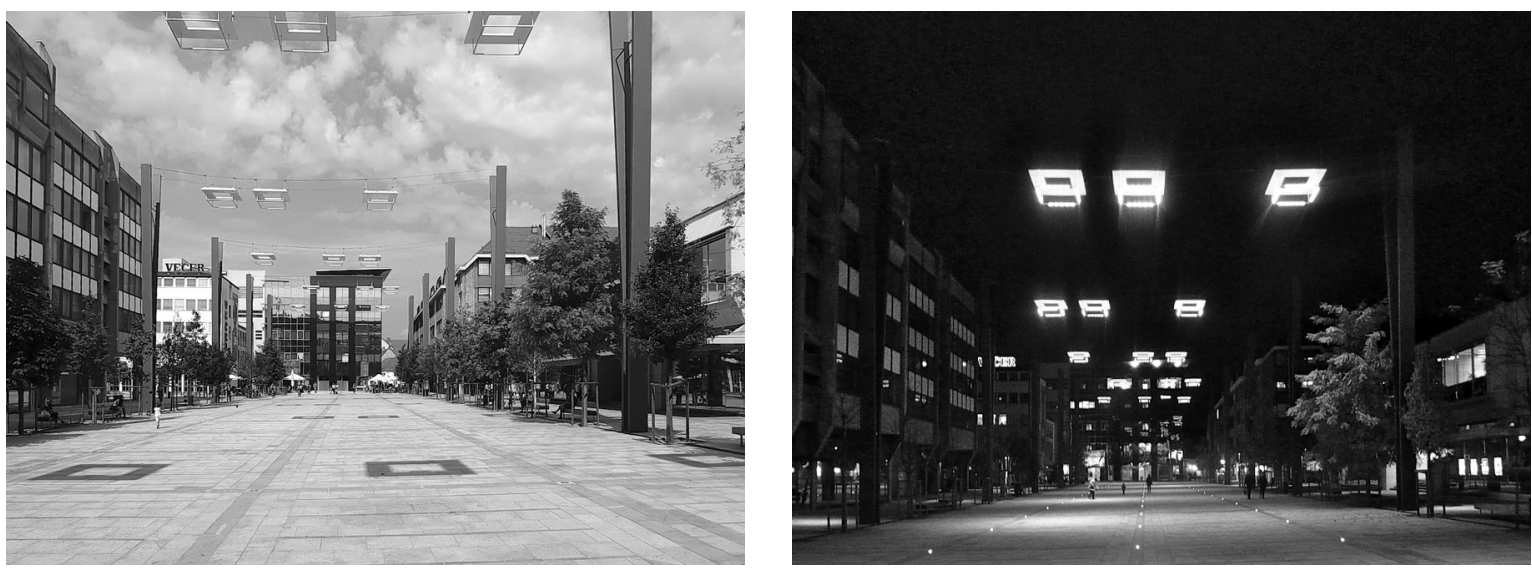

Figure 5 Leon Štukelj Square During Daytime (left) and Leon Štukelj Square During Nighttime (right)

option. The location has historical value and architectural renovation would be a better option.

\section{Example 3: Location Leon Štukelj Square (High Spatial Sensitivity Value)}

The square is situated in the city pedestrian zone. Redesigned, it was opened in 2011. The square is surrounded by public buildings. The central part of the square is devoted to public events and is therefore only occasionally occupied. Trees, benches, and bins are lined on both sides of the square. Hanging lamps are stretched across the area. Floor lamps are installed throughout the place. The square has a pleasant, unobtrusive illuminated atmosphere. At night, artificial light colour is changing and creates different ambiences. Hanging lamps illuminate the paved area. Facades are not illuminated.

The research results show high noticed frequency for both daytime and nighttime. Obviously, tourists noticed it and perceive a pleasant atmosphere during both time sequences. Based on the results, the location is very appropriate to be included in daytime as well as nighttime sightseeing routes. The tourist can sit, rest and enjoy the atmosphere.

\section{Conclusions}

Emerging tourism destinations can play a significant role in championing the adoption of sustainable tourism development (Sasidharan \& Križaj, 2018). Goeld- ner and Ritchie (2006) describe urban tourism as a complex phenomenon and extremely difficult to be described adequately. Any given location is primarily characterised by its natural environment, architecture and people. New opportunities must be sought in order to keep or to make all city areas attractive. Nowadays, tourists seek to maximize their environment with all the senses and appreciate observing everyday life. Social innovation needs to be constantly in place. This is even more important for occasionally visited places than for well-known tourists spots. Nowadays modern management companies and organisations must incorporate a psychological approach into their operations. It is a big challenge to satisfy tourists, because societal expectations are high. What do tourists remember and take home? What makes them come back and visit the same place again? Tourists certainly do not remember every architectural detail and historical fact. After a while, just a positive attitude and well-being remain. Sightseeing locations should be attractive, pleasant, safe, and should relax tourists at the same time. It is very important to plan the best possible sightseeing routes with the best sightseeing locations.

After analytical research work it is confirmed that modified spatial circumstances affect the perception and utilisation of urban space. Spatial sensitivity is subjective mental image reflection influenced by psychological, sociological and aesthetic-functional fac- 
tors. It provides an indication of a person's ability to perceive and remember visual information about a certain environment. It depends on time and changes as soon as spatial circumstances change, for example, day and night. Spatial sensitivity value is not always equal. The higher the value, the more important the location, the more it is suitable for integration into sightseeing routes. Summarising the graphical results obtained by the mental mapping method, it can be concluded that from the number of 34 exposed locations, 32 have different appearance frequency between day and night. Based on the value of spatial sensitivity, it is possible to design sightseeing routes adapted? to the time component. Some locations, although considered as important local tourist destinations, are not appropriate to be included in sightseeing routes. Only locations with high spatial sensitivity value in certain time sequences should become a part of sightseeing routes.

Obtained research results: (1) new definition of Pillars of Spatial Sensitivity (p s locations) set for the locations with high spatial sensitivity value, (2) the use of the already-known method of mental mapping for a new purpose (to identify pss locations and their spatial sensitivity value), and (3) hypothesis confirmation are original scientific contributions presented in this paper.

It is very important to plan the best possible sightseeing routes, but the proposed scientific approach cannot help the tourist organisation to make a location more attractive. Obtained research results provide insight into the spatial situation of Maribor city (Slovenia, Europe) and could support tourism development in a specific city area. The presented approach could be integrated as good practice in any other city worldwide. It supports identification of suitable sightseeing locations that are memorable and can be inherited by mobile city guides or used by tourist guides. Of course, other fields, such as tourist infrastructure and service quality, should also be considered.

\section{References}

Arthur, P., \& Passini, R. (1992). Wayfinding: People, signs, and architecture. Hill Ryerson.

Ashworth, G., \& Page, S. J. (2011). Urban tourism research:
Recent progress and current paradoxes. Tourism Management, 32(1), 1-15.

Canter, D. (1977). The psychology of place. Architectural Press.

Downs, R. M., \& Stea, D. (1973). Image and environment: Cognitive mapping and spatial behaviour. Aldine.

Evans, G. W. (1980). Environmental Cognition. Psychological Bulletin, 88(2), 259-287.

Fistola, R., Gargiulo, C., Battarra, R., \& La Rocca, L. A. (2019). Sustainability of urban functions: Dealing with tourism activity. Sustainability, 11(4), 1071.

Gavalas, D., Kasapakis, V., Konstantopoulos, C., Pantziou, G., \& Vathis, N. (2017). Scenic route planning for tourists. Pers Ubiquit Comput, 21, 137-155.

Goeldner, C. R., \& Ritchie, J. R. B. (2006). Tourism: Principles, practices, philosophies. Wiley.

Golledge, R. G. (1978). Learning about urban environments. In T. Carlstein, D. Parkes, \& N. Thrift (Eds.), Timing space and spacing time: Volume 1. Making sense of time (pp. 76-98). Edward Arnold.

Gregory, R. L. (1998). Eye and brain, the psychology of seeing. Oxford University Press.

Hasuike, T., Katagiri, H., Tsubaki, H., \& Tsuda, H. (2014). Sightseeing route planning responding various conditions with fuzzy random satisfactions dependent on tourist's tiredness. In S. I. Ao, O. Castillo, C. Douglas, D. D. Feng, \& J.-A. Lee (Eds.), Proceedings of the International Multiconference of Engineers and Computer Scientists 2014 (pp. 1232-1236). Newswood.

Larsen, J. (2001). Tourism mobilities and the travel glance: Experiences of being on the move. Scandinavian Journal of Hospitality and Tourism, 1(2), 80-98.

Liben, L. S., Patterson, A. H., \& Newcombe, N. (1981). Spatial representation and behavior across the life span. Academic Press.

Lynch, K. (1960). Image of the city. Institute of Technology.

Rangus, M., Brumen, B., \& Potočnik Topler, J. (2017). Sustainable tourism development in rural areas: The role of stakeholders. Academica Turistica, 10(2), 167-173.

Rozman Cafuta, M. (2015). Open space evaluation methodology and three dimensions evaluation model as a base for sustainable development tracking. Sustainability, 7 (10), 13690-13712.

Rozman Cafuta, M., \& Brumen, B. (2016). The innovative methodology of recognition the most appropriate places with a great potential for tourist satisfaction. In D. F. Kocaoglu, (Ed.), PICMET 2016: Technology management for social innovation (pp. 1824-1829). Portland International Center for Management of Engineering and Technology. 
Sasidharan, V., \& Križaj, D. (2018). Tourism ecolabels and social sustainability: Challenges and innovations from Slovene perspective. Academica Turistica, 11(1), 19-29.

Shoval, N., \& Isaacson, M. (2007). Tracking tourists in the digital age. Annals of Tourism Research, 34(1), 141-159.

Souffriau, W., Vansteenwegen, P., Vertommen, J., Berghe, G. V., \& Oudheusden, D. V. (2008). A personalized tourist trip design algorithm for mobile tourist guides. Applied Artificial Intelligence, 22(10), 964-985.

Šerman, K. (1997). O bîti i prostoru - Behrens i Loos*. Prostor: znanstveni časopis za arhitekturu i urbanizam, 5(2(14)), 201-238.
Tolman, E. C. (1984). Cognitive maps in rats and men. Psychological review, 55(4), 189-208.

Walmsley, D. J., \& Jenkins, J. M. (1992). Tourism cognitive mapping of unfamiliar environments. Annals of Tourism research, 19(2), 268-286.

Younghee Lee, M., Hitchcock, M., \& Wengsi, L. (2018). Mental mapping and heritage visitors' spatial perceptions. Journal of Heritage Tourism, 13 (4), 305-319.

Zografos, K. G., \& Androutsopoulos, K. N. (2008). Algorithms for itinerary planning in multimodal transportation networks. IEEE Transactions on Intelligent Transportation System, 9(1), 175-184. 


\title{
Spiritual Intelligence and Business Environments
}

\author{
Fadil Mušinović \\ Faculty of Commercial and Business Sciences, Slovenia \\ fadil.musinovic@siol.net
}

The article combines two development-oriented concepts, spiritual intelligence and business systems, composed of four elements. Spiritual intelligence, according to King (2008), consists of critical existential thinking, production of personal meaning, transcendental awareness, and conscious state expansion. Business systems, according to Bulc (2006), evolve evolutionarily in four stages, from the working environment, through the learning and thinking environments, to the conscious environment. The purpose of the study was to determine whether the factors of spiritual intelligence are related to the developmental stages of business systems and whether they differ in the various developmental stages of business systems. The empirical data was collected electronically, using a composite questionnaire in different business environments. 601 employees participated in the study. The results showed positive correlations between the factors of spiritual intelligence and learning, thinking, and the conscious environment, but no correlation to the working environment. In various development stages of business systems, certain differences have been revealed between the factors of spiritual intelligence. Regarding spiritual intelligence and business environments, the research has also shown differences based on gender, work experience, and the level of education.

Keywords: spiritual intelligence, evolution, business environments, individual, development

(cc)BY-SA https://doi.org/10.26493/2335-4194.13.167-177

\section{Introduction}

Intelligence has been evolving as a discipline through different milestones. The beginnings of research date back to the age of Plato and Aristotle (see http://www .intelltheory.com), while the one of the first scientific definitions dates back to the end of the 18th century. That is when Galton tried to measure the basic abilities of the mind through sensory discrimination and reaction times (Jensen, 2002). Later on, James Cattell broadened Galton's work with psychological testing and by using surveys and questionnaires, targeted at studying intelligence (Cianciolo \& Sternberg, 2004). The next milestone was the work of two French psychologists, Alfred Binet and Theodore Simon, who have developed an objective test for mea- suring a child's intelligence, while the development in this direction led to Terman's adaptation of the test and the use of the IQ. In comparison to the individual tests, the Army alpha and Army beta group tests can also be considered as milestones (Detterman, 2009).

The consequence of such a long period of study is an abundance of definitions, in which each offers their own aspect (e.g. the classical aspect, the biological aspect) in defining the intelligence of a person in a slightly different way. For Gottfredson (1998), intelligence is an individual's ability to deal with cognitive complexity, for Sternberg and Salter (1982), intelligence is goal-oriented and environmentally-adjustable behaviour, while the Merriam Webster Dictionary (https://www.merriam-webster.com) states that intel- 
ligence is the ability to learn and understand or work or try to work in new situations; skillful use of reasoning; the ability to use knowledge to manage one's environment; or abstract thinking, as is measured with objective criteria (e.g. tests). Different reasoning and arguments of what intelligence is and is not has gone so far, that a group of 52 scientists signed a statement in December 1994, declaring what intelligence is and what it is not (Gottfredson, 1997).

The spirituality of an individual has also been researched relatively well, as it has been studied since the time of William James (1902), who believed that our spiritual experiences have the potential to broaden and deepen our lives. However, there are more definitions of what spirituality is. Some authors define spirituality as an inner instinct (Emmons, 2000), while others define it as a sequence of topmost experiences and transcendent moments (MacDonald, 200o). But some authors believe that spirituality is represented as an integration of both the inner instinct as well as topmost experiences (Coyle, 2002; George et al., 2000; Vaughan, 2002).

Historically, spirituality was not separate from religious experiences, but nevertheless some theorists believe that key differences between religion and spirituality do exist (Del Rio \& White, 2012). The thought that spirituality could be a form of intelligence was developed with the theory of multiple intelligences (Gardner, 1995). In this theory, intelligence is a series of connected and, at the same time, separate cognitive processes and abilities that allow us to understand the world, our development, and our improvements. It is also the ability to solve problems in different fields of human activity. In his own theory, Gardner (1995) speaks of multiple intelligences: the lingual, logical-mathematical, spatial, musical, motor, interpersonal, and inner personal intelligence. The author first thought that spirituality cannot be a form of intelligence, but later changed his mind. He added a new type of intelligence, the existential or moral intelligence (Gardner, 2000), which has the characteristics of spiritual intelligence (Emmons, 2000; King, 2008; King \& DeCicco, 2009; Vaughan, 2002). It includes different development processes and adapts to a human's life (Gardner, 1995).
Spiritual intelligence, as defined in this paper, is not spiritually inspirational or religious identity and practice. If we possess spiritual intelligence, we do not require a belief system linked to religion, and we are not required to identify ourselves as a spiritual person (King, 2008).

Spiritual intelligence is, just like general intelligence (where we measure the person's IQ), differently defined. According to Emmons (2003, p. 176), spiritual intelligence is 'an adaptive use of spiritual information with the purpose of easing daily problem solving and reaching set goals.' It is composed of the ability to transcend the physical and material, the experience of a heightened state of consciousness, dedication to daily experiences, and the use of spiritual resources to solve problems.

Vaughan (2002) states that spiritual intelligence, along with self-awareness, also means that we are aware of our own relationship to the excess in regards to the Earth and to all living beings.

On the other hand, Zohar and Marshall (200o, p. 3) believe that spiritual intelligence 'enables people to be creative, to change the rules, and to change their situations. It enables us to play with boundaries, it gives us moral meaning, it enables us to confront the questions of good and evil, and enables us to imagine the unrealized possibilities.'

Wolman (2001, p. 84) established that spiritual intelligence is 'a human capacity for asking final questions about the purpose of life and, at the same time, a capacity to embrace these questions in experiencing seamless connections between all of us and the world, in which we live in.'

King and DeCicco (2009, p. 69) have defined spiritual intelligence as 'a collection of mental capacities, which contribute to awareness, integration, and adjustment of immaterial and transcendent aspects of an individual's existence, which lead to consequences, such as: critical existential thinking, producing personal meaning, transcendent awareness, and conscious state expansion.' Reaching and experiencing these spiritual abilities is supposed to - while taking into account Gardner's criteria for measuring and determining the field of intelligence - strengthen the quality of an individual's life (Gardner, 1995; 2000). 
The quality of an individual's life can be strengthened within different contexts. We can, for example, strengthen it at home, in a business environment or in other social systems in which we are included in our life, as these social systems influence our lives and our spiritual intelligence (Yang \& Wu, 2009). The influence can differ. For example, Schneider (1987) states that the influence between the social system and the individual is mutual. According to the theory (model) of ASA - Attraction - Selection - Attrition, social systems attract certain types of people, in which, if they get along with the system or organisation, they stay based on selection, or leave it later on.

Business systems are also social systems. In these systems we conduct our work and go about our business. Structurally they are diverse; they can be, for example, hierarchical (e.g. the police, the military, the fire brigade), or they can be flatter (e.g. Google), but compared to personal, family, and leisure social systems, they are different. People, with whom we socialise there, are different. The way of thinking and behaving is different. Even goals that we follow with the context of business systems are different.

Business systems can be understood as living beings, or at least they have some characteristics of living beings: they have their own evolutional dynamic, history, present, and future; they are independent organisms with feelings, fears, and dreams; they have their own mission, goals, and life span. They differ among each other and at the same time they are connected, because 'for each new phase [stage] it is absolutely necessary to possess the vital forces of its predecessors' (Bulc, 2006, p. 20).

According to Bulc (2006), the development of business systems encompasses four development stages: the working environment, the learning environment, the thinking environment, and the conscious environment. These stages run in sequence, by business rules, resources, and leverages. Between the stages there are transitional transformational periods of conduct, in which it comes to disorders or dialectical fights between the old and the new (e.g. dialectical fight between the working and the learning environment).

The working environment is the first developmental stage of business systems. Added value in this sys- tem is created with diligent work, which results in creating a product as the key part of the working process. Work is conducted through manufacture; it is partly automated and computerised. Methods for systematic cost management are developed to some extent, including the optimisation of support services. The key competitive advantage is the productivity and its constant increase.

The second developmental stage - the learning stage - is characterised by added value that is created with knowledge. Diligence, which posed as added value in the previous stage, does not suffice anymore in this stage. It needs to be upgraded with knowledge, which is accumulated in ever more accessible literature that, through in-depth studies, enables bigger productivity management. As a consequence, the difference in productivity between individual companies gets smaller, which by itself demands a different type of added value or a different competitive advantage. The latter is seen in this stage in knowledge, which also manifests itself in the quality of the product. In this developmental period the key observed item is not the product or the emotional attachments of workers and managers to the product, but the customers, who think the product is interesting and, later on, buy it. Or they decide not to buy it. In relation to this - comparatively with the working environment - the work processes also change. These are based on knowledge and change through time or circle through constant improvements. In consequence, the management process, interpersonal relations, work organisation, values, etc. also comparatively change or develop.

Creativity brings added value into the thinking environment, while the key element is innovation. Quality is improving comparatively with the learning environment, while the improvements are based on creative innovations, which are unknown and different. A growing emphasis is given to the individual and the inter-functional teams, which can only function in relaxed and dynamic environments, where there is enough time to think and get creative ideas. It is also important to collaborate with the environment, where, in a mix of hard work, knowledge, and thinking, new ideas and innovative processes arise, which the market or the environment need. 
The conscious environment is the last developmental stage. It represents a growing humanisation of work; added value is represented by intuitiveness in deep connection with spirituality. The key factor is the life energy of the individual, group, or company, values and informal forms of collaboration with the environment.

The researched topic is in our opinion scientifically relevant, because spiritual intelligence is an interesting and poorly researched concept, especially in the context of developmental stages of business systems, which was the main purpose and goal of this paper. We wanted to determine whether there is a connection between spiritual intelligence and developmental stages of business environments, what kind of connection it is and also, whether spiritual intelligence is different in various stages of business systems and, if it is, what are the differences.

Given that such research has not been conducted yet, we based the logic of establishing hypotheses from links in the content of cited papers. We checked two hypotheses:

$\mathrm{H} 1$ In higher developmental stages of business systems employees have a more developed spiritual intelligence.

$\mathrm{H} 2$ Spiritual intelligence is significantly different in individual developmental stages of business systems.

\section{Method}

The research was done through the usual steps; the first part was theoretical and intended for reviewing literature and previous research, and forming theoretical fundamentals based on known concepts. Descriptive, compilation, comparative, and analysis and synthesis methods were used in this part.

In the second - the empirical part, validity, reliability, objectivity, and other measurable characteristics of the tools used were introduced. Later, results were introduced and explained, after which discussion follows.

\section{Respondents}

The sample was opportunistic and self-selective. 615 people chose to participate. 14 questionnaires were dis- carded from the survey, as they were either blank or participants answered every question with the same values, therefore, they were useless for the purposes of the survey.

601 questionnaires were used in the survey. 227 (37.8 \% of the sample) men and 372 (61.9\%) women participated. Two participants did not mark their genders. This represented $0.3 \%$ of all included questionnaires.

Participants were 18 to 70 years old. The average age was 40 years. Five individuals did not disclose their age. Age data was divided into categories of 10 years. The categories were: under 20 years, $20-30$ years, $30-$ 40 years, $40-50$ years, 50-60 years, and 60-70 years. Due to the fact that there were only 4 participants under the age of 20, we put them into the category 20-30 years. There were $132(22 \%)$ individuals in this category. The category $20-30$ years included 207 (34.4\%) individuals. The category 40-50 years included 163 (27.1\%) individuals. The category $50-60$ years included 76 (12.6\%) individuals. The last category included 18 (3\%) participants.

Years of work experience of participants varied from o to 47 years. 13 participants did not disclose this information. The data was divided into categories of 10 years; from o to 10 , from 11 to 20 , from 21 to 30 , from 31 to 40 , and from 41 to 50 years. The first category included 192 (31.9\%) participants. The category 11-20 included 184 (30.6\%) individuals. The category 21-30 included 134 (22.3\%) participants. The following category was $31-40$. This category included $70(11.6 \%)$ individuals. The last category included 8 (1.3\%) participants.

Based on education, the participants were divided into these groups: 3 (0.5\%) participants had primary education, 102 (17\%) had secondary education, 178 (29.6\%) participants had the first Bologna level of education, 252 (41.9\%) participants had the second Bologna level of education, while $60(10 \%)$ individuals had the third Bologna level of education. $6(1 \%)$ participants did not disclose their education level.

523 ( $87 \%$ of the sample) participants were employed, $40(6.7 \%)$ were students, $20(3.3 \%)$ were retired, while 16 (2.7\%) were unemployed. 2 (0.3\%) participants did not disclose their employment status. 


\section{Tools}

We used a questionnaire in our survey and have named it Spiritual intelligence (sQ) in business environments (Po). It was composed of two different sources. We used the Spiritual intelligence self-report inventory SISRI-24 (King, 2008; King \& DeCicco, 2009) for the part regarding spiritual intelligence, while for the part regarding business environments we used our own four items that were produced based on Bulc's (2006) statements. The questionnaire included 28 items and demographic data. The Cronbach alpha for the 50 stated items was 0.908.

The Spiritual Intelligence Self-Report Inventory SISRI-24 (King, 2008; King \& DeCicco, 2009) measures two kinds of abilities and skills: critical existential thinking, personal meaning production, transcendent awareness, and conscious state expansion. For this we used the 5-point Likert scale with 1 meaning is not true at all' and 5 meaning 'absolutely true.' The Cronbach alpha for all 24 items was 0.944; for the 7-item factor 'critical existential thinking' the Cronbach alpha was 0.874 , for the 5 -item factor 'personal meaning production' it was 0.817 , for the 7 -item 'transcendent awareness' it was 0.736 , and for the 5 -item 'conscious state expansion' it was 0.888 .

The following were four items of our own designed questionnaire for measuring the evolutionary developmental stage of business environments, which was designed based on the theory (Bulc, 2006). The questionnaire is composed of four items: the working environment, the learning environment, the thinking environment, and the conscious environment. We used a 3-point scale, where 1 means 'does not apply to us,' 2 means 'partly applies to us, and 3 means 'it applies to us almost entirely. The Cronbach alpha for the abovementioned items was 0.630 .

\section{Procedures}

Data was collected with an electronic questionnaire with the help of Google docs tools. For data gathering we used snowball non-random sampling (Biernacki \& Waldorf, 1981; Faugier \& Sergeant, 1997) that took place via various organisation managements.

The link to the questionnaire was sent to various email addresses with included requests that the e-mail recipients participate in the survey and share the invitation to the survey through their social networks their friends, acquaintances, coworkers, etc.

The gathered forms were then exported to the relevant format for later processing in the SPss software (Statistical Package for Social Sciences). The database was also refined in order to obtain more stable results for processing. First, we discarded the 9 blank questionnaires. After that structural analysis followed. Based on this analysis, we also removed 5 questionnaires that had the same value filled out in all the questions (e.g. all the items had the value 3 ). The remaining 601 were then included in the statistical analysis.

The statistical analysis was then conducted according to the instructions for each concept. So, for the analysis regarding spiritual intelligence it was taken into account that the overall result, after the reverse coding of the 6th item is done, is the sum of all answers on the items. We named it Spiritual intelligence and marked it with $s \mathrm{Q}$. We have also taken into account that the higher the result, the higher is the level of spiritual intelligence or individual capacities (King, 2008). The items in Spiritual intelligence were divided into 4 factors based on factor analysis (King, 2008), namely:

1. The factor critical existential thinking - abbreviated as CET - was calculated by summing the seven items which, according to King (2008), fall into this category. These items are 1, 3, 5, 9, 13, 17, and 21.

2. The factor personal meaning production - abbreviated as PMP - was calculated by summing the five items which, according to King (2008), fall into this category. These items are 7, 11, 15, 19, and 23.

3. The factor transcendent awareness - abbreviated as TA - was calculated by summing the seven items which, according to King (2008), fall into this category. These items are 2, 6 (reverse coding), 10, 14, 18, 20, and 22.

4. The factor conscious state expansion - abbreviated as CSE - was calculated by summing the five items which, according to King (2008), fall into this category. These items are 4, 8, 12, 16, and 24. 
The evolutionary development of business environments - abbreviated as POK - is covered in one item that was designed based on the questionnaire results. It was done so that from a collection of four evolutionary development stages we added up the raw results and divided them into individual categories or stages of the evolutionary development. Consequently, the values 4 and 5 were classified into the work business environment, 6 and 7 into the learning business environment, 8 and 9 into the thinking business environment, and 10, 11, and 12 were classified into the conscious business environment. The evolutionary development of business environments is also defined through individual developmental stages of business systems, namely 4 variables, named after the developmental stages: the working environment, the learning environment, the thinking environment, and the conscious environment.

\section{Results}

Table 1 shows the correlation between spiritual intelligence (sQ) and its factors critical existential thinking (СET), personal meaning production (PMP), transcendent awareness (TA), conscious state expansion (CSE), and the evolutionary developmental stages of business systems - work, learning, thinking, and conscious environment.

The table also shows a statistically significant positive correlation between the learning environment and spiritual intelligence ( $\mathrm{s} Q$ ) and its factors critical existential thinking (СЕT), personal meaning production (Р МP), transcendent awareness (TA) and conscious state expansion (CSE). A statistically significant positive correlation is also shown between the learning environment and spiritual intelligence ( $\mathrm{s} Q$ ) and its factors critical existential thinking (CET), personal meaning production ( $\mathrm{PM}$ ), transcendent awareness (TA) and conscious state expansion (CSE). There is also a statistically significant positive correlation between the conscious environment and spiritual intelligence $(\mathrm{s} Q)$ and its factors critical existential thinking (CET), personal meaning production ( $\mathrm{PMP}$ ), transcendent awareness ( $\mathrm{TA})$ and conscious state expansion (CSE).

In the first column the table shows that the corre-
Table 1 Correlation between Spiritual Intelligence and Developmental Stages of Business Systems

\begin{tabular}{lrccc}
\hline Item & $(1)$ & $(2)$ & $(3)$ & $(4)$ \\
\hline SQ & -0.047 & $0.184^{\star *}$ & $0.108^{\star}$ & $0.104^{\star}$ \\
CE T & -0.039 & $0.122^{\star *}$ & 0.060 & 0.041 \\
PMP & -0.060 & $0.168^{\star *}$ & $0.130^{\star *}$ & $0.141^{\star *}$ \\
TA & -0.064 & $0.160^{\star *}$ & $0.102^{\star}$ & 0.075 \\
CSE & 0.026 & $0.148^{\star *}$ & $0.102^{\star}$ & $0.140^{* *}$ \\
\hline
\end{tabular}

Notes Column headings are as follows: (1) working environment, (2) learning environment, (3) thinking environment, (4) conscious environment. $N=601$. Displayed are the derived variables $S Q$ - spiritual intelligence, CET - critical existential thinking, PMP - personal meaning production, TA - transcendent awareness, CSE - conscious state expansion and individual developmental stages of the business environment; the working, learning, thinking, and conscious environment. ${ }^{*} p<0.05,{ }^{* *} p<0.01$.

lation between the working environment and spiritual intelligence and its three factors are mostly negative and are not statistically significant.

Table 2 shows the results of the one-way variance analysis, carried out by dependent variables spiritual intelligence (sQ), critical existential thinking (CET), personal meaning production ( $\mathrm{PM}$ ), transcendent awareness (TA), conscious state expansion (CSE), and by the independent variable business environment (Рок).

Results show statistically significant differences between the evolutionary developmental stages of business systems, namely by spiritual intelligence ( $\mathrm{s} Q$ ), personal meaning production ( $\mathrm{PMP}$ ), and conscious state expansion (CSE). The Tukey HSD post hoc test showed that the differences are statistically significant between the working environment and the learning environment, and between the learning environment and the conscious environment at spiritual intelligence $(\mathrm{SQ})$, personal meaning production (PMP), and conscious state expansion (CSE). There were no differences between the averages of critical existential thinking (СET) and transcendent awareness (TA).

Table 3 shows correlations between spiritual intelligence (sQ) and its factors critical existential thinking (СЕT), personal meaning production (PMP), tran- 
Table 2 One-Way ANovA - Differences in Spiritual Intelligence by Work Environments

\begin{tabular}{|c|c|c|c|c|c|}
\hline Item & & (1) & (2) & (3) & (4) \\
\hline \multirow[t]{5}{*}{ SQ } & (a) & 122 & 79.54 & 20.118 & \\
\hline & (b) & 203 & 80.26 & 18.591 & \\
\hline & (c) & 157 & 82.71 & 18.188 & \\
\hline & (d) & 62 & 88.03 & 18.664 & \\
\hline & Sum & 544 & 81.69 & 18.964 & $3.415^{\star} \quad 1-4,2-4$ \\
\hline \multirow[t]{5}{*}{ CET } & (a) & 129 & 22.78 & 6.946 & \\
\hline & (b) & 217 & 22.74 & 6.799 & \\
\hline & (c) & 172 & 23.37 & 6.351 & \\
\hline & (d) & 65 & 24.43 & 6.586 & \\
\hline & Sum & 583 & 23.12 & 6.684 & ns \\
\hline \multirow[t]{5}{*}{ РМP } & (a) & 129 & 17.54 & 4.150 & \\
\hline & (b) & 215 & 17.70 & 3.874 & \\
\hline & (c) & 175 & 18.44 & 3.854 & \\
\hline & (d) & 66 & 19.59 & 3.827 & \\
\hline & Sum & 585 & 18.10 & 3.968 & $5.231^{\star * *} 1-4,2-4$ \\
\hline \multirow[t]{5}{*}{ TA } & (a) & 126 & $24 \cdot 30$ & 5.603 & \\
\hline & (b) & 210 & $24 \cdot 31$ & 5.513 & \\
\hline & (c) & 173 & 24.94 & 5.648 & \\
\hline & (d) & 68 & 26.18 & 5.810 & \\
\hline & Sum & 577 & 24.72 & 5.626 & ns \\
\hline \multirow[t]{5}{*}{ CSE } & (a) & 130 & 14.82 & 5.116 & \\
\hline & (b) & 215 & 15.09 & 4.628 & \\
\hline & (c) & 174 & 15.75 & 4.604 & \\
\hline & (d) & 69 & $17 \cdot 32$ & 4.539 & \\
\hline & Sum & 588 & 15.49 & 4.771 & $5.010^{\star *} 1-4,2-4$ \\
\hline
\end{tabular}

Notes Column headings are as follows: (1) sample size, (2) average, (3) standard deviance, (4) variance ratio, (5) - differences between categories after post hoc analysis. Row headings are as follows: (a) working environment, (b) learning environment, (c) thinking environment, (d) conscious environment. Displayed are the dependent derived variables SQ - spiritual intelligence, CET - critical existential thinking, PMP - personal meaning production, TA - transcendent awareness, CSE - conscious state expansion and the independent variable POK - business environments, which has four values: working environment, learning environment, thinking environment, and conscious environment. The Tukey HSD test was used for the post hoc analysis. ${ }^{*} p<0.05,{ }^{* *} p<$ $0.01,{ }^{* * *} p<0.001$, ns - no statistically significant differences.
Table 3 Correlations between the Variable Business Environments and Spiritual Intelligence

\begin{tabular}{lcccccc}
\hline Item & POK & SQ & CET & PMP & TA & CSE \\
\hline POK & - & & & & & \\
SQ & $0.125^{\star *}$ & - & & & & \\
CET & 0.068 & $0.902^{* *}$ & - & & & \\
PMP & $0.152^{\star *}$ & $0.857^{* *}$ & $0.652^{\star *}$ & - & & \\
TA & $0.095^{*}$ & $0.939^{* *}$ & $0.789^{\star *}$ & $0.786^{* *}$ & - & \\
CSE & $0.147^{\star *}$ & $0.882^{* *}$ & $0.699^{* *}$ & $0.719^{* *}$ & $0.774^{* *}$ & - \\
\hline
\end{tabular}

Notes $N=601$. Displayed are the derived variables SQ - spiritual intelligence, CET - critical existential thinking, PMP - personal meaning production, TA - transcendent awareness, CSE - conscious state expansion, and POK business environments. ${ }^{*} p<0.05,{ }^{* *} p<0.01$.

scendent awareness (TA) and conscious state expansion (CSE), and the derived variable business environments (РОК).

Results show a statistically significant positive correlation between the derived variable business environment (РОк) and spiritual intelligence (sQ) and its factors personal meaning production ( $\mathrm{PMP}$ ), transcendent awareness ( $\mathrm{TA}$ ), and conscious state expansion (CSE).

Visible are also positive intercorrelations between spiritual intelligence (sQ) and its factors critical existential thinking (СЕT), personal meaning production (РмP), transcendent awareness (TA), and conscious state expansion (CSE).

Table 4 shows the results of the one-way variance analysis, namely the statistically significant differences between genders. The table shows that by spiritual intelligence (SQ), critical existential thinking (CET), personal meaning production (PMP), and by transcendent awareness (TA) women had statistically significantly higher average scores, except by the last variable, namely the business environment (РОК), where men had higher scores on average.

Table 5 shows the results of the one-way variance analysis, namely between the levels of education. The table shows that there are statistically significant differences between levels of education by spiritual intelligence ( $\mathrm{SQ}$ ), personal meaning production ( $\mathrm{PMP}$ ), conscious state expansion (CSE), and by business en- 
Table 4 One-Way AnovA - Differences by Variables between Genders

\begin{tabular}{|c|c|c|c|c|c|}
\hline Item & & (1) & (2) & (3) & (4) \\
\hline \multirow[t]{3}{*}{$S Q$} & Male & 204 & 77.64 & 18.167 & \\
\hline & Female & 339 & 84.18 & 19.049 & \\
\hline & Sum & 543 & 81.72 & 18.972 & $15.516^{* * *}$ \\
\hline \multirow[t]{3}{*}{ CET } & Male & 222 & 21.54 & 6.356 & \\
\hline & Female & 360 & 24.13 & 6.702 & \\
\hline & Sum & 582 & 23.14 & 6.687 & $21.399^{* * *}$ \\
\hline \multirow[t]{3}{*}{ PMP } & Male & 221 & 17.52 & 3.969 & \\
\hline & Female & 363 & 18.46 & 3.934 & \\
\hline & Sum & 584 & 18.10 & 3.970 & $7.861^{\star *}$ \\
\hline \multirow[t]{3}{*}{$\mathrm{TA}$} & Male & 218 & 23.33 & $5 \cdot 348$ & \\
\hline & Female & 358 & 25.56 & 5.641 & \\
\hline & Sum & 576 & 24.72 & 5.632 & $21.952^{* * *}$ \\
\hline \multirow[t]{3}{*}{ POK } & Male & 226 & 2.46 & 0.934 & \\
\hline & Female & 372 & 2.21 & 0.933 & \\
\hline & Sum & 598 & 2.30 & 0.941 & $10.709^{* * *}$ \\
\hline
\end{tabular}

Notes Column headings are as follows: (1) sample size, (2) average, (3) standard deviance, (4) variance ratio. Displayed are only the items where statistically significant differences were found. Displayed are the variables SQ - spiritual intelligence, CET - critical existential thinking, PMP - personal meaning production, TA - transcendent awareness, CSE - conscious state expansion, and POK - business environments. ${ }^{* *} p<0.01,{ }^{* * *} p<0.001$.

vironment (рок). In the table we can see that the participants who scored the highest average spiritual intelligence had also achieved the third Bologna level of education. The same applies to the variable personal meaning production (PMP) and to conscious state expansion (CSE). These are the variables that refer to spiritual intelligence. The results also show that the highest average score by depersonalization (DEP) were achieved by those with a secondary level of education, while those with the first level of education scored the highest on average by business environment.

Table 6 shows the correlation between spiritual intelligence (sQ) and its factors critical existential thinking (СET), personal meaning production (Р MP), transcendent awareness (TA), conscious state expansion (CSE), and two dimensions of business environments.
Table 5 One-Way ANOvA - Differences Based on Achieved Level of Education

\begin{tabular}{|c|c|c|c|c|c|c|}
\hline Item & & (1) & (2) & (3) & (4) & (5) \\
\hline \multirow[t]{7}{*}{ SQ } & (a) & 3 & 74.67 & 15.631 & & \\
\hline & (b) & 89 & 81.21 & 19.065 & & \\
\hline & (c) & 162 & 81.44 & 18.879 & & \\
\hline & (d) & 232 & 80.23 & 18.598 & & \\
\hline & (e) & 54 & 89.06 & 19.178 & & \\
\hline & Sum & 540 & 81.61 & 18.915 & $2.542^{\star}$ & $2-5,3-5$, \\
\hline & & & & & & $4-5$ \\
\hline \multirow[t]{7}{*}{ PMP } & (a) & 3 & 14.67 & 4.726 & & \\
\hline & (b) & 98 & 17.72 & 4.104 & & \\
\hline & (c) & 174 & 17.86 & 4.010 & & \\
\hline & (d) & 247 & 18.13 & 3.800 & & \\
\hline & (e) & 58 & 19.45 & 3.844 & & \\
\hline & Sum & 580 & 18.09 & 3.947 & $2.681^{\star}$ & $1-5,2-5$, \\
\hline & & & & & & $3-5,4-5$ \\
\hline \multirow[t]{7}{*}{ CSE } & (a) & 3 & 14.00 & 5.196 & & \\
\hline & (b) & 98 & 15.60 & 4.657 & & \\
\hline & (c) & 174 & 15.28 & 4.840 & & \\
\hline & (d) & 249 & 15.13 & 4.574 & & \\
\hline & (e) & 59 & 17.32 & 5.097 & & \\
\hline & Sum & 583 & 15.47 & 4.754 & $2.749^{\star}$ & $2-5,3-5$, \\
\hline & & & & & & $4-5$ \\
\hline \multirow[t]{8}{*}{ POK } & (a) & 3 & 3.67 & 0.577 & & \\
\hline & (b) & 101 & 2.11 & 0.989 & & \\
\hline & (c) & 178 & 2.24 & 0.846 & & \\
\hline & (d) & 252 & 2.31 & 0.954 & & \\
\hline & (e) & 60 & 2.68 & 0.965 & & \\
\hline & Sum & 594 & 2.30 & 0.943 & $5.435^{\star *}$ & $1-2,1-3$ \\
\hline & & & & & & $1-4,2-5$ \\
\hline & & & & & & $3-5,4-5$ \\
\hline
\end{tabular}

Notes Column headings are as follows: (1) sample size, (2) average, (3) standard deviance, (4) variance ratio, (5) - differences between categories after post hoc analysis. Row headings are as follows: (a) primary, (b) secondary, (c) first Bologna, (d) second Bologna, (e) third Bologna. Displayed are only the variables where statistically significant differences were found, namely $S Q$ - spiritual intelligence, CET - critical existential thinking, PMP - personal meaning production, $\mathrm{TA}$ - transcendent awareness, CSE - conscious state expansion, and POK - business environments. The LSD test was used for post hoc analysis. ${ }^{\star} p<0.05,{ }^{* *} p$ $<0.001$ 
Table 6 Correlation between Two Dimensions of Business Environments and Spiritual Intelligence

\begin{tabular}{lll}
\hline Item & $\mathrm{D} 1$ & $\mathrm{D} 2$ \\
\hline SQ & $0.119^{\star *}$ & $0.118^{* *}$ \\
CET & 0.070 & 0.057 \\
PMP & $0.095^{\star}$ & $0.150^{* *}$ \\
TA & $0.086^{*}$ & $0.099^{\star}$ \\
CSE & $0.101^{\star}$ & $0.134^{* *}$ \\
\hline
\end{tabular}

Notes $N=601$. Displayed are the derived variables SQ - spiritual intelligence, CET - critical existential thinking, PMP - personal meaning production, TA - transcendent awareness, CSE - conscious state expansion, D1 - first dimension of business environments, and D2 - second dimension of business environments. ${ }^{\star} p<0.05,{ }^{* *} p<0.01$.

In the first dimension we have the work and learning environments and in the second we have the thinking and conscious environments.

The table also shows statistically significant positive correlations between spiritual intelligence ( $\mathrm{sQ}$ ) and both dimensions of business environments.

Also statistically significant and positive are correlations between personal meaning production (PMP), transcendent awareness (TA) and conscious state expansion (CSE) and both dimensions of business environments.

\section{Discussion}

The paper shows two separate concepts, which at first sight have nothing in common. But if we look closely, we can see that they have at least one common denominator - the human. The human is the one who asks himself whether there is only one type of intelligence built into him, or are there more, and whether or not he is more or less spiritually intelligent. And the human is the one who enabled us to be asking ourselves about different developmental stages of business systems and be able to research them.

With the survey we wanted to research the potential relationship between a human's spiritual intelligence and the developmental stages of business systems. We wanted to know whether spiritual intelligence is different regarding the developmental stages of business systems. That is why we established two hypotheses that relate to the connections between the factors of spiritual intelligence that, according to King and DeCicco (2009), are critical existential thinking (СET), personal meaning production ( $\mathrm{PMP}$ ), transcendent awareness (TA), conscious state expansion (CSE), and the developmental stages of business systems, which are: working environment, learning environment, thinking environment, and conscious environment (Bulc, 2006).

Obtained data shows that spiritual intelligence is connected with various developmental stages of business environments. The data also shows that through developmental stages of business systems the intensity of spiritual intelligence differs.

The first hypothesis predicted that the connection between spiritual intelligence and business systems is positive. A higher average level of spiritual intelligence would therefore be in higher developmental stages of business systems. This can mean two things. One, according to the AS A theory (Schneider, 1987), the more spiritually intelligent people attract each other and stay in developmentally higher business systems, or two, the developmental stage of a business system has an effect on an employee's average level of spiritual intelligence. Results showed that the lowest developmental stage of business systems - the working environment - does not correlate with spiritual intelligence and its factors. The correlation between spiritual intelligence and its factors are first evident with the learning environment and then continue in the next two developmental stages - the thinking and the conscious environment. But the results are not consistent in a sense that the higher developmental stages of the business system would point to higher average developmental stages of spiritual intelligence. This is shown by the correlation between spiritual intelligence and the learning business environment, which is also statistically more reliable than correlation of spiritual intelligence with the thinking and the conscious business environments. Extra evidence for this can be found in the factor critical existential thinking, where the statistically significant correlation was evident only by the learning business environment (Table 1).

The answer to this question is given to us in Table 2, where it can be clearly seen that, on one hand, the 
second hypothesis must be partly confirmed, because spiritual intelligence significantly differs by individual developmental stages of business systems. On the other hand, the differences can be attributed to only two dimensions. In one we have the work and learning environments and in the second we have the thinking and conscious environments (Table 6).

The results also showed statistically significant differences in the level of spiritual intelligence (sQ) by individual developmental stages of business systems $F(3.540)=3.415, p=0.017$. Differences can also be seen by individual factors of spiritual intelligence (see Table 2), by certain variables, between genders (see Table 4 ), and between the achieved levels of education (see Table 5).

Such research has not been done yet, which is why there is no comparable data. But we can say that, roughly, our findings are in compliance with King's (2008) and King's and DeCicco's (2009) findings, as well as with the findings of Yang and $\mathrm{Wu}$ (2009). The latter two also state that social systems have an influence on spiritual intelligence.

Both the above-mentioned concepts - spiritual intelligence and development of business systems - are individually important for the human being, which we proved in a broad sense in this paper.

As with every research, even this one has room for improvement. It is based on the assumption that we will get enough information with the snowball method that will, on the one hand, be useful for understanding and concluding and, on the other hand, that this data will reflect the actual state of the spirit, beliefs, and the aspects of the surveyed phenomenon. Of course, the number of participants can be understood in two ways, especially in a time of saturation, with more or less felicitous and more or less professionally evaluated questionnaires, which are everything but a contribution to the already known. On one hand, there are people who wanted to participate and, on the other, there are people who are interested in the topic.

It is different with our questionnaire. We have meticulously designed in accordance with the theory. We also done a pilot survey on a sample of students, which showed that we are on the right path and that the instrument for measuring spiritual in- telligence is actually valid, reliable, objective, and in accordance with King's (2008) published data. Nevertheless, a word on executing random sampling with big-enough samples is in order.

Future surveys on the topic should also address limitation of the sample being opportunistic and selfselective. In this context also, a distribution of demographic data of the sample does not allow generalisations - we recommend at least a poststratification of gathered data.

We see the limitation of our research in the elements which are based on electronic data collection. But the electronic data collection is also an advantage, as it is more economic in regards to saving money and time.

This contribution is therefore a theoretical and empirical upgrade to the concept of spiritual intelligence within the evolutionary development of business systems. It took place in the Slovenian cultural space, which, in the sense of international comparison, represents a contribution to science.

The research has limitations. Therefore, we can summarise that the results are mostly indicative - they point to connections of spiritual intelligence with business systems and indicate that the spiritual intelligence of participants in different business environments is, indeed, different.

Our set research problem could therefore be expanded in ways by connecting with stress, burnout, and other negative consequences of life and working in business systems. In this context it would be sensible to research whether stress has an influence on spiritual intelligence, is spiritual intelligence a catalyst for stress, and how are these relations in context with individual developmental stages of business systems.

Despite the limitations mentioned, our research is important. Not only for the individuals but also for business systems and leaders of these systems.

As Zohar and Marshall (2000) state, spiritual intelligence is the highest level of human intelligence and as such also combines classical intelligence and emotional intelligence. Positive influences of classical and emotional intelligence are well established in literature (e.g. Goleman, 1995; Ciarrochi et al., 2001; Shen et al., 2008; Mayer et al., 2008); in addition we could learn 
some aspects of spiritual intelligence (Zareei \& Sedrpooshan, 2015). If that is true, then leaders in all business systems should train to heighten their spiritual intelligence and consequently be better leaders, which will in addition change interpersonal relationships between employees and between employees and leaders and that should lead in two directions. First in more advanced business systems, and second in a higher degree of spiritual intelligence of working individuals.

\section{References}

Biernacki, P., \& Waldorf, D. (1981). Snowball sampling: Problems and techniques of chain referral sampling. Sociological Methods \& Research, 10(2), 141-163.

Bulc, V. (2006). Ritmi poslovne evolucije. Vibacom.

Cianciolo, A. T., \& Sternberg, R. J. (2004). Intelligence: A brief history. Wiley-Blackwell.

Ciarrochi, J., Forgas, J. P., \& Mayer, J. D. (2001). Emotional intelligence in everyday life: A scientific inquiry. Psychology Press.

Coyle, J. (2002). Spirituality and health: Towards a framework for exploring the relationship between spirituality and health. Journal of Advanced Nursing, 37 (6), 589-597.

Detterman, D. K. (2009). Intelligence. In Microsoft Student 2009 [DVD]. Microsoft.

Emmons, R. A. (200o). Is spirituality an intelligence? Motivation, cognition and the psychology of the ultimate concern. The International Journal of Psychology and Religion, $10(1), 3-26$.

Faugier, J., \& Sargeant M. (1997). Sampling hard to reach populations. Journal of Advanced Nursing, 26(4), 790797.

Gardner, H. (1995). Razsežnosti uma: teorija o več inteligencah. Tangram.

Gardner, H. (2000). A case against spiritual intelligence. International Journal for Psychology of Religion, 10(1), 2734.

George, L. K., Larson, D. B., Koenig, H. G., \& McCullough, M. E. (200o). Spirituality and health: What we know, what we need to know. Journal of Social and Clinical Psychology, 19(1), 102-116.

Goleman, D. (1995). Emotional intelligence: Why it can matter more than IQ. Bantam.
Gottfredson, L. (1997). Mainstream science on intelligence: An editorial with 52 signatories, history and bibliography. Intelligence, 24(1), 13-23.

Gottfredson, L. (1998). The general intelligence factor. Scientific American, 9(4), 24-29.

James, W. (1902). The varieties of religious experience: A study of human nature. https://csrs.nd.edu/assets/59930/ williams_1902.pdf

Jensen, A. R. (2002). Galton's legacy to research on intelligence. Journal of Biosocial Science, 34(2), 145-172.

King, D. (2008). Rethinking claims of spiritual intelligence: A definition, model, and measure [Unpublished Master's thesis]. Trent University, Peretborough.

King, D., \& DeCicco, T. L. (2009). A viable model and selfreport measure of spiritual intelligence. International Journal of transpersonal Studies, 28(1), 68-85.

MacDonald, D. A. (2000). Spirituality: Description, measurement, and relation to the five factor model of personality. Journal of Personality, 68(1), 153-197.

Mayer, J. D., Roberts, R. D, \& Barasade, S. G. (2008). Human abilities: Emotional intelligence. Annual Review of Psychology, 59(1), 507-536.

Schneider, B. (1987). The people make the place. Personnel Psychology, 40(3), 437-453.

Shen, W., Groves, K. S., \& McEnrue, P. M. (2008). Developing and measuring the emotional intelligence of leaders. Journal of Management Development, 27(2), 225-250.

Sternberg, R. J., \& Salter, W. (1982). Handbook of human intelligence. Cambridge University Press.

Vaughan, F. (2002). What is spiritual intelligence? Journal of Humanistic Psychology, 42(2), 16-32.

Wolman, R. N. (2001). Thinking with your soul: Spiritual intelligence and why it matters. Harmony Books.

Yang, K. P., \& Wu, X. J. (2009). Spiritual intelligence of nurses in two Chinese social systems: A cross-sectional comparison study. Journal of nursing research, 17(3), 189-197.

Zareei, M. H., \& Sedrpooshan, N. (2015). The relationship between spiritual intelligence and components of burnout in female teachers. Occupational Medicine, 6(4), 66-74.

Zohar, D., \& Marshall, I. (200o). Duhovna inteligenca. Učila International. 



\section{Professional and Organisational Commitment in the Hospitality Sector}

\author{
Marjetka Rangus \\ University of Maribor, \\ Faculty of Tourism, Slovenia \\ marjetka.rangus@um.si \\ Srđan Milošević \\ Educons University, \\ Faculty of Sport and Tourism, Serbia \\ srdjan.milosevic@tims.edu.rs \\ Iva Škrbić \\ Educons University, \\ Faculty of Sport and Tourism, Serbia \\ iva.skrbic@tims.edu.rs
}

\author{
Bojana Radenković-Šošić \\ Educons University, \\ Faculty of Sport and Tourism, Serbia \\ radenkovicbojana@gmail.com \\ Jože Hočevar \\ Terme Čatež d.d, Slovenia \\ joze.hocevar@terme-catez.si \\ Mladen Knežević \\ Libertas International University, \\ Faculty for International Relations \\ and Diplomacy, Croatia \\ mknezevic@libertas.hr
}

The purpose of the study is to examine whether two different work commitment profiles influence service quality in the hospitality sector in Slovenia and Serbia and how the implications of the differences can be used in the tourism and hospitality industry. Combining a qualitative and quantitative approach, two new instruments were developed for this study. The first instrument was created on the basis of short, structured interviews with employees. Two factors explaining the two different commitment profiles were determined with statistical analysis and with the method of clustering, four dimensions of commitment profiles forming were extracted. The second instrument was developed on the basis of existing evaluation forms for employees in the tourism industry and interviews with leading and middle managers of hotels. The findings of the study show that there is a small proportion of professionallyoriented employees in the tourism sector, and the difference among employees is evident in the ranking of working values. These results could be useful for managers in planning and organising their human resources and also in planning further development of their companies' human resource policies. The original contribution of the article is the ranking of working values and the perception of quality work by employees in the hospitality sector. The study also reveals new evidence on different types of commitment profiles.

Keywords: tourism, hospitality, organisational commitment, professional commitment, human resources management

(cc) BY-SA https://doi.org/10.26493/2335-4194.13.179-191

\section{Introduction}

There is a widely-accepted opinion in academic and professional circles that the tourism and hospitality sector does not provide an optimum environment for successful career building and professional growth. Research in the field of hospitality offers different ex- 
planations for this phenomenon. The tourism and hospitality industry records high employee turnover rates (Iverson \& Deery, 1997; Hjalager \& Andersen, 2001; Baum \& Thompson, 2007; Hussey et al., 2010; Karatepe \& Shahriari, 2014; Kim, 2014), such that turnover is often acceptable and is understood to be the norm (Iverson \& Deery, 1997). One reason for the lack of good, stable careers in the sector is that tourism and hospitality jobs involve long working hours, especially during weekends and holidays, sometimes extreme working and weather conditions, stress and demands, as well as special attitudinal norms, which are in the domain of personal character traits rather than skills and knowledge (see Hussey et al., 2010; Hussey et al., 2011; Mackenzie \& Kerr, 2013; Lee, 2014). Employment in the hospitality industry is expected to grow more slowly in the coming years (Baum, 2015; Dogru et al., 2019).

Research (Ap \& Wong, 2001; Brown et al., 2011; Kim, 2014) shows that good working conditions and career opportunities are crucial for building stable employment and the development of professionalism. Employees respond to high levels of organisational support with high levels of organisational commitment and psychological attachment, obligation, and loyalty (Brougham \& Haar, 2018). These also play a part in the execution of excellent tourism service, resulting in keeping customer loyalty. Also, organisational culture and values are an important part of career development perceptions and employee structure, since they attract people with similar values, beliefs, knowledge, skills and abilities (Gorenak \& Ferjan, 2015). Human potential is increasingly recognized as an essential asset for organisations (Silva \& Martins, 2016). However, Hjalager and Andersen (2001) suggest that, because of the high fluctuation of workers in the industry, low-skilled jobs and low rates of relevant tourism education among tourism employees, the tourism sector is a border market for human resources that shares a pool of possible employees with many other sectors that offer better salaries and career opportunities. According to Hjalager and Andersen (2001), tourism jobs tend to be temporary solutions for new employees in the workforce or in times of economic crisis, which together with the often sea- sonal nature of the jobs explains the high turnover rate in the sector. It is important to point out that high turnover rates and lack of professionalism are not only confined to developing countries or countries in transition (Baum, 2007).

Previous research in the field also shows that employees who have had professional tourism education tend to change jobs less frequently than those who have not or have different qualifications (Hjalager \& Anderson, 2001). Moreover, people with previous job experience in the sector tend to develop a more professional attitude towards their jobs (Kim, 2014).

Employees with elevated levels of turnover intentions have low morale, deliver poor service and erode service recovery efforts, which in the end have an impact on guests and can result in bad reviews, complaints and finally loss of guests (Ap \& Wong, 2001; Karatepe \& Shahriari, 2014). Satisfied, stimulated and professional employees in the service sector are thus crucial to all service industries and should be a main concern of hospitality management (Brown et al., 2011; Ineson et al., 2013; Karatepe \& Shahriari, 2014).

To assure high quality of service, tourism companies should be aware of the importance of human resources management and should strive for optimal employee profiles in the business. In order to determine what type of work commitment profiles predict quality of service, we set up two hypotheses:

H1 Employees who have high professional commitment will perform their tasks better.

$\mathrm{H} 2$ Employees who have high professional commitment are more likely to have had a proper education relevant to the job they are doing.

\section{Theory}

Research in the field suggests that employees have different types or profiles of work commitment. The latest research on employee commitment profiles shows that commitment profiles have substantial temporal stability and do not change easily over time (Kam et al., 2016). Research indicates that different forms of work commitment are connected to job involvement and quality of service (Gouldner, 1957; 1958; Carson et al., 1999; Cohen, 1999; Sinclair et al., 2005; Kam et al., 
2016). In his pioneer study on different types of loyalty, Gouldner established that over the years employees in an organisation develop different types of loyalty or commitment to their work (Gouldner, 1957; 1958). Gouldner's research suggests that employees have two types of loyalty orientation. The first group of employees (locals) tend to be more committed to organisations they work in and their local subgroup in the organisation. They are high on loyalty to the employing organisation and low on commitment to specialized skills (Gouldner, 1957). The second group (cosmopolitans) of employees tend to be high on commitment to specialized role skills, low on loyalty to employing organisations and likely to use an outer reference group orientation (Gouldner, 1957), thus they are more likely to be mobile and pursue their careers in other organisations.

Later research on work commitment has resulted in different models of commitment forms (see Randal \& Cote, 1991; Meyer \& Allen, 1997; Carson et al., 1999). In accordance with Gouldner, four committed (Carson et al., 1999) profiles of workers have been identified, thus answering Gouldner's dilemma of whether both types of loyalty can be recognised in one person (Carson et al., 1999). Morrow (1993), in her research, determines five universal forms of work commitment, which are relevant to many employees. These foci of work commitment are affective commitment to organisation, continuance commitment to organisation, career commitment, work ethic and job involvement (see Cohen, 1999). Morrow's study suggests the possible interrelationships among the five commitment forms. Cohen's (1999) research on Morrows' theory has determined that it is only a presumption that each of the five forms is an independent construct. Cohen's research further shows that job involvement seems to be the key mediating variable in the interrelationships among work commitment constructs (Cohen, 1999).

In other scholarly literature on work commitment, professionalism is defined as the predominance of career commitment in an employee's commitment profile compared to other work commitment profiles (e.g. Blau, 1985; Ellemers et al., 1998; Cohen, 1999). In typologies where professional commitment is not defined (e.g. Gouldner, 1957; 1958; Randall \& Cote, 1991;
Carson et al., 1999), terms like 'career commitment,' 'professional commitment' and 'occupational commitment' are used to explain commitment to vocation, career or profession. Morrow (see Cohen, 1999) connected career commitment to the Protestant work ethic, suggesting that this is the most stable commitment form, because it is learned through the socialisation process and is less related to characteristics of the work setting (Morrow, 1993, in Cohen, 1999) where one is more narrowly focused on one's own career or vocation. In other research, career commitment is connected to high job withdrawal cognitions, feelings of self-efficacy, ongoing training and continuing education (Carson et al., 1999). Although the definitions have some commonalities and are sometimes used in all contexts, they should not be interchanged. According to Blau (1985), career commitment can be defined as one's attitude towards one's profession or vocation, whereas professional commitment can be operationalised in terms of the individual's reluctance to leave his/her professional role (Thornton in Blau, 1985), i.e. commitment to his/her vocation or profession. In theory, professionalism and professional commitment is related to outer reference groups, i.e. professional associations (Gouldner, 1957; 1958), reading journals, attending meetings and joining associations (Price \& Mueller, 1981). In the tourism sector, professionalism is based on many dimensions, not all of which can be learned or trained. Hussey et al. (2011) argue that professionalism in tourism can be conceptualised by the following ten dimensions: profession as a referent group, altruism, belief in self-regulation, sense of calling, autonomy, body of knowledge, concern for service quality, code of ethics, special skills and expertise, and professional identity.

Organisational commitment refers to the predominance of one's attachment to the organisation in one's work commitment profile (Ellemers et al., 1998, pp. 717-718). Affective organisational commitment is related to employees' emotional attachment to an organisation, the match of personal values and the values of the organisation and identification with the company (Ellemers et al., 1998; Cohen, 1999; Sinclair et al., 2005; Kam et al., 2016). Continuance commitment, on the other hand, is defined as the perception that the 
cost of leaving exceeds the cost of remaining (Ellemers et al., 1998; Cohen, 1999; Sinclair et al., 2005; Kam et al., 2016). Organisational commitment has a significant direct influence on job performance (Youn et al., 2018). According to Dhar (2015) organisational commitment strongly influences the quality of guest services. Perceived organisational support, such as the value of contributions and caring about the well-being of the employee, significantly affects organisational commitment (Kim et al., 2016).

For the purpose of our research, we needed to develop a new kind of instrument that would differentiate the two types of work commitment profiles of employees in tourism as extreme poles in work commitment profile categorisations. This distinction was first set up by Gouldner (1957). Later, Ellemers et al. (1998) polarised career oriented-commitment to team-oriented commitment, of which the latter proved to be closely related to organisational commitment. Their research has shown that organisational commitment is stronger among respondents with longer job tenure and greater work satisfaction (Ellemers et al., 1998). They have also shown that employees who are more career oriented are less likely to help their team colleagues at the expense of their own work and that those committed to the organisation are more likely to work overtime (Ellemers et al., 1998). Another very important finding from their research is that a certain type of work commitment profile does not predict task performance ratings (Ellemers et al., 1998).

This study set out to analyse whether there is a difference in the quality of work (performance) between two groups of employees (those who are more committed to the organisation and those who are more committed to the profession).

\section{Materials and Methods}

In order to realise the objectives of our research, we used two instruments. In spite of all the provided definitions, we decided to take an emic approach to this research and to establish definitions which would be understandable and unified to employees participating in the research. The first instrument was created to assess whether an individual is more committed to an organisation in which he or she is employed or to his/her profession. We assumed that employees would either be typically committed to their organisation (both affective and continuance) or to professionalism. The second instrument was developed to evaluate the quality of work of employees who participated in the project.

To establish the two commitment profiles, a new instrument was designed especially for this project. To make the instrument as comprehensible as possible, we made certain that the use of words and definitions were from the employees' points of view. Accordingly, definitions of the two commitment profiles as explained by the participating employees were used.

In the first stage of creating the instrument, we employed a qualitative methodology. Researchers in the field were students from the Faculty of Tourism of the University of Maribor, Slovenia, and young associates and teaching assistants from the Faculty of Sport and Tourism in Novi Sad, Serbia. In this way, we assured the results from culturally diverse backgrounds in order to avoid local determination of the results. All interviewers, before conducting fieldwork, were educated in techniques of conducting interviews and how to take notes from the interviews - they were informed that they had to take completely verbatim notes. Each group was supervised in the field by one of the researchers. No one needed the intervention of the researchers.

The interviewers visited various hospitality organisations and asked employees to answer two structured questions: (1) What are the characteristics of someone who is committed to her/his profession? and (2) What are the characteristics of someone who is committed to the organisation in which she/he is employed? Researchers worked in pairs, with one asking questions and the other recording the answers verbatim. We did not want to record conversations for reasons of confidentiality between the interviewers and the employees. We were aware that some employees might consider the questions and their responses to be threatening to both their relationships with their superiors and their careers. To minimise any kind of influence or the interviewees' discomfort with the process, we asked students to do the interviews. Interviews were 
Table 1 Dimensions of Indexes Explaining the Factors

\begin{tabular}{ll}
\hline Commitment to organisation & Commitment to professionalism \\
\hline Attitude towards respecting the house rules & Attitude towards guests \\
Attitude towards co-workers & Attitude towards knowledge \\
\hline
\end{tabular}

conducted with a total of 60 employees. Researchers recorded a total of 314 responses to our questions.

Next, a panel of researchers was organised where researchers from the universities, as well as practitioners, professionals employed in the hospitality and hotel industry, were engaged. Out of the total collected statements, we first isolated the ones that were repetitions. In the next step, statements that did not meet the purposes of the research were isolated. The remaining total of 103 claims was prepared for further processing. Of this number, there were 45 statements related to commitment to the profession and 58 to commitment to the organisation in which the interviewees were employed. The statements were formulated in sentences and an instrument with a 5-point Likert scale was created. The sentences were formulated in the first person: 'I am aware of the importance of team-work.'

To create the final form of the questionnaire, we offered the instrument to students of various faculties at the University of Maribor (Slovenia), Libertas Business School of Zagreb (Croatia) and the University Educons in Novi Sad (Serbia). The research included a total of 867 male and female students. All students participated voluntarily. The research was conducted in groups of up to 50 students. Before each group of students filled in the questionnaires, a researcher from the team gave instructions on how to use the instrument and each student filled out a questionnaire individually.

In the first step of the instrument design, we made a correlation analysis of all statements in the questionnaire. We decided to exclude all claims that did not reach the value of Pearson's correlation coefficient of o.50. In this way, we excluded another 64 statements from further procedures. The remaining 39 statements were analysed using principal components analysis. Four principal components explained 57.35 per cent of the variance. Following that, we excluded from further analysis another seven statements that had not achieved more than 0.50 communality. Thus, all the components explained 59.67 per cent of the variance. The remaining 32 were deployed into two predicting factors (commitment to the profession and commitment to the organisation).

To achieve the highest internal consistency, each individual factor was adjusted until we achieved a satisfactory value for Cronbach's alpha coefficient. For the scale 'commitment to the profession,' Cronbach's alpha coefficient was 0.878 . The scale consisted of nine statements. The scale of 'commitment to the organisation' also contained nine statements and Cronbach's alpha was 0.904. These internal consistencies are satisfactory for an instrument of this kind (Table 1). Thus, through our research, the two types of commitment were determined by two clusters of indexes. The commitment to the organisation profile was explained by dimensions of 'attitude towards house rules' and 'attitude towards co-workers', while the commitment to professionalism profile was explained by the dimensions of 'attitude towards guest' and 'attitude towards knowledge.'

To assess the quality of employees' performance, we used an improved instrument, routinely used for this purpose, in one of the largest Slovenian hotel companies. Standard instruments for assessing the quality of service were not included, since they only assess the service from the guests' points of view and do not give any information on employees' attitudes in an organisation or they are too complex to be used in such a study. The basic instrument was supplemented with the criteria suggested by the groups of managers in various tourist organisations. The instrument evaluated the following categories on a Likert scale from 1 to 5 (Table 2).

The final instrument for employees consisted of 18 statements and some demographic questions. The statements were put in random order to minimise the influence of previous statements on the rating of the 
Table 2 Categories Evaluated by the Managers

1 Communication
2 The ability to participate in a team
3 Respect for colleagues
4 Ingenuity, continuous search for solutions
5 Ability to innovate
6 Compliance with superiors
7 Organisational skills
8 Self-initiative
9 The ability to transfer problems to their superiors -
are able to propose solutions
10 Flexibility
11 Loyalty to the company, identify with the vision of the
company
12 Tidiness and accuracy
13 Knowledge of complete range of businesses offered
14 Professionalism on the job
15 Care for the guests (kindness, knowledge of service,
potential appeals to service

participants' next statements. The instrument was offered to 249 employees in hotels in Serbia and Slovenia. Of all, 66 of them refused to participate. It was explained to employees that the survey could not be anonymous, because their performance in the workplace would be assessed by their direct superiors. In order to be able to connect both types of data, the employees had to agree to put their names on the questionnaires. Employees were assured that the results of their answers would not be available to their managers. Once employees agreed on the method of the research and responded to the questionnaires, the names of the participating employees were submitted to their managers. Managers were asked to rate each employee according to the scale presented above. Managers were presented with special evaluation forms for each employee.

\section{Results and Discussion}

The vast majority of our respondents were female, which approximates the situation in the tourism sector in Slovenia and Serbia. This industry is dominated by the female population. In our sample, there were
Table 3 Employees' Education

\begin{tabular}{lrr}
\hline Type of education & $f$ & $\%$ \\
\hline Unknown & 14 & 7.7 \\
High school & 106 & 57.9 \\
College education & 22 & 12.0 \\
University or equal professional education & 35 & 19.1 \\
Master of Science or higher & 6 & 3.3 \\
\hline Total & 183 & 100.0 \\
\hline
\end{tabular}

slightly more women than men, but this fact did not affect the general statistical impression.

Most employees had secondary education (Table 3). The number of employees with college or university education was relatively high. This result differs from the educational structure that is typical for this sector, which has been shown to have a relatively lower educational level. As stated, in our sample, the proportion of employees with higher levels of education was unexpectedly high. There are probably two explanations for this situation. First, in the participating countries, in the past 10 years, there has been a great stimulation of education by the government, especially of higher education. This expansion has occurred in both the private and public education sectors. The second reason could be attributed to the period of economic crisis, which is why many highly educated people work in jobs that are far below their educational qualifications. This is particularly evident in the fact that 66 per cent of employees with secondary education and 44 per cent of employees with higher levels of education do not work in the professions they are educated for. Exceptions are employees with college education who work mostly as managers. Only 27.3 per cent of them work in jobs that they are not educated for.

In our study, 54.6 per cent of the respondents were currently working in jobs for which they were not properly educated. In the Slovenian and Serbian education system, the field of hospitality is inflexible and students are educated in only a few very traditional occupations. There is little variability and therefore students are not trained to adapt to business conditions that are dynamically changing. On the other hand, the hospitality industry has never set standards and 
demands for specific forms of education in the sector, which leaves the question of professionalism in tourism open. Closely related to this argument is the case of the private sector and small tourism businesses that avoid hiring educated employees because, according to state work legislation, employers should provide them with better salaries.

The average age of the participants, 37.65 years, indicated a relatively low level of employment dynamics. The average number of companies where they were employed was 2.48 , which is another proof of the relative immobility of the workforce in the sector. The youngest participant in our research was 19 years old and the oldest 62 years. Almost 76 per cent of the employees had worked for 3 or even fewer organisations, which indicates low turnover rates. This fact, not commonly referred to in the tourism sector, can be attributed to a specific working culture and ethic stimulated by the previous socialist regime. Kalleberg and Stark's (1993) research shows that employees in socialist economies are not primarily concerned with their careers, compared to their us colleagues. Vodopivec (2014), in her interviews with workers and directors of a textile company in the socialist regime in Slovenia, reports on the importance and intentional building of company loyalty and solidarity among co-workers.

Low labour mobility has proved to be related to traditionalism in family relationships. Thus, in our study, among employees who had 5 years' working experience, 71 per cent of those were not married and stated their marital status as 'single.' In the group where employees had 5-10 years of experience, the number of unmarried employees was 31 per cent and the number of employees who were married was 59 per cent. Changes of employment in small communities with these conditions can be highly complicated and risky, because there are many factors that are sometimes impossible to reconcile with each other. Small communities offer very limited employment opportunities, as there are only a small number of companies and therefore low dynamics of the workforce. For example, unfavourable working hours and childcare is a particularly important factor. However, what is probably an equally important contributor to relatively low labour mobility is the conviction of almost 60 per cent of our respondents that they had the possibility of advancing in their companies. This idea was rejected by the remaining nearly 40 per cent of respondents (38.8 per cent). In contrast to this view, almost half of the respondents (46 per cent) claimed that they were thinking about leaving their companies. The share of those respondents with families was fully equal to those who were single or divorced. When it came to thinking about leaving their current companies, there were an equal proportion of those who were employed for an indefinite period and those who were employed for a limited time.

Results of the assessment of the level of commitment to the profession and commitment to the organisation were more than surprising. In many studies of the labour force in this profession, it has been pointed out that people working in the tourism sector are those who prefer social contact and who therefore tend to be more professionally oriented. In our study, only 17 respondents or 9.3 per cent were somewhat to a greater extent committed to their profession than to the organisation in which they were employed. Thus, asymmetric data makes further statistical analysis more or less meaningless.

Nearly 60 per cent had completed high school, which was completely in line with the educational structure of the respondents in the sample. Most of them were in the between 29 and 36 years age group. In this age group, we found that 41 per cent of those were more committed to their professions than the organisations. So this was a group with solid life experience, and also solid work experience, who obviously had a strong desire to advance in their professional development. Among them, there were an equal number who had families and those who did not yet have them, which is surprising to some extent.

Although the theory states that commitment to profession has different roots, it also suggests that employees with higher levels of professional orientation will place a primacy on work in their lives (Blau, 1985). This is also related to the belief that individuals can influence or control their careers. More than half of them said that their companies did not provide for systematic additional professional education. Again, awareness of the importance of life-long learning ex- 
periences and additional professional qualifications is expected from those employees who rank higher on professional commitment, since they are looking for something more than just a job. Almost 60 per cent of them had already considered leaving their companies and wanted to find a good grounding for their professional ambitions elsewhere, which is also in line with previous research in the field, suggesting that withdrawal cognition predicts career or professional commitment (Price \& Mueller, 1981; Blau, 1985; Ellemers et al., 1998; Carson et al., 1999).

Results of the research confirmed some previous hypotheses on work commitment profiles. When polarising work commitment types, according to Gouldner's division, only 9.3 percent of employees could be defined as clearly high on professional commitment and more than 90 percent were high on organisational commitment. Since we did not analyse all other types, namely dually committed and uncommitted, we can only assume that there was also a large proportion of those among those interviewed. Results also suggest that there were only a handful of those who were really dedicated to their professions in the hospitality sector, which perhaps has alarming implications for quality of service in Slovenia and Serbia.

Along with the studies of Price and Mueller (1981), Blau (1985), Ellemers et al. (1998) and Carson et al. (1999), we found that in the tourism sector organisational commitment is related to job tenure and age. But, surprisingly, the tourism sector in Slovenia and Serbia does not report high turnover rates, as seems to be the case all over the world, since the participants in the research worked in fewer than 3 companies on average and many of them had worked in the same company all their work life. Nearly 20 per cent of respondents (18.8 per cent) had remained with their original companies.

When the participants were divided into groups according to the quintiles, the majority of those who had never changed companies were from the oldest group of respondents. 84 per cent of the members of the oldest group had changed a maximum of 2 companies or had not changed companies at all. This again indicates very low labour mobility in this sector. Here, it is worth mentioning that in the group of those who appeared to be somewhat more committed to their professions than to the companies, there was almost no one who had not changed companies (only 1 person). Members of all age groups were equally prone to move from one company to another. This tendency changes a little bit more intensively in the second quartile with those members of the group who had an average of between 8 and 15 years of work experience. Although on the basis of our results we cannot make generalisations, it seems that mobility is statistically slightly higher with those who were more committed to their professions than to the organisations in which they work. This is again in accordance with previous findings, because commitment to a profession also means seeking the best possible conditions for professional development.

As previously mentioned, this can be explained by the specific historical influence of the socialism regime ideology, as ethics lie in organisational loyalty and community solidarity and not in the endeavour for individual and successful careers.

Research also shows the need for a more structural and strategic approach to the system of formal education for tourism professions, as already pointed out by Hussey et al. (2011). In spite of high overall levels of education, there is still an evident lack of proper education for tourism vocations at all levels. According to our findings, more than half of employees also reported that tourism companies themselves do not provide for additional training, i.e. they do not express very much interest in additional training for their employees and are not yet aware of the importance of professional knowledge and skills for their front-line employees.

Data on individual performance ranking bring some other interesting evidence to consider. Due to the extreme asymmetry of distribution, there is no justification for the statistical comparison of the two groups. But if the item from the structured questionnaire is treated as the value associated with the work, it makes sense to analyse the hierarchy of these values. Average values and their standard deviations are shown in Table 4.

Both groups of employees, those who were committed to their companies and those who were com- 
Table 4 Comparison among the ranks of Some Items

\begin{tabular}{|c|c|c|c|c|c|c|}
\hline \multirow[t]{2}{*}{ Item } & \multicolumn{3}{|c|}{ Organisation } & \multicolumn{3}{|c|}{ Profession } \\
\hline & (1) & $(2)$ & (3) & (1) & (2) & (3) \\
\hline I do my work fairly. & 1. & 4.86 & 0.531 & 1. & 4.65 & 0.996 \\
\hline I try to be friendly and kind to the guests. & 2. & 4.86 & 0.531 & 2. & 4.59 & 1.004 \\
\hline I am aware of the importance of good team work. & 3 . & 4.81 & 0.454 & 8. & $4 \cdot 35$ & 1.057 \\
\hline I try to be good at my work. & 4. & 4.78 & 0.555 & 13. & 4.24 & 1.091 \\
\hline The company can rely on me. & 5 . & 4.76 & 0.626 & 11. & 4.24 & 1.033 \\
\hline I try to do my work with utmost quality. & 6. & 4.69 & 0.548 & 16. & 4.00 & 1.000 \\
\hline At work, I try to be in a good mood. & 7. & 4.68 & 0.705 & 3 . & 4.59 & 0.795 \\
\hline I am always neat at work. & 8. & 4.67 & 0.616 & 10. & 4.24 & 1.033 \\
\hline My attitude is the same in the pres. of sup. and when they are not around. & 9. & 4.67 & 0.655 & 15 & 4.06 & 1.088 \\
\hline I believe I know how to serve a guest. & 10. & 4.63 & 0.654 & 7 . & 4.41 & 1.064 \\
\hline I respect the instructions of superiors. & 11. & 4.63 & 0.724 & 18. & 3.88 & 1.054 \\
\hline I have good relations with my colleagues. & 12. & 4.57 & 0.673 & 17 & 3.88 & 1.054 \\
\hline I strive for improvements of work organisation and work processes. & 13. & 4.45 & 0.702 & 9. & 4.29 & 1.047 \\
\hline I work in my profession with enthusiasm. & 14. & $4 \cdot 37$ & 0.876 & 14. & 4.18 & 0.883 \\
\hline I enjoy my work. & 15 & 4.11 & 1.000 & 5 . & 4.47 & 1.007 \\
\hline I constantly train for my profession. & 16. & 4.07 & 1.075 & 4 . & 4.47 & 1.007 \\
\hline I invest in my knowledge in my free time. & 17. & 3.86 & 1.057 & 6. & 4.41 & 1.064 \\
\hline I work together with students on their res. papers and practical education. & 18. & 3.73 & 1.261 & 12. & 4.24 & 1.147 \\
\hline
\end{tabular}

Notes Column headings are as follows: (1) rank, (2) mean, (3) standard deviation.

mitted to their professions, put the same two values on the first two places. These are the values of fairness at work and kind and friendly attitudes towards guests, which in a way are universal values in the hospitality industry. In general, we can say that those groups who were more committed to their companies ranked higher in values associated with respect for the rules of the company, while the groups of dedicated professionals highlighted individual values showing enjoyment of the work being performed and education for the job. Thus, for example, the item 'I enjoy my work' was ranked in 15 th place by those who were dedicated to their organisations, but 5 th by those who were dedicated to their professions. It is important to note that constant training for the job was essentially assessed differently by the two groups. Those who were more committed to their profession put far more value on education than those who were committed to the or- ganisation. The organisation clearly represents a collective identity in which it is necessary to respect the rules of the collective.

Occupation, on the other hand, represents a personal relationship to work, and the constant improvement of knowledge and skills reflects the relationship towards oneself and one's profession. As a result, the latter group may neglect teamwork, ignoring the importance of collective rules. For them, the general rules of the profession are more important than the particular rules of their company. Those who are more committed to the profession assign less importance to the instructions of superiors, but at the same time behave the same whether superiors are present or not. It is a good reflection of their relationship to the profession in which they work.

If we list the items according to the four dimensions presented in Table 1, we see another interesting distri- 
Table 5 List of Dimensions of the Items Rated by Employees

\begin{tabular}{|c|c|c|}
\hline & Commitment to the organisation & Commitment to the profession \\
\hline 1 & Attitude towards respecting the house rules & Attitude towards respecting the house rules \\
\hline 2 & Attitude towards guests & Attitude towards guests \\
\hline 3 & Attitude towards co-workers & Attitude towards guests \\
\hline 4 & Attitude towards respecting the house rules & Attitude towards knowledge \\
\hline 5 & Attitude towards respecting the house rules & Attitude towards knowledge \\
\hline 6 & Attitude towards respecting the house rules & Attitude towards knowledge \\
\hline 7 & Attitude towards guests & Attitude towards guests \\
\hline 8 & Attitude towards respecting the house rules & Attitude towards co-workers \\
\hline 9 & Attitude towards co-workers & Attitude towards knowledge \\
\hline 10 & Attitude towards guests & Attitude towards respecting the house rules \\
\hline 11 & Attitude towards respecting the house rules & Attitude towards respecting the house rules \\
\hline 12 & Attitude towards co-workers & Attitude towards knowledge \\
\hline 13 & Attitude towards knowledge & Attitude towards respecting the house rules \\
\hline 14 & Attitude towards knowledge & Attitude towards knowledge \\
\hline 15 & Attitude towards knowledge & Attitude towards co-workers \\
\hline 16 & Attitude towards knowledge & Attitude towards respecting the house rules \\
\hline 17 & Attitude towards knowledge & Attitude towards co-workers \\
\hline 18 & Attitude towards knowledge & Attitude towards respecting the house rules \\
\hline
\end{tabular}

bution of values connected to the work. In the group of employees who tend to be more committed to the organisation, all the items connected to attitudes towards knowledge are put in the last 6 places (see Table 5). In the first half of the values, only two, those connected to attitudes towards guests, can be found. Similarly, concerning the first half of the items of employees who tend to be more committed to the profession, only two items connected with attitudes towards respecting the house rules and co-workers are found. Also, it is evident that employees who tend to be more committed to the profession rate the values connected to knowledge and guests higher than the other group. They also put all three items, which express attitudes towards guests, in the first half of the values. Again, it is important to stress that both groups rate the same items as the majority and consider them to be of the same importance. Of the two, one is connected to attitudes towards respecting house rules and the other with attitudes towards guests.

\section{Testing the Hypotheses}

Our first hypothesis, that employees who are higher on professional commitment will get better performance ratings, must also be rejected. As indicated by Ellemers et al. (1998), our research shows no relationship to any type of work commitment. Thus, we can say that the type of work commitment does not predict performance ratings. There were few differences between the two types of commitment, according to specific dimensions of the measure.

The only difference between the two types of work commitment was seen in the category of innovativeness, where employees with higher levels of professional commitment were rated statistically better than the others. This result seems logical but is again surprisingly different from Ellemers et al's research where they report that contextual performance, which they understand to be initiative or enthusiasm, is related to the dimension of commitment to teams of co-workers (Ellemers et al., 1998). The latter has been exposed as 
a dimension of commitment to organisation in our study.

Related to our second hypothesis on relationship between the type of commitment and proper education for tourism we can hardly draw any conclusion because the distribution of data is asymmetrical. It is interesting that of those who were more committed to the profession, 13 of them are women. As many as 16 of them had more than 5 years of experience, so these were people who had good insights into the profession. About half of them were educated in a profession in which they work, which made them virtually indistinguishable from the majority of respondents. According to this result, we can reject our hypothesis that employees who are higher on professional commitment are more likely to have the proper education for the job in which they work.

\section{Conclusion}

Research on different forms of work commitment profiles shows that characteristics of profiles are not uniform all over the world. The study demonstrates that cultural and societal dimensions on the micro level of the globalised hospitality sector influence work commitment profiles, which, as in the case of Slovenia and Serbia, may differ from work commitment profiles in other parts of the world. The study also points out the relatively modest number of those employees in the hospitality sector who are more committed to their professions than to the organisations. However, the only statistically proven difference between the two profiles in this research is the category of innovativeness, so we can say that employees who rank highly on professional commitment are slightly more innovative than those who are more committed to the organisation. Research also shows that instruments and criteria usually used for assessing the quality of work of employees do not necessarily apply to all professionally oriented employees. Further development of assessment criteria is needed.

Another point that is evident from the results of the research is the fact that professionals in the hospitality sector differ to some extent from professionals in other fields in that they have the same educational background as those employees who are more committed to their organisations. Furthermore, there is also the same proportion of those who have families in both groups of employees.

The most interesting information on the two types of commitment profiles is the ranks of values connected to the work. Those employees who are more professionally oriented ranked the items on the list more carefully and there is a smaller difference between the highest and the lowest rank of items than in the group of more organisationally-oriented employees. The least important work values for this group proved to be respecting instructions and having good relationships with colleagues, while items connected with high quality of work (being in a good mood and constant training in the profession) were ranked 3 rd and 4th place. These results could be useful for managers in planning and organising their human resources and also in planning further development of their companies' human resource policies. On the basis of the results of the research, we can assume that the type of work commitment profile that is more dedicated to an organisation is better suited for big organisations or hotel resorts where respect for rules and strict organisation is necessary for providing high levels of service. On the other hand, we can assume that employees who are more professionally oriented can better perform in working environments where they can express their creativity and where deviation from specific arrangements is even desirable. The instrument for assessing the individual level of work commitment profile could be used in the process of a cadre selection, helping managers find optimal work positions for their employees and vice versa.

The research, however, leaves room for further study on differences between the profiles and the characteristics of both profiles. Also, there is another field open for research, namely assessing the quality of work performance. The instrument used in this study proved to be inadequate for measuring all the categories of work quality and thus more research needs to be done in order to develop new measures.

\section{References}

Ap, J., \& Wong, K. K. F. (2001). Case study on tour guiding. Tourism Management, 22(5), 551-563. 
Baum, T, (2007). Human resources in tourism: Still waiting for change. Tourism Management, 28(6), 1383-1399.

Baum, T. (2015). Human resources in tourism: Still waiting for change? A 2015 reprise. Tourism Management, 50(6), 204-212.

Baum, T., \& Thompson, K. (2007). Skills and labour markets in transition: A tourism skills inventory of Kyrgyzstan, Mongolia and Uzbekistan. Asia Pacific Journal of Human Resources, 45(2), 235-255.

Blau, G. J. (1985). The measurement and prediction of career commitment. Journal of Occupational Psychology, 58(4), 277-288.

Brougham, D., \& Haar, J. (2018). Smart technology, artificial intelligence, robotics, and Algorithms (s T A R A). Journal of Management \& Organization, 24(2), 239-257.

Brown, S., McHardy, J., McNabb, R., \& Taylor, K. (2011). Workplace performance, worker commitment, and loyalty. Journal of Economics and Management Strategy, 20(3), 925-955.

Carson, K. D., Carson, P. P., Roe, C. W., Birkenmaier, B. J., \& Phillips, J. S. (1999). Four commitment profiles and their relationships to empowerment, service recovery, and work attitudes. Public Personnel Management, 28(1), $1-13$.

Cohen, A. (1999). Relationship among five forms of commitment: An empirical assessment. Journal of Organizational Behaviour, 2o(3), 285-308.

Dhar, R. L. (2015). Service quality and the training of employees: The mediating role of organizational commitment. Tourism Management, 46, 419-430.

Dogru, T., McGinley, S., Line, N., \& Szende, P. (2019). Employee earnings growth in the leisure and hospitality industry. Tourism Management, 74, 1-11.

Ellemers, N., de Gilder, D., and van den Heuvel, H. (1998). Career-oriented versus team-oriented commitment and behaviour at work. Journal of Applied Psychology, 83(5), 717-713.

Gorenak, M., \& Ferjan, M. (2015). The influence of organizational values on competencies of managers. Business Administration and Management, 18(1), 67-83.

Gouldner, A. W. (1957). Cosmopolitans and locals: Toward an analysis of latent social roles 1. Administrative Science Quarterly, 2(3), 281-306.

Gouldner, A. W. (1958). Cosmopolitans and locals: Toward and analysis of latent social roles 2. Administrative Science Quarterly, 2(4), 444-480.

Hjalager, A-M., \& Andersen, S. (2001). Tourism employment: Contingent work or professional career? Employee Relations, 23(2), 115-129.
Hussey, J., Holden, M. T., \& Lynch, P. (2010, 15-17 June). Defining professionalism in the tourism context. Paper presented at the Tourism and Hospitality Research in Ireland Conference (THRIC).

Hussey, J., Holden, M. T., \& Lynch, P. (2011, 19-22 October). A concept of professionalism in tourism. Paper presented at the 29th EUROCHRIE Conference.

Iverson, R. D., \& Deery, M. (1997). Turnover culture in the hospitality industry. Human Resources Management Journal, 7(4), 71-82.

Kalleberg, L. A., \& Stark, D. (1993). Career strategies in capitalism and socialism: Work values and job rewards in the United States and Hungary. Social Forces, 72(1), 181-198.

Kam, C., Morin, A. J. S., Meyer, J., \& Topolnytsky, L. (2016). Are commitment profiles stable and predictable? A latent transition analysis. Journal of Management, 42(6), 14621490.

Karatepe, O. M., \& Shahriari, S. (2014). Job embeddedness as a moderator of the impacts of organisational justice in turnover intention: A study in Iran. International Journal of Tourism Research, 16(1), 22-32.

Kim, N. (2014). Employee turnover intention among newcomers in travel industry. International Journal of Tourism Research, 16(1), 56-64.

Kim, J. S., Song, H. J., \& Lee, C. K. (2016). Effects of corporate social responsibility and internal marketing on organizational commitment and turnover intentions. International Journal of Hospitality Management, 55, 25-32.

Lee, K.-J. (2014). Attitudinal dimensions of professionalism and service quality efficacy of frontline employees in hotels. International Journal of Hospitality Management, 41, 140-148.

MacKenzie, S. H., \& Kerr, J. H. (2013). Stress and emotion at work: An adventure tourism guide's experiences. Tourism Management, 36, 3-14.

Meyer, J. P., \& Allen, N. J. (1997). Commitment in the workplace: Theory, research and application. Sage.

Morrow, P. C. (1993). The theory and measurement of work commitment. JAI Press.

Price, J. L., \& Mueller, C. W. (1981). A causal model of turnover for nurses. The Academy of Management Journal, 24(3), 543-565.

Randall, D. M., \& Cote, J. A. (1991). Interrelationships of work commitment constructs. Work and Occupation, 18(2), 194-211.

Silva, S., \& Martins, D. (2016). Human resource management in hotel units: The Portuguese case. Academica Turistica, 9(1), 5-18.

Sinclair, R. S., Tucker, J. S., \& Cullen, J. C. (2005). Perfor- 
mance difference among four organisational commitment profiles. Journal of Applied Psychology, 9o(6), 12801287.

Vodopivec, N. (2014). Družbene solidarnosti v času socialističnih tovarn in individualizacije družbe. Ars \& Humanitas: Revija za Umetnost in Humanistiko, 8(1), 136-150.
Youn, Lee, K., \& Lee, S. (2018). Effects of corporate social responsibility on employees in the casino industry. Tourism Management, 68, 328-335. 



\title{
Utilization Analysis of Slovenian Hotel Websites
}

\author{
Mitja Petelin \\ Vocational College of Hospitality and Tourism Maribor, Slovenia \\ mitja.petelin@vsgt-mb.si \\ Dejan Križaj \\ University of Primorska, Faculty of Tourism Studies Turistica, Slovenia \\ dejan.krizaj@fts.upr.si
}

The purpose of the article is to get an insight into the content of the websites of Slovenian four- and five-star hotels and, based on the set criteria, to determine which websites are more utilized than others. We defined the utilization criteria and analysed all four and five-star hotels in Slovenia using data clustering analysis. The content of the websites, analysed in 2017 , at the first glance seems diverse, but when comparing their content, we concluded that there are no major statistical differences. An important discovery of the research falls on the security of most of the analysed websites - it is very flawed and sometimes misleading. The potential for interactivity and gamification remains untapped despite the various recommendations of experts and academics.

Keywords: website, hotel, Slovenian hotel websites, security

(cc)BY-SA https://doi.org/10.26493/2335-4194.13.193-200

\section{Introduction}

The consumer decision-making process in hotel selection is compromised by many different factors; one of them is how the consumer receives information (Zabukovec \& Čivre, 2012). The latter remains a great challenge for the hospitality industry and we can perceive it as a hotel website among other things.

Website research is widespread and there are several different approaches focusing on hotel characteristics and utilization, benchmarks of website design and marketing, conceptualising website quality, developing a performance indicator of hotel websites, usability and evaluation, etc.

Website characteristics as an important factor of measurement and development of appropriate instruments (leveraging structural equation modelling) were discussed in detail by Schmidt et al. (2008). More revealing was an article of Jeong et al. (2003) which came to the conclusion (data was collected using elec- tronic surveys) that the website quality is an important antecedent of information satisfaction. The research results suggested that hoteliers should adopt a more strategic approach to the Internet, preparing the ground for direct contact with customers. Understanding hotel websites via strategies pursued by hotel websites in correlation of the hotel size and the website proved that significant relationships were not identified (Escobar-Rodríguez \& Carvajal-Trujillo, 2013).

Focusing on performance among the luxurious, mid-priced, and budget hotel websites revealed significant differences among them (Chung \& Law, 2003), which was further supported with research in website attribute utilization and effectiveness for hotels of various class levels (using the Star Rating system approach) (Musante et al., 2009).

Research with a focus on marketing showed that hotels are not utilizing the internet to its full potential and effectively e-marketing their hotels regardless of 
the hotel type (Baloglu \& Peckan, 2006). Approaching the problem via benchmarking and analyzation (over 200 different websites criteria) revealed significant differences in website tools across hotel category and size, but no differences across geographic or linguistic region (Schegg et al., 2002). The geographical aspect could be further discussed since Ping-Ho et al. (2013) used content analysis and the eMica model, realising that hotels in Asia had more features than those on other continents.

Usability as a very important factor of a hotel website was researched using a heuristic technique and showed no significant difference among luxury, midpriced, and economy hotels (Yeung \& Law, 2006), but this does not mean that mid-priced and economy hotels are more informative than luxury ones, since class cluster analysis, bivariate analysis and the Chi-Square methodological approach proved otherwise (Díaz and Koutra, 2013).

Establishing a link between quality and profitability of websites was established by Yang et al. (2014) via two stage DEA (CCR and в $\mathrm{CC}$ ) methodology, but it was concluded that it is difficult to obtain detailed financial information from individual companies, therefore such a research approach should be reserved to organisations that have direct access to financial data.

The presented theoretical and practical insights have enabled us to consider an appropriate model and taxonomy for evaluating websites of Slovenian four and five-star hotels. Our goal was to get insights into the websites and to determine which websites are more utilized than others on the basis of the set criteria. We were also looking for research outcomes that would give useful insights for practitioners. For achieving those goals, we had to:

- create the utilization taxonomy,

- collect information about all Slovenian four- and five-stars hotels and their websites,

- try to determine which Slovenian hotels have the most utilized websites.

\section{Methodology}

We decided to use and adapt a methodological approach developed by Križaj et al. (2014) as a part of the scientific article 'A Tool for Measurement of Innovation Newness and Adoption and Tourism Firms,' combining a quantitative and qualitative methodological approach. The model combines three research problems, (1) measuring newness levels and the adoption of tourism innovations, (2) developing taxonomy allowing the calculation of correct innovation newness levels and (3) statistical analysis of innovation adoption in tourism destinations. The advantage of the model is its flexibility and architecture, which enables the addition of various elements of a tourist company, in our example, of a website.

Their basic mechanism originates from the introduction of all the necessary descriptive attributes of innovation in tourism companies. They created a database of the adopted innovations and classified and calculated similarities between companies through a data clustering approach. Clusters were represented by a dendrogram in which individual companies stood out based on their more innovative products and processes. The authors collected the data of 351 tourist companies in Slovenia in the two most widely spread daily Slovenian newspapers, the most widely read weekly business newspaper, five professional tourism journals, three portals managed by the Slovenian Tourist Board, and the national TV web portal. Data collection covered publications from 1 January 2007 to 1 June 2010. The first step in the processing of data was (1) an appropriate description of the tourist companies' adopted innovations, by means of which (2) the differences between the companies were defined, followed by (3) calculating, displaying and analysing the differences.

Taxonomy was an important part of the research model since it is the key to the correct calculation of the differences between the adopted innovations in tourism companies. The flexible development of the research information input interface allowed ongoing reorganisation or reclassification of the innovation attributes they have used and eventually changed during the taxonomy scheme optimisation process and data entry. The data, organised with the help of the developed taxonomy, enabled the statistical analysis of the introduction of innovations in tourist companies.

The presented approach was reused in our paper in 
Table 1 Website Utilization Taxonomy

\begin{tabular}{|c|c|c|}
\hline Category & Subcategory & Further subcategories \\
\hline \multirow[t]{3}{*}{ Experience } & Fulfilment & $\begin{array}{l}\text { On-line booking, sliding photos, high quality photos, hotel video, 3D panoramic } \\
\text { view, brochure, website search, etc. }\end{array}$ \\
\hline & Personalisation & Changing the colour of the website, costumisation of the website. \\
\hline & Gamification & Games, sweepstakes, quiz, etc. \\
\hline \multirow[t]{5}{*}{ Information } & $\begin{array}{l}\text { Feedback and } \\
\text { support for users }\end{array}$ & $\begin{array}{l}\text { Confirmation messages, calendar of hotel activities, faq, live chat, check-in and } \\
\text { check-out information, web forums, history of the hotel, newsletter, etc. }\end{array}$ \\
\hline & Contact information & E-mail, telephone, location, fax, contact form, Google Maps or similar, Skype \\
\hline & Security & Safe payment systems (https). \\
\hline & $\begin{array}{l}\text { Multimedia and } \\
\text { interactivity }\end{array}$ & Attractive graphics, sounds, videos, gifs, animations, smart devices applications, etc. \\
\hline & Multilingualism & EN, DE, RU, IT, HR, etc. \\
\hline \multirow[t]{4}{*}{ Marketing } & Advertising & $\begin{array}{l}\text { 'Best Price' guarantee, Green Globe Certificate, Congress Star, Zlati sejalec 2010, } \\
\text { Trip Advisor Travelers Choice 2015, special hotel offers and packages, etc. }\end{array}$ \\
\hline & Social media & Share page option, Facebook, Youtube, Twitter, Pinterest, blog, etc. \\
\hline & Loyalty programmes & $\begin{array}{l}\text { Kempinski discovery, ihg rewards club, le club accord hotels, best western awards, } \\
\text { etc. }\end{array}$ \\
\hline & OTA's & Booking.com, Tripadvisor, Expedia, Agoda, Hotels.com, etc. \\
\hline \multirow[t]{5}{*}{ Destination } & Weather & Weather forecast, temperature, extraordinary weather conditions \\
\hline & Events & $\begin{array}{l}\text { Festivals, conferences, symposium, visits of important persons, calendar of local } \\
\text { events, etc. }\end{array}$ \\
\hline & Transport & Road conditions, public transport, nearby airports, taxi, other forms of transport \\
\hline & Sights & $\begin{array}{l}\text { History and or description of destinations, attractions, natural and cultural } \\
\text { specialties }\end{array}$ \\
\hline & Local products & Gastronomic local specialties, special crafts, special products and services \\
\hline
\end{tabular}

order to determine which websites of Slovenian fourand five-stars hotels are more utilized than others. The main difference in our case is the different content we were analysing: adoption of different types of websites' content. As in the case of Križaj et al. (2014), we also used a cluster analysis technique (Ferligoj, 1988). Cluster analysis is a task of grouping a set of objects in such a way that objects in the same group are more similar to those in other groups (Gan et al., 2007).

Our taxonomy consists of nominal variables or utilization categories, which we defined in Table 1. We merged some of them into groups based on similarity. Each category can have several levels of subcategories. We have chosen the ones that we can objectively measure. In solving the problem of grouping we also had to use intuition to narrow down the possible choices and options as recommended by Ferligoj (1988).

We used a hierarchical joining method in order to present the groups in the dendrogram (Ferligoj, 1988), created based on the Jaccard index matrix of differences between the websites. The Jaccard's index (sometimes called the Jaccard similarity coefficient) compares the similarity and variety of data sets (in our case, tree leaves, since every website is presented as a tree of its utilization categories and subcategories). Jaccard's index is the ratio of the number of common tree leaves divided by the number of all common leaves and all the different leaves on two trees (Jaccard, 1912). By calculating the distances between all pairs of hotel websites, we got a matrix of distances (a comparison 
of sequences) that shows the levels of similarities between the trees.

To determine the taxonomy for website utilization categories and subcategories, we have largely used the article 'A hybrid multi-criteria decision-making model to evaluate the hotel website' of the authors Akincilar and Dagdeviren from 2014. They created an advisory board composed of academics, businessmen and experts to determine categories. The purpose of the board was to identify and evaluate categories collected from various publications that affect the quality of the website. Academics were selected from a variety of disciplines such as tourism, engineering, management, and the economy, and experts from successful hotels were added to the mix.

Akincilar and Dagdeviren (2014) identified categories focusing on (A) user, (B) technology, (C) marketing, (D) security, and (E) other, where they included everything they could not include in the categories A-D. After reviewing Akincilar and Dagdeviren's categories for the purpose of our research, we have made some modifications to reflect the actual website content in our study dataset.

The categories in Table 1, representing our website utilization taxonomy approach, are based on the mBsc ('modified balanced scorecard') scheme and Akincilar and Dagdeviren's (2014) categories, enhanced with insights and findings from Yeung and Law (2004), Ping-Ho et al. (2013), Yang et al. (2014), Díaz and Koutra (2013) and Bastida and Huan (2014).

The category experience is based on how the user experiences the hotel website and consists of three subcategories (fulfilment, personalisation and gamification). Fulfilment is seen as the option of online booking, sliding photos and their quality, panoramic and 3D views, brochure, website search features and other similar aspects.

The information category is directed towards how hotel information is presented and how detailed it actually is (does it include feedback and support, contact information, security in terms of online payment and н т т PS protocol, language support and interactivity).

The marketing category compromises features that could be described as advertising (different certificates, recognitions, special offers and packages), so- cial media presence, different loyalty programmes and presence on different Online Travel Agencies (booking.com, hotels.com, etc.).

The destination category is more focused on the destination itself including weather, events, transport, sightseeing opportunities and local products.

\section{Results}

We obtained a list of 346 Slovenian hotels, as available on June 4,2017 , from the eCategorization web registry (www.slovenia.info). Out of 130 four- and five-star hotels we found in the list we excluded four hotels that were closed or their website was not working on the selected day. The survey sample therefore covers 126 hotels $(n=126)$, of which 116 are four-star hotels and 10 are five-star hotels.

A more in-depth presentation of the sample is as follows:

- Number of hotels in each of the Slovenian statistical regions: 23 Gorenjska, 5 Goriška, 10 SouthEast Slovenia, 1 Koroška, 23 Obalno-Kraška, 16 Osrednjeslovenska, 1o Podravska, 8 Pomurska, 4 Posavska, 2 Primorsko-Notranjska, 24 Savinjska.

- Superior: 32 yes, 93 no.

- Hotel type: 20 mountain, 7 castle/mansion/estate, 6 gaming, 1 cave, 10 lake, 29 city, 20 seaside, 34 spa/thermal.

- Hotel chains: 3 Best Western Premier, 2 Eurotas hoteli, 1 Marriott Four Points by Sheraton, 7 H I т/H Iт Alpinea, 1 Hotel Lek, 2 Hotel Sava Rogaška, 3 Hoteli Bernardin, 1 I H G/Intercontinental Hotels \& Resorts, 6 Istrabenz turizem, $3 \mathrm{JGZ}$ Brdo, 2 Relais \& Châteaux, 2 Remisens Hotels \& Villas, 3 Rimske terme, 9 Sava turizem, 2 Terme Dobrna, 9 Terme Krka, 5 Terme Maribor, 2 Terme Olimia, 2 Thermana, 4 Union hoteli, 4 Unior.

After categorisation of all 126 hotels and running data clustering analysis we got one statistically significant cluster and two trees that do not belong to it. These two websites had the least characteristics or features that we have categorised (Hotel 002 had 20 and hotel 054 had 9 characteristics. The average of characteristics of all hotels is 30.7). Despite the high level of 
similarity of all other hotels in the statistically significant cluster, we looked more closely into the five most diverse sub-clusters $1-5$.

\section{Cluster 1}

The cluster 1 websites are Grand Hotel Toplice Bled, Hotel Park, Hotel Golf, Grand Hotel Primus, Hotel Izvir, Hotel Radin, Hotel Livada Prestige, Hotel Ajda and Hotel Termal. All hotels are owned by the company Sava Turizem, d. d., which has a general website template for all of their hotels. There are no significant differences between these websites, only minor alterations (for example a special offer or a prize/recognition that a hotel in the chain has, and not others), which is no surprise.

\section{Cluster 2}

The websites of cluster 2 are Hotel Krka, Hotel Šmarjeta, Hotel Svoboda, Hotel Kristal, Hotel Vital, Hotel Sport, Hotel Balnea and Hotel Vitarium. All of the hotels are owned by the company Terme Krka, which, similar to Sava Turizem, d. d., has a general website for all of their hotels except Grand Hotel Otočec, which has its own website structure and content. Nevertheless, the calculated difference was small.

\section{Cluster 3}

Cluster 3 sites belong to three different hotel chains:

- Hotel Sava Rogaška (Hotel Zagreb, Grand Hotel Sava),

- Rimske terme (Hotel Zdraviliški dvor, Hotel Rimski dvor, Hotel Natura, Hotel Sofijin dvor),

- Unior (Hotel Vital, Hotel Atrij, Hotel Planja).

The reason is the considerable generic characteristic of their chosen websites' structure.

\section{Cluster 4}

Cluster 4 sites belong to two hotel chains:

- Hit/hit Alpinea (Hotel Kompas, Ramada Hotel \& Suites, Ramada Resort),

- Terme Maribor (Hotel Piramida, Hotel Habakuk, Hotel Bolfenk, Hotel Arena, Hotel Bellevue).

There is also no major difference between the above-mentioned hotel websites. It again seems that hotel websites are very similar in spite of their diverse ownership.

\section{Cluster 5}

Cluster 5 sites belong to two hotel chains:

- Istrabenz Turizem (Hotel Apollo, Mind Hotel Slovenia, Hotel Mirna, Hotel Neptun, Grand Hotel Portorož, Hotel Riviera),

- Terme Olimia (Hotel Breza, Hotel Sotelia).

Again, there are no major differences between them. It is more than obvious that hotel chains have standardised websites when it comes to content.

\section{Discussion}

We have selected a set of criteria that define the utilization of hotel websites through various sources and literature and prepared an extensive list of four- and five-star Slovenian hotels and their websites, and processed data using developed taxonomy and existing data clustering methodology, which, at the end, provided us with relatively generic data. Hotel websites seem much different at first, but after comprehensive research and in-depth analysis, we can draw a conclusion that they are very similar. There are no major and statistically significant differences between the analysed websites. The presented research was extensive since taxonomy development and categorisation of 126 hotels was time-consuming.

Although the initial quest gave no other statistically significant answer than that the hotels' website utilization in Slovenia is very uniform, several other findings were gathered through the analysis and categorisation of the used (and missing) websites' functions divided into three areas: security, gamification, and interactivity and multimedia.

\section{Security}

The biggest and most interesting conclusion is the challenging security of Slovenian four- and five-star hotel websites. Security is a big part of tourism and must be upheld on all levels, not to mention the sensitivity of the relationship between security, human rights, pleasure, discretion, and integrity (Mekinc \& Bončina, 2006, p. 14). 
When booking a room, tourists submit a lot of personal information (name, surname, contact, address, phone number, gender, bank details, etc.). The н т т PS URL address gives us much more security than H T TP. Our research showed that, in the time window of our research from 26 June 2017 to 2 October 2017, 62 hotels (49\% of all analysed hotels) did not use the н т т P s protocol. The situation is serious and one would expect that this kind of security malfunction would be spotted in smaller private hotels. But it is the opposite. Smaller hotels often use booking systems for online travel agencies (for example, booking.com) that are installed as plug-ins on the site and have state-of-the-art security protocols. Bigger Slovenian hotel chains, that were mostly included in our research, develop their own booking engines that, as shown, lacked appropriate security in almost half of the cases in 2018.

On the positive side and due to the European Data Protection Regulation (GDPR), effective from 25 May 2018, and the Slovenian Personal Data Protection Act (Jadek \& Pensa, 2019), the security situation has changed a few months after our research. On 14 April 2018, we re-checked most of the analysed hotel websites and foundthat they have changed their booking sites to н т T PS, confirming the need for systematic and regularly updated safety and security legislation in highly digitalised tourism.

Reviewing the security of hotel website booking systems showed that on 29 May 2020 the vast majority of the analysed websites were using нт т Ps protocol when making a reservation but approximately $18 \%$ of the hotel websites landing pages (some of the websites are not accessible any more) are still using the vulnerable and outdated н т т р protocol.

\section{Gamification}

Gamification can be understood as an activity that combines the mechanisms of games and prizes in order to motivate users and thus increase the customers' interest in the hotel and consequent loyalty (Lucassen \& Jansen, 2014). A good example is Starwood Hotels and Resorts, which linked its loyalty programme with Foursquare. In this way, the guests collected points that could be redeemed for special services. Additionally, the 'ambassador' ('the SPG Mayor') was selected on a monthly basis, encouraging them to share their experience and advice, thereby increasing their virality (Mashable, 2011). In 2011, the InterContinental Hotels Group (IHG) introduced the gamification approach with the 'Win It in a Minute' incentive, allowing users to compete for free points for IHG's Priority Club. In the first two weeks, users played the game 100,000 times and earned more than 100 million points. In the game, there were five questions related to travel, which had to be answered in a limited time (InterContinental Hotels Group, 2011). Both presented examples are considered to be very successful, as they have achieved very good results and have increased brand loyalty and visibility.

Gamification features on Slovenian four- and fivestar hotel websites were totally ignored during the time of the presented research. Even the simple features such as sweepstakes were rare, not to mention more elaborate approaches. There were only 36 fourand five-star hotel websites (28.5\%) that had some sort of sweepstakes. We must emphasise that these were very simple approaches that can be understood as a very simple gamification process (for example: send an email address and participate in a prize game). Perhaps we can connect the lack of the gamification functions in the analysed hotel websites with the smaller size of the Slovenian hospitality market.

\section{Interactivity and Multimedia}

The definition of interactivity can be understood as the extent to which users can participate in changing the shape and content in real time (Steuer, 1992). Important elements of interactivity are two-way communication, simultaneity and control (Mollen \& Wilson, 2010). The consistency refers primarily to the ability of the site to quickly provide response or feedback (Yoo et al., 2010). The possibility of control is understood as the possibility that the user can choose the time, content and sequence of communication (Dholakia et al., 2000). In addition to the above-mentioned basic features of interactivity, there is also a possibility of sociability, which allows users to connect with other people (chat channels, blogs, online social networks, etc.) (Macias, 2003).

Our taxonomy categories covered the usage of mul- 
timedia and interactivity of Slovenian four- and fivestar hotel websites. We found that most hotel websites have plug-ins for various online social networks (some more, others less), and some also used blogs, which largely acted as marketing announcements of various campaigns. We analysed which websites have attractive graphics, sounds, videos, GIFs, animations, web applications for mobile devices and videos. We found that only a few websites included sounds or music, and attractive animation. 21 hotels had a virtual tour of the premises and only one had a bird's eye perspective of the whole property facilities allowing visitors interactivity (Pule Estate). GIF S and animations were not found on any hotel website, and only 7 hotels had videos portraying more than just the hotel's property.

The development of applications for hotel mobile devices demands a high level of experience personalisation, conducting effective dialogue and providing sufficient resources to customers in order to facilitate their value creation process (Lei et al., 2019). Such a process could be a very expensive endeavour, so it is understandable that only hotels of major international chains can usually afford it, which was confirmed in the study (only one hotel in Ljubljana had it). Another special feature found in our dataset was a hotel with their own application informing guests about the ski slopes situation in the vicinity. With all the presented Interactivity and Multimedia findings we can conclude that the area of interactivity of the hotel website in Slovenia has a lot of development potential.

\section{Conclusion}

Our research provides an overview of Slovenian four and five-star hotels' characteristics and contents of their websites for the year 2017. The methodology and sample of 126 hotel websites provided us with little statistically significant differences, but revealed a lack of interactivity and multimedia, gamification leverages and, foremost, weak protection of user personal data. The latter seems to be the biggest revelation. Results of this study are therefore a valuable resource of information for Slovenian hoteliers in order to review the most common weakness and opportunities. Further research could reassess the condition of the sample in order to see if hoteliers acted accordingly with the
GDPR (General Data Protection Regulation) requirements. Another research opportunity could be more detailed analysis of website interactivity.

Further recommendations to the Slovenian hotel industry would be to focus more on digital transformation (blending physical and digital), mobile applications and data driven customer experience. The latter could be described as a transformation trend and unavoidable future of the hotel industry and customer experience.

\section{References}

Akincilar, A., \& Dagdeviren, M. (2014). A hybrid multicriteria decision making model to evaluate hotel website. International Journal of Hospitality Management, 36, 263-271.

Baloglu, S., in Peckan, Y. A. (2006). The website design and internet site marketing practices of upscale and luxury hotels in Turkey. Tourism Management, 27(1), 171-176.

Bastida, U., \& Huan, T. C., (2014). Performance evaluation of tourism websites information quality of four global destinations brands: Beijing, Hong Kong, Shanghai and Taipei. Journal of Business Research, 67(2), 167-170.

Chung, T., \& Law, R. (2003). Developing a performance indicator for hotel websites. International Journal of Hospitality Management, 22(1), 199-125.

Dholakia, R. R., Zhao, M., Dholakia, N., \& Fortin, D. (2000). Interactivity and revisits to websites: A theoretical framework (Working Paper). Research Institute for Telecommunication and Internet Marketing.

Díaz, E., \& Koutra, C. (2014). Evaluation of the persuasive features of hotel chains websites: A latent class segmentation analysis. International Journal of Hospitality Management, 34(1), 338-347.

Escobar-Rodríguez, T., \& Carvajal-Trujillo, E. (2013) An evaluation of Spanish hotel websites: Informational vs. relational strategies. International Journal of Hospitality Management, 33, 228-239.

Ferligoj, A. (1988). Razvrščanje v skupine: teorija in uporaba $v d r u z ̌ b o s l o v j u$. Fakulteta za sociologijo, politične vede in novinarstvo.

Gan, A., Ma, C., \& Wu, J. (2007). Data clustering: Theory, algorithms, and applications. Society for Industrial and Applied Mathematics.

InterContinental Hotels Group. (2011, 2 February). IHG launches online rewards game. https://www .meetingstoday.com/Magazines/ArticleDetails/ RegionID/o/ArticleID/15242 
Jaccard, P. (1912). The distribution of the flora in the alpine zone. New Phytologist, 11(2), 37-50.

Jadek \& Pensa. (2019). Slovenian personal data protection Act (zVOP-2) proposal - overstepping the GDPR boundaries? https://www.jadek-pensa.si/en/the-slovenian -personal-data-protection-act-zvop-2-proposal -overstepping-the-gdpr-boundaries

Jeong, M., Oh, H., \& Gregoire, M. (2003). Conceptualizing web site quality and its consequences in the lodging industry. Hospitality Management, 22(2), 161-175.

Križaj, D., Brodnik, A., \& Bukovec, B. (2014). A tool for measurement of innovation newness and adoption in tourism firms. International Journal of Tourism Research, 16(2), 113-125.

Lei, L. S., Wang, D., \& Law, R. (2019). Perceived technology affordance and value of hotel mobile apps: A comparison of hoteliers and customers. Journal of Hospitality and Tourism Management, 39, 201-211.

Lucassen, G., \& Jansen, S. (2014). Gamification in consumer marketing: Future or fallacy? Procedia: Social and Behavioral Sciences, 148, 194-202.

Macias, W. (2003). A preliminary structural equation model of comprehension and persuasion of interactive advertising brand web sites. Journal of Interactive Advertising, $3(2), 36-48$.

Mashable. (2011). Starwood Hotels adds Foursquare to loyalty program. https://mashable.com/2011/05/10/ starwood-and-foursquare/?europe=true

Mekinc, J., \& Bončina, I. (2006). Safety and security in space tourism. Academica Turistica, 9(2), 13-24.

Mollen, A., \& Wilson, H. (2010). Engagement, telepresence and interactivity in online consumer experience: Reconciling scholastic and managerial perspectives. Journal of Business Research, 63(9/10), 919-925.
Musante, M. D., Bojanic, D. C., \& Zhang, J. (2009). An evaluation of hotel website attribute utilization and effectiveness by hotel class. Journal of Vacation Marketing, 15(3), 203-215.

Ping-Ho, T., Shu-Tai, W., Dong-Yih, B. \& Miai-Lingl C. (2013). Website evaluation of the top 100 hotels using advanced content analysis and еміс A model. Cornell Hospitality Quarterly, 54(3), 284-293.

Schegg, R., Steiner, T., Frey, S., \& Murphey, J. (2002). Benchmarks of website design and marketing by Swiss Hotels. Information Technology \& Tourism, 5(1), 73-89.

Schmidt. S., Cantallops, A. S., \& Dos Santos, C. P. (2008). The characteristics of hotel websites and their implications for website effectiveness. International Journal of Hospitality Management, 27(4), 504-516.

Steuer, J. (1992). Defining virtual reality: Dimensions determining telepresence. Journal of Communication, 42(4), 73-93.

Yang, Z. F., Shi, Y. Wang, B., in Yan, H. (2014) Website quality and profitability evaluation in ecommerce firms using two-stage DE A. In Procedia Computer Science, 30, 4-13.

Yeung, T., \& Law, R. (2004). Extending the modified heuristic usability evaluation technique to chain and independent hotel websites. International Journal of Hospitality Management, 23(3), 307-313.

Yeung, T., in Law, R. (2006). Evaluation of usability: A study of hotel web sites in Hong Kong. Journal of Hospitality \& Tourism Research, 30(4), 452-479.

Yoo, W.-S., Lee, Y., \& Park, J. (2010). The role of interactivity in e-tailing: Creating value and increasing satisfaction. Journal of Retailing and Consumer Services, 17(2), 89-96.

Zabukovec, P., \& Čivre, Ž. (2012). How do guests choose a hotel? Academica Turistica, 5(1), 75-84. 


\title{
Travel Motivations as Criteria in the Wellness Tourism Market Segmentation Process
}

\author{
Ana Težak Damijanić \\ Institute of Agriculture and Tourism, Croatia \\ tezak@iptpo.hr
}

The purpose of this paper is to explore travel motivations as criteria in the segmentation process of wellness tourists. Data was collected through a self-complete questionnaire on a sample of tourists staying in one out of 15 wellness hotels situated in four wellness tourism regions of the Republic of Croatia. Research was conducted from May through June in 2013. The data were processed using univariate, bivariate and multivariate statistics. Univariate statistics was used for a general description of the sample; bivariate analysis was applied to examine the differences among the clusters, while multivariate statistics was employed in order to determine the factors underlying the travel motivation construct and to discover the clusters. A total of nine travel motivation factors were identified by applying the theory of the push and pull travel motivations (three push motivation factors, and six pull motivation factors). Push travel motivation factors were labelled as Health trend, Relaxation and reward, and Novelty; pull motivation factors related to a wellness tourist product were labelled as Basic wellness, Intangible wellness, and Extra wellness, while pull motivation factors related to tourist destination were labelled as Cultural and natural heritage, Entertainment and recreation, and Landscape. Three clusters emerged by using travel motivation factors as segmentation criteria (high wellness, immaterial wellness, and low wellness clusters). Relaxation, wellness infrastructure and natural resources are important factors in wellness tourism research. However, both push and pull motivation factors are important variables in distinguishing among the segments.

Keywords: travel motives, market segmentation, wellness tourists, segmentation criteria

(cc)BY-SA https://doi.org/10.26493/2335-4194.13.201-213

\section{Introduction}

Due to the competitive nature of tourism, tourist destinations and tourism providers must focus their efforts on developing an adequate strategic plan for the wellness tourism market (Sheldon \& Park, 2008). In order to achieve this, it is necessary to get deeper insights into this market. Market segmentation may aid in the process of developing an adequate strategic plan. In general, market segmentation is used in different fields, e.g. retailing (Segal \& Giacobbe, 1994), and the online game industry (Lee et al., 2004); and different segmentation methodologies are applied, like ratings of proposed product design (Sewall, 1978), cost benefit approach (Winter, 1979), purchased-based market segmentation methodology (Tsai \& Chiu, 2004), etc. It is also widely applied in tourism settings, mostly with the purpose of determining the profile of tourists (Tkaczynski, 2009) and often focusing on different 
tourists' special interests like food (Su et al., 2020), recreation experience (Lee et al., 2018), and wine (Gu et al., 2018). However, to achieve appropriate results adequate segmentation criteria need to be selected (Dolnicar, 2008; Tkaczynski, 2009).

Selection of the segmentation criteria or base is the first step in the market segmentation process (Dolnicar, 2008; Yankelovich, 1964). Different criteria are used for segmentation purposes (Tkaczynski, 2009) and this problem is evident even in wellness tourism (Dryglas \& Salamaga, 2018; Mueller \& Lanz Kaufmann, 2001; Voigt et al., 2011; Mak et al., 2009; Hallab et al., 2003; Konu, 2010; Kim \& Batra, 2009). Namely, criteria like travel motives (Dryglas \& Salamaga, 2018; Huh et al., 2019), emotions (Sharma \& Nayak, 2019), lifestyle (Konu, 2010; Kucukusta \& Denizci Guillet, 2016) and benefits (Koh et al., 2010; Pesonen et al., 2011) are often used for segmentation purposes.

Wellness tourism is a form of special interest tourism and is considered as a certain niche market. However, different wellness tourist segments are detected (Dimitrovski \& Todorović, 2015; Dryglas \& Salamaga, 2017; Koh et al., 2010; Mueller \& Lanz Kaufmann, 2001) due to the usage of different variables as segmentation criteria. Thus, the purpose of this paper is to explore travel motivations as criteria in the segmentation process of wellness tourists. With this in mind, the goals of this paper are mainly twofold: (1) to determine travel motives dimensions of wellness tourists; and (2) to classify wellness tourists based on their travel motives. Therefore, this research contributes to theory and practice by analysing travel motives as criteria in the segmentation process of one special interest tourist segment. Furthermore, it highlights the most commonly identified travel motivations related to wellness tourists.

\section{Theoretical Background}

Market segmentation was first introduced in literature in order to make a clear distinction between market segmentation and product differentiation (Smith, 1956). It includes selection of the segmentation criterion/base, grouping of respondents, and profiling and managerial assessment of the usefulness of the market segments (Dibb, 1998; Dolnicar, 2008). The aim of market segmentation is to achieve the segments where members of one segment are as similar as possible to each other and where members of different segments are as different as possible (Dolnicar, 2008), thus selection of the appropriate variables used as segmentation criteria is crucial.

The market segmentation procedure in tourism does not differ compared to other industries, however, due to certain peculiarities of the tourism market, the main difference is evident in the segmentation criteria variables. Variables used as segmentation criteria are often divided into different categories (Swarbrooke \& Horner, 2007) like geographical (e.g. region), socioeconomic (e.g. occupation, income), demographic (e.g. age, gender, nationality), psychographic (e.g. lifestyle, attitudes, opinions and personality) and behaviouristic (e.g. loyalty, purchase occasion, benefits, user status, attitude). Although these variables are used in tourism settings as well, an additional category emerged, i.e. tourism specific segmentation criteria (Swarbrooke \& Horner, 2007).

Tourism-specific segmentation criteria includes variables like purpose of travel, travel motivations, and benefits received from the travel (Dimitrovski \& Todorović, 2015; Koh et al., 2010). Although travel motivation is often used for segmentation purposes (Bieger \& Laesser, 2002; Boksberger \& Laesser, 2008; Heung et al., 2001; Jönsson \& Devonish, 2008; Kozak, 2002; Sangpikul, 2008), variables in 'classical' segmentation criteria categories, like age, gender, education level, and income, are very often used for segmenting the tourist market (Tkaczynski, 2009). Therefore, to gain better understanding of tourist market segments, more frequent usage of tourism-specific segmentation criteria is desired, like travel motivations.

Travel motivations are inner drives that cause people to take action to satisfy their needs (Hudson, 2008). In tourism settings they are either analysed by grouping them considering different types of travel that share some common characteristics or by using a behavioural marketing approach (Middleton \& Clarke, 2001). The former is a more simplistic approach to travel motivations because travel motivations are presented in a very straightforward way. In contrast, the latter approach is a more complex one and it encom- 
passes different theories like behavioural theory of travel motivation, theory of classified purpose, theory of personal and/or interpersonal experiences in destination settings, theory of personal and/or interpersonal experiences in destination settings, etc. (Awaritefe, 2004; Chang, 2007). However, the theory of push and pull motivations is the most widely applied motivation theory within the behavioural approach and it will be examined in this paper.

The theory of push and pull motivations distinguishes between two main groups of factors that motivate tourists to travel: push factors and pull factors. Push factors refer to internal forces that motivate or create a desire to satisfy a need to travel, while pull factors are recognised as destination attributes (Kozak, 2002; Lubbe, 2003). Both groups of motivation factors are delineated by various dimensions, e.g. escape (Crompton, 1979; McGehee et al., 1996; Uysal \& Jurowski, 1993; Yoon \& Uysal, 2005), relaxation (Crompton, 1979; Kozak, 2002; McGehee et al., 1996; Suni \& Pesonen, 2019), education (Crompton, 1979; Yoon \& Uysal, 2005), heritage and culture (Kozak, 2002; McGehee et al., 1996; Uysal \& Jurowski, 1993), and comfort (McGehee et al., 1996). Health preservation and promotion may also be a travel motivation dimension. Additionally, preservation and promotion of one's health is one of the oldest motivators in tourism (Swarbrooke \& Horner, 2007).

Health as a travel motivation resulted in the creation of health tourism. Wellness tourism is regarded as a subcategory of health tourism and tourists whose prime aim is preserving or promoting their health are labelled as wellness tourists (Kim \& Batra, 2009; Mueller \& Lanz Kaufmann, 2001). Wellness tourists are usually interested in various programmes and treatments centred on health preservation and promotion, e.g. natural agents, exercise, anti-stress programmes, therapy, and beauty programmes (Andrijašević \& Bartoluci, 2004), although they may also include aspects like spirituality, and social interaction (Smith \& Puczkó, 2009). Therefore, the wellness tourist segment can be very heterogeneous.

The two main reasons why the wellness tourist segment is so heterogeneous are the numerous elements that can constitute a wellness tourist product (Chi, Chi
\& Ouyang, 2020; Smith \& Puczkó, 2009) and different segmentations basis (Chen et al., 2013, Dimitrovski \& Todorović, 2015; Dryglas \& Salamaga, 2017; Hallab, 2006; Kucukusta \& Denizci-Guillet, 2016; Mueller \& Lanz Kaufmann, 2001). Different wellness tourist product elements like natural agents, exercise, antistress programmes, therapy, beauty programmes (Andrijašević \& Bartoluci, 2004) may result in different sub-segments, e.g. demanding health guests, and independent infrastructure users (Mueller \& Lanz Kaufmann, 2001). Chi et al. (2020) have proposed a conceptual framework for wellness hotels that focuses on three main domains: physical wellness (fitness facilities and workout opportunities), mind wellness (mind wellness activities and education programmes), and environmental wellness (clean environment and healthy environment). Additionally, usage of different variables, e.g. lifestyle, travel motivations, and benefits, also yields different sub-segments (Azman \& Chan, 2010; Hallab, 2006; Konu \& Laukkanen, 2009; Mak et al., 2009).

The push and pull motivation theory is also used for analysing the travel motivation of wellness tourists in general (Bennett et al., 2004; Hallab, 2006; Konu \& Laukkanen, 2009; Mak et al., 2009; Mueller \& Lanz Kaufmann, 2001), examining the link between travel motives, and satisfaction and behaviour intentions (Kim et al., 2017; Lim et al., 2016) and for determining different sub-segments (Dimitrovski \& Todorović, 2015; Dryglas \& Salamaga, 2017; 2018; Huh et al., 2019). In analysis of travel motivation in wellness tourism, certain scholars have examined both the push and the pull travel motivation factors (Azman \& Chan, 2010; Hallab, 2006), only push travel motivation factors (Dimitrovski \& Todorović, 2015; Dryglas \& Salamaga, 2018; Huh et al., 2019; Koh et al., 2010; Konu \& Laukkanen, 2009; Lim et al., 2016; Mak et al., 2009; Voigt et al., 2011) or only pull travel motivation factors (Chen et al., 2013; Dryglas \& Salamaga, 2017; Mueller \& Lanz Kaufmann, 2001).

By examining both push and pull travel motivations, Hallab (2006) found five push motivation factors (healthy living, excitement, education, indulgence and escape) and five pull motives (health and fitness, hygiene and the environment, history and nature, vig- 
ilance and health, and arts and urban luxury), while Azman and Chan (2010) identified three push motivation factors (escape - relay and pamper, destress/time out, and regeneration) and two pull motivation factors (tangible resources and marketing image). Focusing exclusively on pull travel motivation, Chen et al. (2013) identified eight pull motivation factors (Personnel services, Health promotion treatments, Environments, Healthy diet, Relaxation, Social activities, Experience of unique tourism resources, Mental learning), and Dryglas and Salamaga (2017) found four pull motivation factors: Natural resources, Cultural and natural environment, Spa/Wellness infrastructure and Social and political environment.

However, most of the research regarding travel motivation of wellness tourists focused on push motivation. With push motivation in mind, Mak et al. (2009) discovered five push motivation factors (friendship and kinship, health and beauty, self-reward and indulgence, relaxation and relief, and escape); Konu and Laukkanen (2009) determined seven push motivation factors (self-development, healthy and physical activity, relaxation and escape, isolation and nostalgia, nature, autonomy and stimulation, and social status); Koh et al. (2010) found four push motivation factors (Social, Relaxing, Healthy, and Rejuvenating); Voigt et al. (2011) uncovered six push travel motivations (Transcendence, Physical health and appearance, Escape and relaxation, Important others and novelty, Reestablish self-esteem, Indulgence); Dimitrovski and Todorović (2015) detected six push motivation factors (Rejuvenating, Socialization and excitement, Hedonism, Obsession with health and beauty, Relaxation, Escape); and Lim et al. (2016) determined four push motivation factors (Relaxation and rest, Selfexploration, Accessibility, and Novelty). In their further work regarding wellness travel motivation, Dryglas and Salamaga (2018) focused on push travel motives and have determined four factors (spiritual and medical care, entertainment and networking, relaxation, and aesthetics). Huh et al. (2019) suggest three new wellness push motivations, namely tourism factor, prevention factor and treatment factor.

In summary, there is no consensus related to the travel motivation dimensions, and the main result is evident in the detection of different wellness tourists segments, e.g. demanding health guests, independent infrastructure users, care-intensive cure guests and undemanding recreation guests (Mueller \& Lanz Kaufmann, 2001); escapists, neutralists and hedonists (Koh et al., 2010); socially active tourists, and self-focused tourists (Dimitrovski \& Todorović, 2015); nature and culture seekers, spa/wellness seekers, and social contact seekers (Dryglas \& Salamaga, 2017): pleasure pursuers, healing pursuers and relaxation pursuers (Dryglas and Salamaga, 2018); and wellness and treatment seekers, treatment seekers, and tourism, treatment and wellness seekers (Huh et al., 2019).

\section{Methodology}

The target population included those tourists who visited hotels offering wellness as an additional tourist product. This study focused on guests staying in wellness hotels because it was a part of a larger research linking health, travel motives and customer value. The survey was conducted from May to June in 2013 in 15 hotels situated in a coastal part of Croatia. For the purpose of sampling, a list of hotels that were members of the Croatian Wellness Tourism Association was obtained. In 2012, a total of 65 hotels in Croatia were members of this Association, and Croatia was divided into 10 regions (Table 1). Most of the hotels were situated in the Istria and Kvarner regions ( 16 hotels in each region), while the Dubrovnik and Split regions were second (9 hotels in each region). Hotels were mostly categorised as four-star hotels (40 hotels), while only 17 hotels had five stars. Therefore, regional dispersion and hotel category were used in designing the sample. Hotels situated in four wellness regions, namely the Istria, Kvarner, Split, and Dubrovnik regions were taken into account because they had hotels with wellness centres categorised as three-star, four-star and five-star hotels.

In the process of onsite data collection, the researcher was stationary while the responders were mobile (Veal, 2006). Hotel guests were approached by the researcher and asked to participate in the survey. The researcher explained the purpose of the survey, stated that the survey was anonymous, and handed out a questionnaire in the appropriate language. Data was 
Table 1 Accommodation Facilities with Wellness Centres in Croatia in 2012

\begin{tabular}{lrrrrr}
\hline Region & $(1)$ & $(2)$ & $(3)$ & $(4)$ & $(5)$ \\
\hline Istria & 17 & 16 & 1 & 11 & 4 \\
Kvarner & 19 & 16 & 4 & 8 & 4 \\
Dalmatia - Zadar & 7 & 5 & 1 & 3 & 1 \\
Dalmatia - Šibenik & 2 & 1 & 0 & 1 & 0 \\
Dalmatia - Split & 9 & 9 & 0 & 7 & 2 \\
Dalmatia - Dubrovnik & 10 & 9 & 1 & 3 & 5 \\
Lika (Karlovac) & 1 & 1 & 0 & 1 & 0 \\
Central Croatia & 7 & 4 & 1 & 3 & 0 \\
Zagreb & 4 & 2 & 0 & 1 & 1 \\
Slavonia & 2 & 2 & 0 & 2 & 0 \\
\hline Total & 78 & 65 & 8 & 40 & 17 \\
\hline Notes Column & &
\end{tabular}

Notes Column headings are as follows: (1) number of wellness community members, (2) total number of hotels with wellness centres, (3) three-star hotels, (4) four-star hotels, (5) five-star hotels.

collected through a self-complete questionnaire. The questionnaire consisted of 15 questions that were divided into four sections: (1) wellness-related lifestyle, (2) perceived value, (3) motivational factors and (4) respondents' characteristics. It was originally designed in Croatian and then back-translated into English, German, Italian, Russian, French, Spanish, and Slovenian. No changes were made to the original translations because the only detected differences were in the usage of different synonyms. As a self-complete questionnaire was administered, the minimal number of 300 responders was set to satisfy the requirement for performing a data analysis (Hair et al., 2010).

The data were processed using statistical methods consisting of descriptive statistics, bivariate and multivariate. Descriptive statistics was used to provide a general description of the sample; bivariate statistics was applied to examine the differences among the clusters, while multivariate statistics was employed in order to determine the factors underlying the travel motivation construct and to discover the clusters. The individual items were examined through checks for accuracy of data entry, missing data and distribution. The cases with the missing values were replaced using an мсмC method for item imputation. Exploratory factor analysis was done using maximum likelihood factor analysis and promax rotation with an eigenvalue of 1.00 or more being used to identify potential factors. Internal reliability was determined by computing Cronbach's alpha. Travel motivation factors were calculated as a mean value for each respondent (DiStefano et al., 2009).

The responders were a posteriori grouped based on the importance they placed on various travel motivations factors. The number of clusters was determined by splitting the sample and using the hierarchical clustering technique. A hundred observations were randomly selected. The Ward method, with squared Euclidean distance, was used to establish the preliminary number of clusters. A three-cluster solution was selected on the basis of the largest and most plausible proportionate change. A non-hierarchical cluster analysis procedure ( $k$-means) was utilised to finalise the cluster solutions using the a priori determined number of clusters. Cluster validation was done using a one-way ANOVA analysis and five measures that were not included as travel motivation items (Hair et al., 2010).

A five-point Likert scale (ranging from 1 - totally not important to 5 - totally important) was used to measure the travel motivation factors' perceived importance. Items measuring travel motivation factors were divided into two main groups based on the theory of push and pull motivation factors and were adopted from general travel motivation literature (tourist destination pull factors) and wellness tourism motivation literature (push factors and wellness tourist product pull factors). A total of 18 items were used for measuring push factors (Bennett et al., 2004; Kim \& Batra, 2009; Koh et al., 2010; Konu \& Laukkanen, 2009; Mak et al., 2009; Monteson \& Singer, 2004; Pesonen et al., 2011; Voigt et al., 2011). Pull factors were divided into two sub-groups: wellness tourist product and tourist destination. A total of 24 items were used for measuring the first group of pull factors (Andrijašević \& Bartoluci, 2004; Bennett et al., 2004; Mak et al., 2009; Mueller \& Lanz Kaufmann, 2001; Pesonen et al., 2011), while 20 items were used for measuring the second group (Awaritefe, 2004; 
Table 2 Descriptive Statistics and Results of Explanatory Factor Analysis of Push Travel Motivations

\begin{tabular}{|c|c|c|c|c|c|}
\hline Variables & Mean & SD & Factor 1 & Factor 2 & Factor 3 \\
\hline Get in better shape & 2.78 & 1.379 & 0.838 & & \\
\hline Health improvement & 3.01 & 1.331 & 0.754 & & \\
\hline Feel younger & 2.55 & 1.361 & 0.733 & & \\
\hline Weight control interest & 2.26 & 1.311 & 0.713 & & \\
\hline Practice healthy lifestyle & 2.94 & 1.322 & 0.699 & & \\
\hline Feel healthier & 3.11 & 1.373 & 0.670 & & \\
\hline Visit trendy place & 2.43 & 1.338 & 0.619 & & \\
\hline Stress release & 4.26 & 1.050 & & 0.808 & \\
\hline Escape from everyday life & 3.99 & 1.213 & & 0.612 & \\
\hline Reward for hard work & 3.72 & 1.286 & & 0.607 & \\
\hline Stay in quiet and peaceful place & 3.99 & 1.138 & & 0.520 & \\
\hline Interest in landscape & 3.73 & 1.291 & & & -0.828 \\
\hline Get to know other cultures & 3.46 & 1.318 & & & -0.800 \\
\hline Try new things & 3.58 & 1.203 & & & -0.455 \\
\hline Eigenvalues & & & 5.242 & 1.949 & 1.367 \\
\hline Percentage of variance & & & 34.162 & 10.215 & 6.736 \\
\hline Percentage of cumulative variance & & & 34.162 & $44 \cdot 377$ & 51.113 \\
\hline Cronbach's $\alpha$ & & & 0.888 & 0.733 & 0.759 \\
\hline
\end{tabular}

Crompton, 1979; Heung et al., 2001; Jönsson \& Devonish, 2008; Kozak, 2002; McGehee et al., 1996; Yoon \& Uysal, 2005). This list was examined by four tourism experts to achieve content adequacy (Hinkin et al., 1997).

\section{Results and Discussion}

In all, 548 responders were used in the analysis. Most of the responders stayed in four-star hotels in the Istria or Kvarner region. The proportion of female responders (56\%) was slightly higher than that of males (44\%). A majority of the responders were between 35 and 54 years of age (48\%). Most of them had obtained higher education (68\%). In general, the responders were employees (45\%), 16\% were self-employed and approximately $14 \%$ were managers. Most of them were from Austria (23\%) and Germany (23\%), almost $11 \%$ were from the $\mathrm{UK}$, and about $10 \%$ originated from Italy. The most frequent monthly net income was between $€ 1,000$ and $€ 2,000$ (38\%). Almost $65 \%$ of the respon- ders came to the hotel with their partner. About $2 / 3$ of the responders visited the hotel for the first time, but most of them (57\%) had already visited the region. Half of the responders obtained information about the hotel using the Internet, travel agencies were the second source of information $(35 \%)$, while recommendation from friends and relatives was the third information source (20\%).

To identify dimensions of push and pull travel motivation, three exploratory factor analyses were done. Items with loading below 0.04 and cross-loadings were deleted, resulting in retention of 14 push travel motivations items (Table 2), 17 pull travel motivations for wellness tourist product items (Table 3), and 15 pull travel motivations for tourist destination items (Table 4).

The push travel motivations means (Table 2) varied from 2.26 ('Weight control interest') to 4.26 ('Stress release'). Initially five factors were detected, however, after purifying the scale, three factors representing 
Table 3 Descriptive Statistics and Results of Explanatory Factor Analysis of Pull Travel Motivations: Wellness Tourist Product

\begin{tabular}{|c|c|c|c|c|c|}
\hline Variables & Mean & SD & Factor 1 & Factor 2 & Factor 3 \\
\hline Sauna & 2.52 & 1.482 & 0.862 & & \\
\hline Steam bath & 2.47 & 1.450 & 0.857 & & \\
\hline Solarium & 2.02 & 1.282 & 0.651 & & \\
\hline Massage (traditional) & 2.86 & 1.433 & 0.619 & & \\
\hline Range of health amenities & 3.00 & 1.403 & 0.568 & & \\
\hline Massage (alternative) & 2.97 & 1.427 & 0.485 & & \\
\hline Beauty treatments & 2.61 & 1.398 & 0.431 & & \\
\hline Atmosphere & 4.44 & 0.878 & & 0.887 & \\
\hline Relaxation & 4.36 & 1.021 & & 0.732 & \\
\hline Surroundings & 4.33 & 0.910 & & 0.663 & \\
\hline Competence & 4.11 & 1.060 & & 0.531 & \\
\hline Tips for back home & 2.65 & 1.356 & & & -0.804 \\
\hline Understanding special needs & 3.05 & 1.406 & & & -0.714 \\
\hline Supervised Sport & 2.52 & 1.363 & & & -0.697 \\
\hline Detoxification & 2.85 & 1.427 & & & -0.663 \\
\hline Tai Chi, Yoga and similar activities & 2.39 & 1.369 & & & -0.590 \\
\hline Mud baths/wraps & 2.26 & 1.330 & & & -0.575 \\
\hline Eigenvalues & & & 7.654 & 2.379 & 1.186 \\
\hline Percentage of variance & & & 42.718 & 11.499 & 4.635 \\
\hline Percentage of cumulative variance & & & 42.718 & 54.217 & 58.852 \\
\hline Cronbach's $\alpha$ & & & 0.912 & 0.800 & 0.881 \\
\hline
\end{tabular}

push travel motivations formed clear factor structures. Jointly, they accounted for $51.11 \%$ of accumulated variance, and most of the factor loadings were greater than o.6o. They were labelled as Health trend, Relaxation and reward, and Novelty. Cronbach's alpha coefficients were between 0.733 and 0.888 . Health trend was comprised of different items related to getting healthier and in better shape. Relaxation and reward included items like stress release, escape from everyday problems, and the feeling of being rewarded. Novelty encompassed various items regarding learning about new things. In general, push travel motivations related to health aspects and luxury were mostly unimportant, while those push travel motivations that emphasise interest in learning new things, and relaxation and reward were mostly important to the responders.
The detection of these three push travel motivation factors are partially supported by the findings of Hallab (2006), Mak et al. (2009), Konu and Laukkanen (2009), Koh et al. (2010), Voigt et al. (2011), Dimitrovski and Todorović (2015), Lim et al. (2016), Dryglas and Salamaga (2018), and Huh et al. (2019). Relaxation as a push motivation factor was the factor most commonly identified in research regarding wellness tourists (Dimitrovski \& Todorović, 2015; Koh et al., 2010; Konu \& Laukkanen, 2009; Lim et al., 2016; Mak et al., 2009; Voigt et al., 2011).

The pull travel motivations means related to a wellness tourist product (Table 3) varied from 2.02 ('Solarium') to 4.44 ('Atmosphere'). Originally four factors were detected, however, after purifying the scale, three factors representing pull travel motivations for a well- 
Table 4 Descriptive Statistics and Results of Explanatory Factor Analysis of Pull Travel Motivations: Tourist Destination

\begin{tabular}{|c|c|c|c|c|c|}
\hline Variables & Mean & SD & Factor 1 & Factor 2 & Factor 3 \\
\hline Variety of architectural styles & 3.14 & 1.309 & 0.769 & & \\
\hline Theatre and performances & 2.49 & 1.263 & 0.693 & & \\
\hline Cultural heritage & 3.44 & 1.257 & 0.690 & & \\
\hline Diversity of attractions & $3 \cdot 34$ & 1.295 & 0.613 & & \\
\hline Natural protected areas & 3.32 & 1.276 & 0.525 & & \\
\hline Variety of entertainment activities & 3.13 & 1.175 & & 0.835 & \\
\hline Entertainment possibilities & 3.43 & 1.112 & & 0.734 & \\
\hline Shopping possibilities & 2.90 & 1.225 & & 0.655 & \\
\hline Local events & 2.91 & 1.254 & & 0.639 & \\
\hline Sports and recreation & 3.29 & 1.176 & & 0.580 & \\
\hline Variety of cultural events & 3.17 & 1.164 & & 0.535 & \\
\hline Beautiful nature & 4.24 & 0.949 & & & 0.781 \\
\hline Ecological preservation of the destination & 3.83 & 1.148 & & & 0.694 \\
\hline Climate & 4.12 & 0.949 & & & 0.540 \\
\hline Picturesqueness and tidiness of the place & 3.86 & 1.131 & & & 0.498 \\
\hline Eigenvalues & & & 5.687 & 1.758 & 1.187 \\
\hline Percentage of variance & & & 35.542 & 10.988 & 7.418 \\
\hline Percentage of cumulative variance & & & 35.542 & 46.530 & 53.948 \\
\hline Cronbach's $\alpha$ & & & 0.877 & 0.850 & 0.767 \\
\hline
\end{tabular}

Table 5 Results of Cluster Analysis

\begin{tabular}{lrrrr}
\hline Measures & $(1)$ & $(2)$ & $(3)$ & $(4)$ \\
\hline Health trend & 2.37 & 3.55 & 1.99 & $185.886^{* * *}$ \\
Relaxation and reward & 3.96 & 4.28 & 3.56 & $30.642^{\star * *}$ \\
Novelty & 3.95 & 4.09 & 2.24 & $319.312^{* * *}$ \\
Basic wellness & 1.81 & 3.58 & 2.41 & $238.519^{* * *}$ \\
Extra wellness & 1.82 & 3.59 & 2.32 & $299.989^{* * *}$ \\
Intangible wellness & 4.22 & 4.60 & 3.98 & $31.867^{* * *}$ \\
Cult. and nat. heritage & 3.22 & 3.57 & 1.96 & $178.557^{\star * *}$ \\
Enter. and recreat. & 3.09 & 3.65 & 2.41 & $110.843^{* * *}$ \\
Landscape & 4.18 & 4.30 & 3.30 & $92.655^{* * *}$ \\
\hline Notes Column headings are as follows: (1) cluster 1- im- \\
material wellness, (2) cluster $2-$ high wellness, (3) cluster 3 \\
- low wellness, (4) F-value. ${ }^{* * *}$ Significant at o.oo1.
\end{tabular}

ness tourist product formed clear factor structures. Jointly, they accounted for $58.85 \%$ of accumulated vari- ance, and most of the factor loadings were greater than o.6o. They were labelled as Basic wellness, Intangible wellness, and Extra wellness. Cronbach's alpha coefficients were between 0.800 and 0.912 . Basic wellness included aspects like massage and sauna; intangible wellness encompassed various items that correspond to intangible aspects of a tourist product e.g. atmosphere and interactions, while extra wellness included attributes like detoxification, Tai Chi, etc. In general, pull travel motivations related to tangible aspects of a wellness tourist product, like Sauna, Solarium, Massages and Steam bath, were mostly unimportant, while the intangible aspects of a wellness tourist product (competence, relaxation and atmosphere) were mostly important to the responders. The detection of these three pull travel motivation factors are partially supported by the findings of Azman and Chan (2010), and Chen et al. (2013).

The pull travel motivations means related to tourist 
destination (Table 4) varied from 2.49 ('Theatre and performances') to 4.24 ('Beautiful nature'). At first, four factors were detected, however, after purifying the scale, three factors representing pull travel motivations for tourist destination formed clear factor structures. Jointly, they accounted for $53.95 \%$ of accumulated variance, and most of the factor loadings were greater than o.6o. They were labelled as Cultural and natural heritage, Entertainment and recreation, and Landscape. Cronbach's alpha coefficients were between 0.767 and 0.877. Cultural and natural heritage was comprised of different items like theatre, architectural styles, and natural protected area. Entertainment and recreation encompassed various activities and objects regarding entertainment, shopping, and sports. Landscape was composed of items referring to geographical features of the tourist destination. The pull travel motivations were mainly important to responders. However, certain cultural activities (e.g. museums and exhibitions, and theatre and performances) and activities related to tourists' special interests (like shopping and events) were marked as rather unimportant. The detection of these three pull travel motivation factors is partially supported by the findings of Hallab (2006), Chen et al. (2013), and Dryglas and Salamaga (2017). Natural resources were identified as a pull travel motivation in all three cases.

The travel motivations dimensions were cluster analysed. The number of clusters was determined by splitting the sample and using the hierarchical clustering technique. A hundred observations were randomly selected. The Ward method, with squared Euclidean distance, was used to establish the preliminary number of clusters. A three-cluster solution was selected on the basis of the largest and most plausible proportionate change. A non-hierarchical cluster analysis procedure ( $k$-means) was utilised to finalise the cluster solutions using the a priori determined number of clusters. The latter procedure confirmed the three-cluster solution (Table 5 and Table 6). The identified clusters were named according to the cluster centroids. Cluster 2 $(N=210)$, being the largest, represented $38.3 \%$ of the guests staying in wellness hotels, while Cluster $3(\mathrm{~N}$ $=133$ ) was the smallest and represented $24.3 \%$ of the guests staying in wellness hotels. Cluster $1(N=205)$ represented $37.4 \%$ of the guests staying in wellness hotels. Although the clusters differed statistically in all nine measures, dimensions that may be considered as more of an intangible kind stood out, i.e. push motivation factors (Relaxation and reward, and Novelty), pull motivation factors (Intangible wellness, as well as Cultural and natural heritage, Entertainment and recreation, and Landscape). Thus, the clusters were subsequently named taking into account these variables.

The guests staying in wellness hotels in Cluster 3 expressed a very low level of importance, or rather unimportance, related to travel motives in general, therefore this cluster was labelled as 'Low wellness.' In contrast, the guests staying in wellness hotels in Cluster 2 expressed the highest importance on all travel motivation dimensions; hence, this cluster was labelled 'High wellness.' Intangible travel motivation dimensions were the variables that differentiated Cluster 1 from the other two clusters, consequently labelling this cluster as 'Immaterial wellness.' The application of travel motivations in wellness tourism settings resulted in three clusters (high wellness, immaterial wellness, and low wellness clusters). The number of identified clusters is in accordance with the findings of Koh et al. (2010), Dryglas and Salamaga (2017), Dryglas and Salamaga (2018) and Huh et al. (2019), who also uncovered three clusters. However, the characteristics of clusters is only partially supported by the findings of Mueller and Lanz Kaufmann (2001), Koh et al. (2010), Dimitrovski and Todorović (2015), Dryglas and Salamaga (2017), Dryglas and Salamaga (2018) and Huh et al. (2019).

In all, 5 measures related to travel motivations that were not included in previous analyses were used to validate the clusters. All of them were significant, verifying the statistical differences among the clusters and providing support for the criterion validity of the items (Table 6).

\section{Conclusion}

This paper explores travel motivations as criteria in the segmentation process of one market niche, more precisely wellness tourism. A total of nine travel motivation factors were identified by applying the theory 
Table 6 ANovA Results for Cluster Validation

\begin{tabular}{|c|c|c|c|c|c|c|c|}
\hline \multirow[t]{2}{*}{ Measures } & \multicolumn{2}{|c|}{ Cluster 1} & \multicolumn{2}{|c|}{ Cluster 2} & \multicolumn{2}{|c|}{ Cluster 3} & \multirow[t]{2}{*}{$F$-value } \\
\hline & Mean & SD & Mean & SD & Mean & SD & \\
\hline Enjoy being pampered & 2.8 & 1.28 & 3.6 & 1.18 & 2.2 & 1.16 & $55.975^{* * *}$ \\
\hline Want to have fun & 3.6 & 1.18 & 4.1 & 0.99 & 3.2 & 1.32 & $27.042^{\star * *}$ \\
\hline Organised short time trips & 2.9 & 1.37 & 3.5 & 1.14 & 2.1 & 1.20 & $55.164^{* * *}$ \\
\hline Personalised service & 2.6 & 1.35 & $3 \cdot 9$ & 0.97 & 2.7 & 1.40 & $65.001^{* * *}$ \\
\hline Healthy diet & 4.0 & 1.08 & 4.4 & 0.71 & 3.8 & 1.19 & $22.638^{* * *}$ \\
\hline
\end{tabular}

Notes $\quad * * *$ Significant at 0.001 .

of the push and pull travel motivations. Three push motivation factors of wellness tourists emerged. They were labelled as Health trend, Relaxation and reward, and Novelty. A group of motivations related to interest in learning new things, and relaxation and reward stood out as important motives to wellness tourists in general, while items related to health aspects and luxury were mostly unimportant. A total of six pull travel motivation factors were established; three motivation factors related to a wellness tourist product and three motivation factors related to tourist destination. Motivation factors related to a wellness tourist product were labelled as Basic wellness, Intangible wellness, and Extra wellness, while those motivation factors related to tourist destination were labelled as Cultural and natural heritage, Entertainment and recreation, and Landscape. Pull travel motivations related to tangible aspects of a wellness tourist product, presented through basic and extra wellness factors, were mostly unimportant, while items measuring the intangible wellness factor were mostly important to the responders. The pull travel motivation factors related to tourist destination were mainly important to responders. However, certain cultural activities (e.g. museums and exhibitions, and theatre and performances) and activities related to tourists' special interest (like shopping and events) were marked as rather unimportant. By using travel motivation as segmentation criteria in wellness tourism settings three clusters were detected. They were labelled as high wellness, immaterial wellness, and low wellness clusters. The high wellness cluster placed high importance on all nine travel motivation factors. Pull motivation factors related to a well- ness tourist product were important in distinguishing between the high wellness segment, and immaterial and low wellness segments, while pull factors related to the destination provided differences between immaterial and high wellness segments, and the low wellness segment. In contrast, push travel motivations were mostly important to all three segments, with only health trend being the motivation factor that stood out in differentiating between the high wellness segment, and the other two.

This paper suggests that both push and pull motivation factors are crucial in the market segmentation process of wellness tourism as a form of niche market. Relaxation as push motivation, wellness infrastructure and natural resources as pull motivation factors are important factors in wellness tourism research. However, push travel motivations related to health issues are vital in differentiation between segments that are highly wellness-oriented and those who are less wellness oriented, i.e. who are more oriented on achieving well-being. The findings have certain implications for tourism managers. This research provides deeper insights into sub-segments of wellness tourists. Thus, in hotels where a wellness tourist product is an additional tourist product, and not the main focus, there may be a certain number of guests who are more interested in intangible wellness aspects like atmosphere, relaxation, and surroundings, compared to tangible wellness aspects. Thus, they do not place importance on tangible wellness aspects and are not likely to use services like massage, sauna, mud baths/wraps, etc. The findings also suggest that tourist destination attributes play an important role for hotel guests who are inter- 
ested in a wellness tourist product as well as for those guests who are more interested in immaterial aspects provided by the wellness concept.

There are certain limitations of this study. This study included guests staying in wellness hotels that offer wellness as an additional tourist product. Therefore, future research could include hotels and resorts that are exclusively focused on wellness. This study was focused on wellness travel motivation and its suitability as segmentation criteria. Therefore, future research may focus on other variables used for segmentation purposes like lifestyle. This research did not include tourists with disabilities or other medical conditions; therefore, future research might focus on these segments as well. The research was conducted in 2013 and since then certain strategic changes may have influenced wellness tourism. Therefore, a similar type of research would be useful to investigate the national tourism strategies' impact on wellness tourism, i.e. wellness hotels.

\section{References}

Andrijašević, M., \& Bartoluci, M. (2004) The role of wellness in contemporary tourism. Acta Turistica, 16(2), 125-142.

Awaritefe, O. D. (2004). Motivations and other considerations in tourism destination choice: A case study of Nigeria. Tourism Geographies, 6(3), 303-330.

Azman, I., \& Chan, K. L. J. (2010). Health and spa tourism business: Tourists' profiles and motivational factors, health, wellness and tourism: Healthy tourists, healthy business? In Proceedings of the Travel and Tourism Research Association Europe 2010 Annual Conference, (pp. 9-24). http://pc.parnu.ee/ htooman/

Proceedingnyomdanak.pdf

Bennett, M., King, B., \& Milner, L. M. (2004). The health resort sector in Australia: A positioning study. Journal of Vacation Marketing, 10(2), 122-137.

Bieger, T., \& Laesser, C. (2002). Market segmentation by motivation: The case of Switzerland. Journal of Travel Research, 41(1), 68-76.

Boksberger, P., \& Laesser, C. (2008). Segmenting the senior travel market by means of travel motivation - Insights from a mature market (Switzerland). http://ro.uow.edu .au/cgi/viewcontent.cgi? article $=3489 \&$ context =commpapers

Chang, J. C. (2007). Travel motivation of package tour travellers. Tourism, 55(2), 157-176.
Chen, K. H., Liu, H. H., \& Chang, F. H. (2013). Essential customer service factors and the segmentation of older visitors within wellness tourism based on hot springs hotels. International Journal of Hospitality Management, 35, 122132.

Crompton, J. L. (1979). Motivations for pleasure vacations. Annals of Tourism Research, 6(4), 408-424.

Dimitrovski, D., \& Todorović, A. (2015). Clustering wellness tourists in spa environment. Tourism Management Perspectives, 16, 259-265.

DiStefano, C., Zhu, M., \& Mîndrilă, D. (2009). Understanding and using factor scores: Considerations for the applied research. Practical Assessment Research \& Evaluation, 14(20), 1-11.

Dolnicar, S. (2008). Market segmentation in tourism. In A. G. Woodside \& D. Martin (Eds.), Tourism management: Analysis, behaviour and strategy (pp. 129-150). С A B I.

Dryglas, D., \& Salamaga, M. (2017). Applying destination attribute segmentation to health tourists: A case study of Polish spa resorts. Journal of Travel and Tourism Marketing, 34(4), 503-514.

Dryglas, D., \& Salamaga, M. (2018). Segmentation by push motives in health tourism destinations: A case study of Polish spa resorts. Journal of Destination Marketing \& Management, 9, 234-246.

Gu, Q., Zhang, H. Q., King, B., \& Huang, S. (2018). Wine tourism involvement: A segmentation of Chinese tourists. Journal of Travel \& Tourism Marketing, 35(5), 633648.

Hair, J. F., Black, W. C., Babin, B. J., \& Anderson, A. E. (2010). Multivariate data analysis. Pearson Prentice Hall.

Hallab, Z. (2006). Catering to the healthy-living vacationer. Journal of Vacation Marketing, 12(1), 71-91.

Hallab, Z. A. A., Yoon Y., \& Uysal, M. (2003). An identification of market segments based on healthy-living attitude. Journal of Hospitality and Leisure Marketing, $10(3 / 4), 185-198$.

Heung, V. C. S., Qu, H., \& Chu, R. (2001). The relationship between vacation factors and socio-demographic and travelling characteristics: The case of Japanese leisure travellers. Tourism Management, 22(3), 259-269.

Hinkin, T. R., Tracey, J. B., \& Enz, C. A., (1997). Scale construction: Developing reliable and valid measurement instruments. Journal of Hospitality and Tourism Research, 21(1), 100-120.

Hudson, S. (2008). Tourism and hospitality marketing: A global perspective. Sage.

Huh, C., Lee, M. J., \& Lee, S. (2019). A profile of spa-goers in the U.S. luxury hotels and resorts: A posteriori market 
segmentation approach. Journal of Hospitality Marketing \& Management, 28(8), 1032-1052.

Jönsson, C., \& Devonish, D. (2008). Does nationality, gender, and age affect travel motivations? A Case of Visitors to the Caribbean Island of Barbados. Journal of Travel and Tourism Marketing, 25(3/4), 398-408.

Kim, B. H., \& Batra, A. (2009). Healthy-living behavior status and motivational characteristics of foreign tourists to visit wellness facilities in Bangkok. In The 2nd Annual PSU Phuket Research Conference proceedings (pp. 1-8). http://www.conference.phuket.psu.ac.th/PSU_OPEN _WEEK_2009/data/Hospitality/Paper6.pdf

Kim, E., Chiang, L., \& Tang, L. (2017). Investigating wellness tourists' motivation, engagement, and loyalty: In search of the missing link. Journal of Travel \& Tourism Marketing, 34(7), 867-879.

Koh, S., Yoo, J. J. E., \& Boger, C. A. Jr. (2010). Importanceperformance analysis with benefit segmentation of spa goers. International Journal of Contemporary Hospitality Management, 22(5), 718-735.

Konu, H. (2010). Identifying potential wellbeing tourism segments in Finland. Tourism Review, 65(2), 41-51.

Konu, H., \& Laukkanen, T. (2009). Roles of motivation factors in predicting tourists' intentions to make wellbeing holidays - A Finnish case. In ANZMAC 2009 conference proceedings (pp. 1-9). http://www.duplication.net.au/ ANZMACo9/papers/ANZMAC2009-376.pdf

Kozak, M. (2002). Comparative analysis of tourist motivations by nationality and destination. Tourism Management, 23(3), 221-232.

Kucukusta, D., \& Denizci Guillet, B. (2016). Lifestyle segmentation of spa users: A study of inbound travelers to Hong Kong. Asia Pacific Journal of Tourism Research, 21(3), 239-258.

Lee, S. C., Suh, Y. H., Kim, J. K., \& Lee, K. J. (2004). A crossnational market segmentation of online game industry using som. Expert Systems with Applications, 27(4), 559570 .

Lee, T. H., Jan, F.-H., Tseng, C. H., \& Lin, Y. F. (2018). Segmentation by recreation experience in island-based tourism: A case study of Taiwan's Liuqiu Island. Journal of Sustainable Tourism, 26(3), 362-378.

Lim, Y.-J., Kim, H.-K., \& Lee, T. J. (2016). Visitor motivational factors and level of satisfaction in wellness tourism: Comparison between first-time visitors and repeat visitors. Asia Pacific Journal of Tourism Research, 21(2), 137-156.

Lubbe, B. A. (2003). Tourism management in Southern Africa. Pearson Education.
Mak A. H. N., Wong, K. K. F., \& Chang R. C. Y. (2009). Health or self-indulgence? The motivations and characteristics of spa-goers. International Journal of Tourism Research, 11(2), 185-199.

McGehee, N. G., Loker-Murphy, L., \& Uysal, M. (1996). The Australian international pleasure travel market: Motivations from a gendered perspective. The Journal of Tourism Studies, 7(1), 45-57.

Middleton, V. T. C., \& Clarke, J. (2001). Marketing in travel and tourism (3rd ed.). Butterworth-Heinemann.

Monteson, P. A., \& Singer, J. (2004). Marketing a resortbased spa. Journal of Vacation Marketing, 10(3), 282-287.

Mueller, H., \& Lanz Kaufmann, E. (2001). Wellness tourism: Market analysis of a special health tourism segment and implications for the hotel industry. Journal of Vacation Marketing, 7(1), 5-17.

Pesonen, J., Laukkanen, T., \& Komppula, R. (2011). Benefit segmentation of potential wellbeing tourists. Journal of Vacation Marketing, 17(4), 303-314.

Sangpikul, A. (2008). A factor-cluster analysis of tourist motivations: A case of U.S. senior travellers. Tourism, $56(1)$, 23-40.

Segal, M. N., \& Giacobbe, R. W. (1994). Marketing segmentation and competitive analysis for supermarket retailing. International Journal of Retail \& Distribution Management, 22(1), 959-552.

Sewall, M. A. (1978). Market segmentation based on consumer ratings o proposed product designs. Journal of Marketing Research, 15(4), 557-564.

Sharma, P., \& Nayak, J. K. (2019). An analysis on the emotional approach to segmentation: A study of yoga tourism. Journal of Convention \& Event Tourism, 2o(1), 1-23.

Sheldon, P. J., \& Park, S. Y. (2008) Sustainable wellness tourism: Governance and entrepreneurship issues. Acta Touristica, 20(2), 151-172.

Smith, M., \& Puczkó, L, (2009). Health and wellness tourism. Butterworth-Heinemann.

Smith, W. R. (1956). Product differentiation and market segmentation as alternative marketing strategies. The Journal of Marketing, 21(1), 3-8.

Su, D. N., Johnson, L. W., \& O’Mahony, B. (2020). Analysis of push and pull factors in food travel motivation. Current Issues in Tourism, 23(5), 572-586.

Suni, J., \& Pesonen, J. (2019). Hunters as tourists - An exploratory study of push-pull motivations. Scandinavian Journal of Hospitality and Tourism, 19(2), 175-191.

Swarbrooke, J., \& Horner, S. (2007). Consumer behaviour in tourism (2nd ed.). Butterworth-Heinemann.

Tkaczynski, A. (2009). Destination segmentation: A recom- 
mended two-step approach [Unpublished $\mathrm{PhD}$ dissertation]. https://eprints.usq.edu.au/6255/2/Tkaczynski _2009_whole.pdf

Tsai, C. Y, \& Chiu, C. C. (2004). A purchase based market segmentation methodology. Expert Systems with Applications, 27(2), 265-276.

Uysal, M., \& Jurowski, C. (1993). An empirical testing of the push and pull factors of tourist motivations. In Proceedings of 1993 CHRIE Conference (pp. 162-163). CHRIE.

Veal, A. J. (2006). Research methods for leisure and tourism: A practical guide. Pearson Education Limited.
Voigt, C., Brown, G., \& Howat, G. (2011). Wellness tourists: In search of transformation. Tourism Review, 66(1/2), 630.

Winter, F. W. (1979). A cost-benefit approach to market segmentation. Journal of Marketing, 43, 103-111.

Yankelovich, D. (1964). New criteria for market segmentation. Harvard Business Review, 42(2), 83-90.

Yoon, Y., \& Uysal, M. (2005). An examination of the effects of motivation and satisfaction on destination loyalty: A structural model. Tourism Management, 26(1), 45-56. 



\title{
Service Quality Measurement in Rural Tourism: Application of RURALQUAL Model
}

\author{
Suzana Marković \\ University of Rijeka, Faculty of Tourism and Hospitality Management, Croatia \\ suzanam@fthm.hr \\ Jelena Kljaić Šebrek \\ WYG Consulting Ltd, Croatia \\ jelenak1o1@gmail.com
}

The purpose of this paper is to evaluate service quality and its relation to customer satisfaction, trust, and behavioural intentions of rural tourism by applying the modified RURALQUAL model derived from the original SERVQUAL model. The survey was conducted on a sample of 307 rural tourists in Croatia. A Partial Least Squares Structural Equation Modelling (PLS-SEM) was applied in order to analyse the relationship between the measured constructs. The modified RURALQUAL model has been proven as a reliable and valid multidimensional scale that includes 27 items divided into 5 dimensions. Results indicate that there is a significant positive relationship between Service quality and Satisfaction as antecedents to Loyalty. The role of Trust as a mediator between Satisfaction and Loyalty has been proven, but its mediation power is rather small. Research results indicate that rural tourism managers and owners paid more attention to the tangible service quality elements, but in order to improve overall tourist experience in the future, they should pay more attention to the intangible service quality elements. The modified RURALQUAL instrument should be periodically used as a tool by practitioners and managers for the future development of rural tourism.

Keywords: service quality, satisfaction, loyalty, rural tourism, RURALQUAL, PLS

SEM

(cc)BY-SA https://doi.org/10.26493/2335-4194.13.215-227

\section{Introduction}

The importance of rural tourism, which has come under the focus of many researchers, has significantly increased in the last decades (Hurst et al., 2009; Osman \& Sentosa, 2013b). Rural tourism may be an answer to the redundant sun and sea concept and an extension of the main tourist season for many tourist economies (Grgić et al., 2017). Furthermore, the urban accelerated lifestyle has become very stressful, causing many tourists to seek calm, rural places surrounded by nature (Kastenholz et al., 2018). Rural tourism presents a powerful development strategy for rural underdeveloped areas as it generates new jobs and increases local incomes (Choi et al., 2018). The development potential of rural tourism is huge, but in order to stay competitive and sustainable in the long term, rural tourism must provide a high level of service quality and satisfaction (Chatzigeorgiou \& Simeli, 2017). According to Rozman et al. (2009), service quality is important for survival in a competitive market. Satisfied tourists are more likely to recommend and return to the rural tourist object. Service quality is a widely researched 
concept in the tourism industry, but only a few studies have measured service quality in rural tourism using Partial Least Squares Structural Equation Modelling (PLS-SEM), including Loureiro and Kastenholz (2011), Osman and Sentosa (2013a, 2013b, and Kastenholz et al. (2018).

Therefore, the purpose of this paper is to determine service quality in rural tourism. The main research objectives of this study are: (a) to assess Service quality, Satisfaction and Loyalty in rural tourism, (b) to evaluate the relationship between Service quality, Satisfaction and Loyalty, (c) to estimate the role of Trust as a mediator between the concepts Satisfaction and Loyalty, and (d) to test the reliability of the modified RU RALQUAL model.

The paper is organised in four sections. The following section provides an overview of the recent literature dealing with the concepts and measurement of service quality, tourist satisfaction and loyalty, primarily in rural tourism. The next section lays out the methodology and is followed by the results of the research. The final section discusses main conclusions, limitations, and future research proposals.

\section{Literature Review}

Although there is no unique definition of the term 'service quality,' most researchers agree that the term defines fulfilment of tourists' expectations in the focus of service quality (Gronroos, 1984; Parasuraman et al., 1985; Lewis \& Mitchell, 1990). According to many authors, service quality is a multidimensional concept, but service quality dimensions should be adapted to the specific features of a measured service (Babakus \& Boller, 1992).

So far, a wide range of research has been conducted on service quality and a variety of different measurement models has been developed and tested, but one of the most popular and frequently used is the SERVQUAL model. SERVQUAL was developed by Parasuraman et al. in 1985. It consists of 22 items which measure five service quality dimensions: Tangibles, Reliability, Responsiveness, Assurance, and Empathy. The SERVQUAL instrument was widely used for measuring service quality in the tourism industry: travel agencies (Bigne et al., 2003; Shahin \& Janatyan,
2011; Katircioglu et al., 2012; Setó-Pamies, 2012; Rajesh, 2018), hotels (Marković, 2004; Ladhari, 2009; Marković \& Raspor, 2010; Marković \& Raspor Janković, 2013; Kim-Soon et al., 2014; Ounsri \& Thawesaengskulthai, 2019), and restaurants (Marković et al., 2010; Nam \& Lee, 2011; Hansen, 2014; Saneva \& Chortoseva, 2018). SERVQUAL was also used to measure the quality of rural tourism. For that purpose, a RURALQUAL model was developed by Loureiro and Gonzalez (2008). The model assesses only perceptions as proposed by Cronin and Taylor (1994) and consists of 22 variables divided into 6 factors (Professionalism, Reservations, Tangibility, Complementary benefits, Rural and cultural environment and Basic benefits). Research on a sample of 198 rural tourists was conducted in 2008 in Portugal. The research proved that the lowest-rated service quality dimension is Rural and cultural environment, and the highest-rated dimensions are Professionalism, Reservations, Tangibility and Basic benefits.

Satisfaction is also a very frequently-researched concept in tourism due to its importance for the success of tourism business, as a satisfied tourist is more likely to recommend or rebuy the service (Baker \& Crompton, 2000; Su \& Fan, 2011). Satisfaction is, by most authors, defined as an emotion that a tourist feels after service consumption or an affective response to a service (Oliver, 1999; Baker \& Crompton, 2000; Zeithaml \& Bitner, 2003; Um et al., 2006). Tourist satisfaction depends on the level of fulfilment of expectations and desires (Chen \& Tsai, 2007; Osman \& Sentosa, 2013a). If a perceived service did not meet expectations, a tourist may feel dissatisfied.

Loyalty presents the ultimate objective for many companies as it reduces costs and increases profit (Almeida-Santana \& Moreno Gil, 2018). Most authors emphasise that loyalty is a positive attitude towards a destination, a company, or a service (Oliver, 1999; Kim \& Brown, 2012; Setó-Pamies, 2012; Osman \& Sentosa, $2013 \mathrm{~b}$ ). The concept of loyalty can be approached from two different directions: attitudinal or behavioural (Zeithaml, 200o). Behavioural loyalty results in repetitive purchasing behaviour while attitudinal includes recommending a service or company to others (Zeithaml, 2000; Cheng, 2011). 
The concept of Trust has been defined as a tourist's 'willingness to rely on tourist attraction operator's ability to deliver what has been promised and meet or exceed the expectation of the tourists which has been built around of the knowledge about the tourist attraction' (Osman \& Sentosa, 2013a, p. 14.). Many studies emphasize that Trust reduces risk and effects future intentions, especially in long-term, strong relationships with the company (Sirdeshmukh et al., 2002; Yieh et al., 2007; Loureiro \& Gonzalez, 2008).

Studies carried out by different authors have proven that Service quality, Satisfaction and Loyalty are related concepts. High quality of service effects tourists' positive emotions and generates high tourist satisfaction. Satisfaction, enhanced by Trust, contributes to Loyalty. Service quality and Tourist satisfaction have been proven to be the key antecedents to customer Loyalty by different studies (Loureiro \& Kastenholz, 2011; Oh \& Kim, 2017). The mediating effect of Trust on Loyalty in rural tourism has been proven by Loureiro and Gonzalez (2008).

The review of selected recent researches on service quality and related concepts in rural tourism is given in Table 1. The data show that Service quality, Satisfaction and Loyalty in rural tourism are measured globally in different tourist countries (Us A, Spain, Greece, Slovenia, Portugal, Malaysia). The authors used quite large samples, ranging from 103 to 632 respondents. Most of the researches followed the SERVQUAL model modified to the needs of the services measured, where the number of factors varied from the original 5 to 8 factors and 22 to 36 variables. The applied statistical methods primarily include factor analysis and structural modelling. The observed studies reported a high level of reliability $(>0.70)$ of applied models. The findings of the research conducted by Choi et al. (2018) indicate that performance exceeds expectations, meaning that rural tourists' needs are met for all the observed variables. On the other hand, Albacete-Saez et. al. (2007) proved a negative gap between perception and expectation in 4 of 5 service quality dimensions. A positive gap is proved for the dimension Empathy, and the largest negative gap is recorded for the dimension Complementary offer.

Furthermore, the previously analysed studies con-

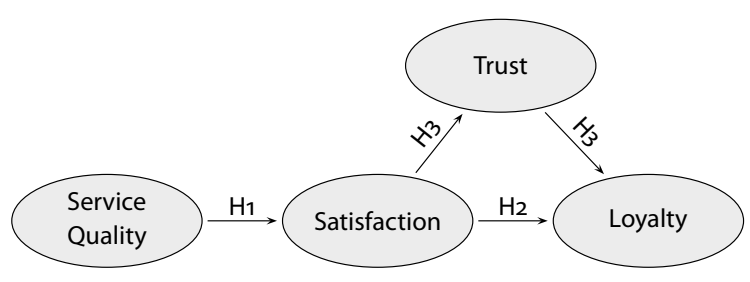

Figure 1 Theoretical Framework

firmed that the concepts Service quality, Satisfaction and Loyalty are related and interdependent. More specifically, Loureiro and Kastenholz (2011) and Su and Fan (2011) found that high service quality significantly increases tourist satisfaction and confirmed that satisfaction is the key antecedent to loyalty. Also, the study of Su and Fan (2011) has proven that there is no direct relationship between service quality and loyalty, but only mediated by tourist satisfaction and trust. Also, this study confirmed that satisfaction is an antecedent to trust, not the opposite. A study of Peãa et al. (2012), conducted in Spain, emphasises the positive effect of the perceived value on tourist satisfaction. Osman and Sentosa (2013b) conducted research on service quality in rural tourism in Malaysia that proved a strong direct relationship between service quality and satisfaction and service quality and loyalty. The same study confirmed that satisfaction and trust could have a mediating role between service quality and loyalty.

The findings of the study carried out in Greece by Chatzigeorgiou and Simeli (2017) confirmed the predicative power of overall service quality and satisfaction on loyalty. Rajaratnam et al. (2015), in their study on 334 rural tourists in Malaysia, have found that satisfaction is positively and significantly correlated to loyalty.

Although there is no consensus on service quality attributes, most of the authors agree that initial SERVQUAL dimensions should be adapted to specific needs of a wide range of rural tourism activities.

Based on the literature review the following hypotheses were tested (Figure 1):

$\mathrm{H} 1$ There is a positive relationship between service quality and customer satisfaction.

$\mathrm{H} 2$ There is a positive relationship between customer satisfaction and customer loyalty. 
Table 1 Literature Review of Measuring Service Quality, Satisfaction and Loyalty in Rural Tourism

\begin{tabular}{|c|c|c|c|c|c|c|}
\hline (1) & (2) & (3) & (4) & (5) & (6) & (7) \\
\hline $\begin{array}{l}\text { Albacete-Saez et al. } \\
(2007)\end{array}$ & Spain & 185 & Service quality & $\begin{array}{l}7 \text { factors, } \\
36 \text { items }\end{array}$ & $\mathrm{EFA}^{*}$ & 0.93 \\
\hline Hurst et al. (2009) & USA & 125 & $\begin{array}{l}\text { Service quality, satisfaction, } \\
\text { loyalty }\end{array}$ & $\begin{array}{l}5 \text { factors, } \\
18 \text { items }\end{array}$ & EFA & $0.82-0.98$ \\
\hline Rozman et al. (2009) & Slovenia & 103 & Service quality & $\begin{array}{l}3 \text { service quality } \\
\text { dim., } 22 \text { items }\end{array}$ & DEX & - \\
\hline $\begin{array}{l}\text { Fotiadis \& Vassiliadis } \\
(2010)\end{array}$ & Greece & 219 & Satisfaction & 15 items & IPA & - \\
\hline $\begin{array}{l}\text { Loureiro \& Kastenholz } \\
\text { (2011) }\end{array}$ & Portugal & 161 & $\begin{array}{l}\text { Service quality, corporate repu- } \\
\text { tation, satisfaction, loyalty }\end{array}$ & $\begin{array}{l}6 \text { factors, } \\
22 \text { items }\end{array}$ & $\begin{array}{l}\text { CFA, } \\
\text { PLS-SEM }\end{array}$ & 0.92 \\
\hline Su \& Fan (2011) & China & 320 & $\begin{array}{l}\text { Service quality, satisfaction, } \\
\text { trust, loyalty }\end{array}$ & 5 factors & SEM & $0.77-0.85$ \\
\hline Peña et al. (2012) & Spain & 632 & $\begin{array}{l}\text { Perceived value, satisfaction, } \\
\text { loyalty }\end{array}$ & - & SEM & $>0.70$ \\
\hline $\begin{array}{l}\text { Osman \& Sentosa } \\
(2013 a)\end{array}$ & Malaysia & 295 & $\begin{array}{l}\text { Service quality, satisfaction, } \\
\text { loyalty }\end{array}$ & $\begin{array}{l}5 \text { factors, } 31 \\
\text { items in total }\end{array}$ & PLS-SEM & $0.84-0.91$ \\
\hline $\begin{array}{l}\text { Rajaratnam et al. } \\
(2015)\end{array}$ & Malaysia & 334 & $\begin{array}{l}\text { Destination quality, satisfac- } \\
\text { tion, loyalty }\end{array}$ & 8 factors & PLS-SEM & $0.90-0.92$ \\
\hline Rozkee et al. (2016) & India & 420 & Service quality, satisfaction & $\begin{array}{l}5 \text { factors, } \\
22 \text { items }\end{array}$ & regression & - \\
\hline $\begin{array}{l}\text { Chatzigeorgiou \& } \\
\text { Simeli }(2017)\end{array}$ & Greece & 400 & $\begin{array}{l}\text { Service quality, satisfaction, } \\
\text { future behavioural intentions }\end{array}$ & $\begin{array}{l}5 \text { factors, } \\
22 \text { items }\end{array}$ & SEM & - \\
\hline Kastenholz et al. (2018) & Portugal & 252 & $\begin{array}{l}\text { Tourists' arousal, memory, } \\
\text { satisfaction }\end{array}$ & - & PLS-SEM & - \\
\hline Choi et al. (2018) & $\begin{array}{l}\text { South } \\
\text { Korea }\end{array}$ & 442 & Service quality & 18 items & $\mathrm{IPA}^{* *}$ & 0.96 \\
\hline
\end{tabular}

Notes Column headings are as follows: (1) author, (2) country, (3) sample size, (4) measured concepts, (5) number of service quality items and factors, (6) methods used, (7) reliability. ${ }^{\star}$ Exploratory Factor Analysis, ${ }^{\star *}$ Importance Performance Analysis.

$\mathrm{H} 3$ There is a positive mediating effect of trust on the satisfaction and loyalty relationship.

A literature review indicates that PLS SEM is an often-used method in research in service quality in tourism. According to the results of a study conducted by Ali et al. (2017), during the period between 2001 and 2015 there were 29 empirical articles published that applied PLS-SEM. Out of 29 articles, only 7 were published up until 2012, and 22 articles were published from 2013 to 2015, indicating an increasing popularity of PLS SEM in recent years.

\section{Methodology}

The perceived quality of the rural tourism was measured using a modified RURALQUAL model based on the SERVQUAL and the original RURALQUAL model (Loureiro \& González, 2008) and modified by the items used in the study of Albacete-Saez et al. (2007). Modifications include adaptation of the items to the specific features of rural tourism in Istria. The dimension Safety was added from the model of AlbaceteSaez et al. (2007). Safety was identified as a very important service quality aspect during the consultation process with key tourist stakeholders in Istria (tour- 
ist board and rural tourism managers and owners).

The scale contains 27 items divided into 5 factors measured on a 7-point Likert-type ordinal scale. The research conducted in this work used measurement of perception only as proposed by Cronin and Taylor (1994).

The survey was conducted from June to September 2017 in central Istria as one of the most developed rural tourism destinations in Croatia. There were 1,400 paper questionnaires in 4 languages distributed to tourists staying in 22 rural accommodations. 307 valid questionnaires were returned (return rate $21.93 \%$ ) using a convenient sample, meaning that only tourists who were available and willing to participate in research filled in the questionnaires. Descriptive statistics, factor analysis and Partial Least Squares Structural Equation Modelling (PLS-SEM) methods were performed using SPSS 20.0 and Smart PLS 2.0 software to test the research hypotheses.

PLS SEM became the preferred technique due to its advantages: accuracy for small sample size, absence of distributional assumptions and a high degree of statistical power (Hair et al., 2019). It is an appropriate technique in the case of complex structural models that include many constructs, indicators, and model relationships (Hair et al., 2019).

PLS SEM is based on an iterative combination of principal components analysis and regression, aiming at explaining the variance of the constructs in the model (Chin, 1998; Peng, 2012). The advantage of PLS SEM lies in simultaneously estimating all relationships in the model including path coefficients and individual item loadings of the model, eliminating concerns about multicollinearity (Henseler et al., 2009).

The model consists of two parts (Hair et al., 2013): the structural model analysing the relationships between the constructs (inner model) and the measurement models displaying the relationships between the constructs and the indicator variables (outer model). The application of PLS SEM is a multi-stage approach that involves three main stages: model specification, outer model evaluation and inner model evaluation (Hair et al., 2014). The inner model evaluation as a last stage is implemented only after the previous stage proves the reliability and validity of the model
(Henseler et al., 2009). PLS-SEM relies on a nonparametric bootstrap procedure to test coefficients for their significance. In bootstrapping, a large number of subsamples are drawn from the original sample and used to evaluate the model (Hair et al., 2013).

This paper presents an evaluation of the structural model including the relationship between constructs of service quality, satisfaction, trust and loyalty.

Since PLS SEM is considered more appropriate for prediction than covariance-based techniques (Loureiro \& Kastenholz, 2011), it has been chosen for the analysis of future behaviour intentions. Adequacy of measurement was assessed by evaluating the reliability and the discriminant validity of the scale. The Partial Least Squares (PLS) approach was employed to estimate the structural paths coefficients, $R^{2}$ for evaluation of predictive power of the model and $Q^{2}$ for assessment of predictive relevance, and the Bootstrap technique to test the hypotheses.

\section{Research Results}

The data analysis of socio-demographic data indicates that there was an almost equal number of female and male respondents. Out of 307 respondents, $68.32 \%$ are foreign tourists. The majority of respondents are between 30 and 49 years old $(58.17 \%)$ with a middle or high school level of education (84.97\%) and dominant marital status 'married' (48.36\%). Most of the respondents were visiting the rural destination facility for the first time (72.04\%) and travelling with a partner or friends $(55.88 \%)$. The main tourist motives for visiting the rural facility are spending time with friends and family (51.14\%) and relaxing (40.39\%). Other motives include tasting local food, learning about tradition and culture, and escaping from stress and city noise. The results of the socio-demographic profile of respondents is shown in Table 2.

The results of the principal components analysis and Promax rotation method were used to reduce 27 variables to 5 factors (Safety, tourist relations and rural surrounding, Tangibility and basic demand, Price and reservation, Professionalism, and Empathy). The communality values of the observed variables are above 0.5 , indicating suitability of the items for performing factor analysis. 
Table 2 Respondents Socio-Demographic Profile

\begin{tabular}{|c|c|c|c|}
\hline Item & Group & $f$ & $\%$ \\
\hline \multirow[t]{3}{*}{ Gender } & Female & 158 & 51.63 \\
\hline & Male & 148 & 48.37 \\
\hline & Total & 306 & 100.00 \\
\hline \multirow[t]{7}{*}{ Age } & Less than 20 & 15 & 4.90 \\
\hline & $20-29$ & 59 & 19.28 \\
\hline & $30-39$ & 96 & 31.37 \\
\hline & $40-49$ & 82 & 26.80 \\
\hline & $50-59$ & 26 & 8.50 \\
\hline & 60 and above & 28 & 9.15 \\
\hline & Total & 306 & 100.00 \\
\hline \multirow{5}{*}{$\begin{array}{l}\text { Educational } \\
\text { level }\end{array}$} & Elementary school or less & 11 & 3.59 \\
\hline & Secondary school & 126 & 41.18 \\
\hline & University & 134 & 43.79 \\
\hline & Master or $\mathrm{PhD}$ & 35 & 11.44 \\
\hline & Total & 306 & 100.00 \\
\hline \multirow{5}{*}{$\begin{array}{l}\text { Marital } \\
\text { status }\end{array}$} & Single & 80 & 26.32 \\
\hline & Married & 147 & 48.36 \\
\hline & In relationship & 67 & 22.04 \\
\hline & Other & 10 & 3.29 \\
\hline & Total & 304 & 100.00 \\
\hline \multirow{7}{*}{$\begin{array}{l}\text { Travelling } \\
\text { group }\end{array}$} & Alone & 35 & 11.44 \\
\hline & Partner & 102 & $33 \cdot 33$ \\
\hline & Partner and children & 60 & 19.61 \\
\hline & Friends & 69 & 22.55 \\
\hline & Work colleagues & 34 & 11.11 \\
\hline & Other & 6 & 1.96 \\
\hline & Total & 306 & 100.00 \\
\hline
\end{tabular}

Continued in the next column

Total variance explained in factor analysis is $65.17 \%$; the majority of total variance is explained by the first factor $42.98 \%$ followed by the second factor $9.79 \%$, third factor $5.09 \%$, fourth factor $3.85 \%$ and fifth factor $3.56 \%$.

The first factor, Safety, tourist relations and rural surrounding, refers to the usage of safety measures, integration of tourists into the local lifestyle, and offer of additional activities and events in the rural surround-
Table 2 Continued from the previous column

\begin{tabular}{|c|c|c|c|}
\hline Item & Group & $f$ & $\%$ \\
\hline \multirow[t]{20}{*}{ Country } & Croatia & 100 & 32.68 \\
\hline & Germany & 47 & $15 \cdot 36$ \\
\hline & Austria & 46 & 15.03 \\
\hline & $\mathrm{UK}$ & 30 & 9.80 \\
\hline & Italy & 29 & 9.48 \\
\hline & Slovenia & 15 & 4.90 \\
\hline & Netherlands & 7 & 2.29 \\
\hline & Ireland & 6 & 1.96 \\
\hline & Switzerland & 5 & 1.63 \\
\hline & USA & 4 & 1.31 \\
\hline & Hungary & 3 & 0.98 \\
\hline & Canada & 3 & 0.98 \\
\hline & Slovakia & 3 & 0.98 \\
\hline & Denmark & 2 & 0.65 \\
\hline & San Marino & 2 & 0.65 \\
\hline & Australia & 1 & 0.33 \\
\hline & Russia & 1 & 0.33 \\
\hline & Spain & 1 & 0.33 \\
\hline & Luxemburg & 1 & 0.33 \\
\hline & Total & 306 & 100.0 \\
\hline \multirow{4}{*}{$\begin{array}{l}\text { Number of } \\
\text { arrivals }\end{array}$} & First time & 219 & 72.04 \\
\hline & 2 to 5 times & 56 & 18.42 \\
\hline & More than 5 times & 29 & 9.54 \\
\hline & Total & 304 & 100.00 \\
\hline
\end{tabular}

ing. The second factor, Tangibility and basic demand, includes attributes like rural facility location, state of rural facilities, and external and internal decoration. The third factor, Price and reservations, describes reservation possibilities and accordance of price and services. The fourth factor, Professionalism, refers to employees' appearance and treatment of tourists. The last factor, named Empathy, includes items regarding employees' knowledge of foreign languages and individual approach to the tourists. The number of items varies from 3 to 10 per factor. Factor mean scores range from 5.46 to 6.05 with the highest mean score for the factor Tangibility and basic demand and the lowest 
Table 2 Continued from the previous column

\begin{tabular}{llrr}
\hline Item & Group & $f$ & $\%$ \\
\hline Travel & Spending time with friends & 157 & 51.14 \\
motives & and family & & \\
& Relaxing & 124 & 40.39 \\
& Tasting local food & 85 & 27.69 \\
& Learning about local tradi- & 55 & 17.92 \\
& tion/culture & & \\
& Escape from stress and city & 77 & 25.08 \\
& noise & & \\
& Beautiful nature & 70 & 22.80 \\
& Searching for tranquillity & 39 & 12.70 \\
& Beauty of a place & 30 & 9.77 \\
& Affordable prices & 28 & 9.12 \\
& Pleasant atmosphere & 23 & 7.49 \\
& Learning new skills & 30 & 9.77 \\
& Other & 14 & 4.56 \\
\hline
\end{tabular}

mean score for the factor Safety, tourist relations and rural surrounding. An overall average mean score for Perceived service quality is 5.79 . The highest mean score was given to the item The lodging is located in a calm place (6.28, St. dev 0.89), and the lowest to the item The Rural establishment observes safety measures during excursions and complementary activities offered (5.20, St. dev. 1.53). The overall average service quality score is relatively high (5.79). The highest score was given to the dimension Tangibility and basic demand (6.05) that refers to infrastructure, equipment and decoration. The lowest score was given to the dimension Safety, tourist relations and rural surrounding (5.46).

All factor loadings for service quality items are significant with the value above 0.5 and the overall Cronbach alpha 0.952 indicating good reliability of the scale. The statistical calculations were performed using SPSS 20.0. The factor structure of modified RURALQUAL model is shown in Table 3.

An overall mean score for Satisfaction is 5.82, Trust 5.98 and Loyalty 5.15. All factor loadings are significant since they are greater than 0.5. The Cronbach alpha coefficient ranges from 0.865 to 0.910 , proving a good internal consistency of the constructs. The results of quantitative analysis for the concepts Satisfaction, Trust and Loyalty are shown in Table 4.

The Cronbach alpha value for all measured constructs is between 0.762 and 0.951 and indicates a good reliability or internal consistency of the modified RU RALQUAL model (Table 5). Convergent validity has also been confirmed as factor loadings prove a strong connection of items to the factors, given that the average variance extracted by the constructs (AVE) was at least 0.5. The results of $R^{2}$ prove moderate predictive power of the model since the values exceed 0.50 . The literature suggests that $R^{2}$ values of $0.67,0.33$, and 0.19 are substantial, moderate, and weak (Chin, 1998; Peng, 2012). The values for $Q^{2}$ are all positive, meaning that the model has predictive relevance.

PLS SEM was used to assess path coefficients between the observed constructs. The results prove a strong direct positive relationship between Service Quality and Satisfaction (0.763) and Between Satisfaction and Loyalty (0.652). Also, Satisfaction has been proven to be strongly related to Trust, but the relationship between Trust and Loyalty is rather weak (0.146). The path coefficient analysis of the service quality dimensions indicates that the most important dimension in forming service quality is Safety, tourist relations and rural surrounding (43\%), while the dimension Empathy has the lowest impact on forming the Service Quality construct (13\%). The results of Path coefficient analysis are shown in Figure 2.

The Bootstrap technique in PLS SEM was applied for the assessment of the significance level of the path coefficients in order to test the hypothesis. According to the results all the relations between the constructs have been proven to be significant at the 0.001 level, except for the relation between Trust and Loyalty that is positive, but weak and significant at the 0.005 level (Table 6). The path coefficient between Satisfaction and Loyalty decreased when the mediator Trust was introduced, proving the existence of the mediation role of Trust.

The strength of the mediating role of Trust was evaluated by calculating VAF (Variance accounted for), as suggested by Hair et al. (2013). A vaf value below $20 \%$ means that the role of the mediator is small. Since 
Table 3 Factor Structure of Modified RURALQUAL Model

\begin{tabular}{|c|c|c|c|}
\hline Factor & Item & (1) & (2) \\
\hline \multirow{10}{*}{$\begin{array}{l}\text { Safety, tourist } \\
\text { relations and } \\
\text { rural } \\
\text { surrounding }\end{array}$} & The rural establishment is fitted with all necessary safety measures. & $5.32(1.58)$ & 0.792 \\
\hline & $\begin{array}{l}\text { The RE observes safety measures during excursions and complementary activities } \\
\text { offered. }\end{array}$ & $5.20(1.53)$ & 0.820 \\
\hline & Staff give us good advice regarding the gastronomy of the place. & $5.50(1.33)$ & 0.811 \\
\hline & All areas are well indicated with signs. & $5.23(1.56)$ & 0.872 \\
\hline & The communication (access) routes are well indicated with signs. & $5.45(1.30)$ & 0.865 \\
\hline & The clients are integrated in the region's rural lifestyle. & $5.30(1.48)$ & 0.873 \\
\hline & Staff give us good advice regarding complementary activities that are available. & $5.65(1.21)$ & 0.800 \\
\hline & Typical gastronomy of the region is included on the menu. & $5.64(1.29)$ & 0.781 \\
\hline & $\begin{array}{l}\text { In the surrounding region there are fairs, local festivities, and other aspects of } \\
\text { cultural interest. }\end{array}$ & $5.62(1.29)$ & 0.626 \\
\hline & Staff at our disposal know the traditions, celebrations and history of the place. & $5.64(1.21)$ & 0.734 \\
\hline \multirow{6}{*}{$\begin{array}{l}\text { Tangibility } \\
\text { and basic } \\
\text { demand }\end{array}$} & The lodging is placed in a calm place. & $6.28(0.89)$ & 0.709 \\
\hline & $\begin{array}{l}\text { Internal decoration (furniture, ceilings, lighting, floors, etc.) is pleasant, simple, } \\
\text { homey and in harmony with the rural surroundings. }\end{array}$ & $6.08(1.02)$ & 0.796 \\
\hline & $\begin{array}{l}\text { External decoration (facade, gardens, etc.) is attractive and in harmony with the } \\
\text { rural surroundings. }\end{array}$ & $6.11(1.00)$ & 0.749 \\
\hline & The rural lodging facilities are in a good state. & $5.96(1.95)$ & 0.667 \\
\hline & The lodging architecture has the regional style. & $5.91(1.07)$ & 0.733 \\
\hline & The lodging is placed in the area of great natural beauty. & $5.95(1.04)$ & 0.711 \\
\hline \multirow{4}{*}{$\begin{array}{l}\text { Price and } \\
\text { reservations }\end{array}$} & Room reservation is easy to do. & $5.82(1.19)$ & 0.832 \\
\hline & $\begin{array}{l}\text { The reservations are confirmed in the most convenient way for client, other } \\
\text { information of interest is sent back too (e.g. access map). }\end{array}$ & $5.72(1.20)$ & 0.844 \\
\hline & Arrival schedules are established but they are quite flexible. & $5.76(1.19)$ & 0.870 \\
\hline & Price is in accordance with the service provided. & $5.86(1.21)$ & 0.775 \\
\hline \multirow[t]{4}{*}{ Professionalism } & The clients are treated cordially and affably. & $6.07(1.00)$ & 0.748 \\
\hline & The rural lodging foods are well presented and flavoursome. & $5.93(1.03)$ & 0.768 \\
\hline & Personalized attention is provided to each client. & $5.84(1.16)$ & 0.738 \\
\hline & The rural lodging employees have a clean, neat appearance. & $6.07(0.95)$ & 0.798 \\
\hline \multirow[t]{3}{*}{ Empathy } & The rural establishment has staff that speak other languages. & $5.99(1.14)$ & 0.812 \\
\hline & Staff go out of their way to make sure customers understand them. & $6.02(1.06)$ & 0.861 \\
\hline & The rural establishment attends to customers individually (not as a group). & $5.87(1.17)$ & 0.830 \\
\hline
\end{tabular}

Notes Column headings are as follows: (1) mean (standard deviation), (2) factor loading.

the calculated VAF value was $\mathbf{1 4 . 2 1} \%$ it can be concluded that the mediator part of the relation between satisfaction and loyalty is very small.

Based on the given results, the Hypothesis $\mathrm{H} 1$ There is a positive relationship between service quality and customer satisfaction, $\mathrm{H} 2$ There is a positive relationship between customer satisfaction and customer loyalty, and $\mathrm{H} 3$ There is a positive mediating effect of trust on the satisfaction and loyalty relationship are supported. 
Table 4 The Results of Quantitative Analysis of the Constructs Satisfaction, Trust and Loyalty

\begin{tabular}{|c|c|c|c|}
\hline Construct & Item & $(1)$ & (2) \\
\hline \multirow[t]{8}{*}{ Satisfaction } & The stay here has been very satisfactory. & $5.83(0.923)$ & 0.727 \\
\hline & The rural lodging satisfies my necessities. & $5.94(1.020)$ & 0.825 \\
\hline & The rural lodging facilities are worthy of highlighting. & $5.69(1.087)$ & 0.807 \\
\hline & I find the lodging personnel pleasant. & $6.13(0.980)$ & 0.723 \\
\hline & $\begin{array}{l}\text { I am happy with cultural, sport and recreational activities provided by the lodging } \\
\text { and surrounding region. }\end{array}$ & $5.51(1.130)$ & 0.736 \\
\hline & The rural lodging delivers the service that I expected to receive. & $5.72(1.208)$ & 0.838 \\
\hline & The rural lodging delivers an excellent service. & $5.52(1.263)$ & 0.825 \\
\hline & In general, my experience here is positive. & $6.19(1.021)$ & 0.789 \\
\hline \multirow[t]{3}{*}{ Trust } & Here the promise is fulfilled. & $6.04(0.960)$ & 0.901 \\
\hline & I trust the service delivered by the rural lodging. & $6.16(0.909)$ & 0.921 \\
\hline & Here exists a real concern for my well-being. & $5.75(1.454)$ & 0.840 \\
\hline \multirow[t]{6}{*}{ Loyalty } & I will speak well about this lodging service to other people. & $5.66(1.009)$ & 0.747 \\
\hline & I will recommend the lodging if someone asks for my advice. & $5.61(1.061)$ & 0.789 \\
\hline & I will encourage my friends and relatives to visit this rural lodging. & $5.06(1.146)$ & 0.725 \\
\hline & In my next vacation I intend to return to this lodging. & $5.06(1.649)$ & 0.854 \\
\hline & I would come continually even if the lodging price increases. & $4.84(1.618)$ & 0.838 \\
\hline & $\begin{array}{l}\text { I prefer to pay a bigger price here than in other rural lodgings for the advantages } \\
\text { that I receive in this rural lodging. }\end{array}$ & $4.66(1.474)$ & 0.803 \\
\hline
\end{tabular}

Notes Column headings are as follows: (1) mean (standard deviation), (2) factor loading.

Table 5 Reliability, Validity and Prediction Attributes of the Modified RURALQUAL Model

\begin{tabular}{|c|c|c|c|c|c|c|}
\hline Construct & (1) & $(2)$ & (3) & (4) & (5) & (6) \\
\hline Service quality & 0.951 & 0.955 & - & 0.997 & 0.421 & 5.801 \\
\hline 1. Professionalism & 0.762 & 0.848 & 0.583 & - & & 5.980 \\
\hline 2. Price and reservations & 0.850 & 0.899 & 0.690 & - & & 5.788 \\
\hline 3. Tangibility and basic demand & 0.823 & 0.871 & 0.532 & - & & 6.056 \\
\hline 4. Empathy & 0.782 & 0.873 & 0.697 & - & & 5.964 \\
\hline 5. Safety, tourist relations and rural surrounding & 0.937 & 0.947 & 0.641 & - & & 5.462 \\
\hline Satisfaction & 0.910 & 0.928 & 0.616 & 0.583 & 0.352 & 5.830 \\
\hline Trust & 0.865 & 0.918 & 0.789 & 0.548 & 0.432 & 6.022 \\
\hline Loyalty & 0.882 & 0.911 & 0.630 & 0.587 & 0.351 & 5.201 \\
\hline
\end{tabular}

Notes Column headings are as follows: (1) reliability Cronbach Alpha, (2) composite reliability, (3) average variance extracted, (4) $R^{2}$ (predictive power of the model), (5) $Q^{2}$ (predictive relevance of the model), (6) latent variable index.

\section{Conclusions, Limitations, and Further Research} Rural tourism has been proven to be a very successful development strategy for rural areas. Competitive rural tourism requires continuous improvement of service quality and integration of different local resources and activities. However, in some cases, this is 


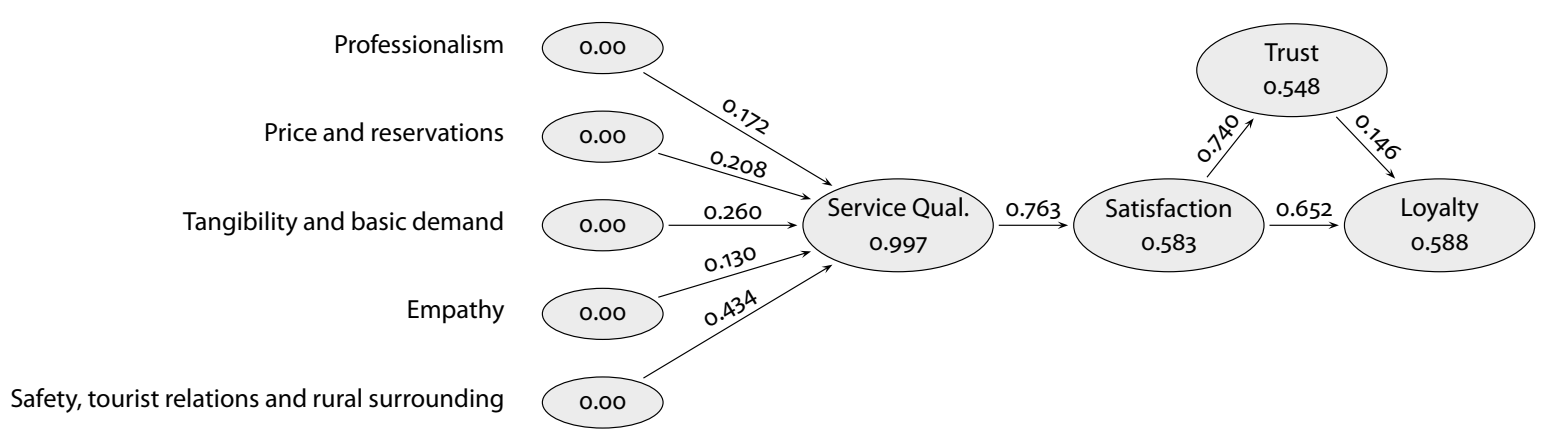

Figure 2 Structural Equation Results

Table 6 Hypothesis Test

\begin{tabular}{llrrrr}
\hline Relation & & $(1)$ & $(2)$ & $(3)$ & $(4)$ \\
\hline Direct & Empathy $\rightarrow$ Service quality & 0.130 & 12.378 & $* * *$ & 0.000 \\
& Professionalism $\rightarrow$ Service quality & 0.172 & 14.187 & $* * *$ & 0.000 \\
& Price and reservationa $\rightarrow$ Service quality & 0.208 & 19.077 & $* * *$ & 0.000 \\
& Safety, tourist relations and rural surrounding $\rightarrow$ Service quality & 0.434 & 20.937 & $* * *$ & 0.000 \\
& Tangibility and basic demand $\rightarrow$ Service quality & 0.260 & 16.010 & $* * *$ & 0.000 \\
& Service quality $\rightarrow$ Satisfaction & 0.763 & 28.914 & $* * *$ & 0.000 \\
& Satisfaction $\rightarrow$ Loyalty (direct relation) & 0.761 & 26.352 & $* * *$ & 0.000 \\
\hline Indirect & Satisfaction $\rightarrow$ Trust & 0.740 & 19.162 & $* * *$ & 0.000 \\
& Trust $\rightarrow$ Loyalty & 0.146 & 2.279 & $* *$ & 0.023 \\
& Satisfaction $\rightarrow$ Loyalty & 0.652 & 12.254 & $* * *$ & 0.000 \\
\hline
\end{tabular}

Notes Column headings are as follows: (1) path coeff., (2) $t$-value, (3) significance level ( $\left.{ }^{* *} p<0.05,{ }^{* * *} p<0.01\right),(4) p$-value.

not sufficiently addressed as most of the rural tourism businesses are small, family-managed rural units often lacking a professional management approach and strategic marketing activities. Better understanding of the key service quality attributes could increase tourist satisfaction and lead to tourist loyalty that manifests as an intention to recommend, to return, and even to pay more.

The results of this study have confirmed that the perceived service quality is formed by 5 dimensions: Professionalism, Price and reservations, Tangibility and basic demand, Empathy, and Safety, tourist relations and rural surrounding. The overall average service quality score is relatively high. Research results indicate that rural tourism managers should pay more attention to the service quality attributes that re- fer to safety measures, including tourists in the local lifestyle, and integration of local activities and events in the tourist offer. Generally, results lead to the conclusions that rural tourism managers and owners paid more attention to the technical service quality elements, but in the future, they need to pay more attention to the soft service quality elements in order to improve overall tourist experience.

Although the mean scores for the Service quality, Satisfaction and Trust are quite high, the mean score for Loyalty as a consequent is lower. This can partly be explained by the motive of novelty where tourists like to visit different tourist destinations rather than to return to the same one. On the other hand, this can serve as useful information to rural tourism managers in rethinking marketing strategies. 
The focus of this study was to examine the relationship between Service quality, Satisfaction and Loyalty and to assess the role of Trust as a mediator. The results of the PLS SEM analysis show that there is a strong significant positive relationship between Service quality and Satisfaction. A similar conclusion has been proven by the study of Loureiro and Kastenholz (2011) and Loureiro and Gonzalez (2008) who applied the RURALQUaL model in Portugal.

Furthermore, it is proven that Satisfaction is an antecedent of Loyalty, although the strength of that relationship is a bit lower than between Service quality and Satisfaction. Due to novelty, not all satisfied tourists tend to return to the same rural tourism unit. The conclusion follows the conceptual background of the relationship Service Quality-Satisfaction-Loyalty. The positive and significant relationship between Service quality, Satisfaction and Loyalty in rural tourism was also confirmed by Loureiro and Gonzalez (2008) and Loureiro and Kastenholz (2011).

The evaluation of the role of Trust as a mediator shows that the mediating role of Trust on the Satisfaction-Loyalty relationship is positive and significant but rather small. Therefore, the hypothesis $\mathrm{H} 3$ is supported. The same results have been proven by the study of Loureiro and Gonzalez (2008), Setó-Pamies (2012), and Lin et al. (2018). The study of Loureiro (2013), conducted on banking services, did not confirm the existence of a relationship between Trust and Loyalty.

In order to understand and meet tourists' expectations and provide a high level of service quality and tourist satisfaction, and finally to increase the rate of loyal tourists, rural tourism managers should periodically use the modified RURALQUAL instrument as a guide for future development actions.

There are some limitations of this study that should be considered in future studies. The main limitation of the research is a relatively small sample size that affects the generalisation of research results. This study included only the actual tourists, but in the following studies it would be useful to evaluate statements of potential tourists. Also, this study was conducted in a geographically limited tourist destination. Future studies could be conducted in different rural tourist regions and in other selective forms of rural tourism. It would be useful to measure service quality solely, in particular rural tourist destinations, in order to obtain more specific results. Since rural tourism is broadly defined and encompasses a wide range of activities, future research should be conducted for specific activities or accommodation types such as diffuse hotels. Also, some other constructs should be considered for inclusion in the model, like, for example, Destination Image or Tourist Experience.

\section{References}

Albacete-Saez, C. A., Fuentes-Fuentes, M. M., \& LlorénsMontes, F. J. (2007). Service quality measurement in rural accommodation. Annals of Tourism Research, 34(1), 45-65.

Ali, F., Rasoolimanesh, S. M., Sarstedt, M., Ringle, C. M., \& Ryu, K. (2018). An assessment of the use of partial least squares structural equation modeling (PLS-SEM) in hospitality research. International Journal of Contemporary Hospitality Management, 3o(1), 514-538.

Almeida-Santana, A., \& Moreno-Gil, S. (2018). Understanding tourism loyalty: Horizontal vs. destination loyalty. Tourism Management, 65, 245-255.

Babakus, E., \& Boller, G. W. (1992). An empirical assessment of the SERVQUAL scale. Journal of Business research, 24(3), 253-268.

Baker, D. A., \& Crompton, J. L. (2000). Quality, satisfaction and behavioural intentions. Annals of Tourism Research, 27(3), 785-804.

Bigne, J. E., Martinez, C., Miquel, M. J., \& Andreu, L. (2003). SERVQUAL reliability and validity in travel agencies. Annals of Tourism Research, 30(1), 258-262.

Chatzigeorgiou, C., \& Simeli, I. (2017). Perception of service quality in agrotourism accommodations: Impact on guest loyalty and re-visit intentions. Journal of Tourism, 3(1), 33-41.

Chen, C. F., \& Tsai, D. (2007). How destination image and evaluative factors affect behavioural intentions? Tourism management, 28(4), 1115-1122.

Cheng, S. (2011). Comparisons of competing models between attitudinal loyalty and behavioral loyalty. International Journal of Business and Social Science, 2(10), 149-166.

Choi, H., Ann, S., Lee, K. W., \& Park, D. B. (2018). Measuring service quality of rural accommodations. Sustainability, $10(2), 443$.

Cronin Jr, J. J., \& Taylor, S. A. (1994). SERvPERF versus SERVQUAL: Reconciling performance-based and per- 
ceptions-minus-expectations measurement of service quality. Journal of marketing, 58(1), 125-131.

Fotiadis, A., \& Vassiliadis, C. (2010). Rural tourism service quality in Greece. E-review of Tourism Research, 8(4), 69-84.

Grgić, I., Hadelan, L., Krznar, S., \& Zrakić, M. (2017). Could rural tourism revitalize rural areas in Croatia? Agroeconomia Croatica, 7(1), 98-108.

Gronroos, C. (1984). A service quality model and its marketing implications. European Journal of Marketing, 18(4), $36-44$.

Hair, J. F., Jr., Hult, G. T. M., Ringle, C., \& Sarstedt, M. (2013). A primer on partial least squares structural equation modeling (PLS-SEM). Sage.

Hair, J. F., Risher, J. J., Sarstedt, M., \& Ringle, C. M. (2019). When to use and how to report the results of PLS-SEM. European Business Review, 31(1), 2-24.

Hair, J. F., Jr., Sarstedt, M., Hopkins, L., \& Kuppelwieser, V. G. (2014). Partial least squares structural equation modeling (PLS-SEM). European Business Review, 26(2), 106121.

Henseler, J., Ringle, C. M., \& Sinkovics, R. R. (2009). The use of partial least squares path modeling in international marketing. In R. Sinkovics \& P. Ghauri (Eds.), New challenges to international marketing (pp. 277-319). Emerald.

Hansen, K. V. (2014). Development of SERVQUAL and DINESERV for measuring meal experiences in eating establishments. Scandinavian Journal of Hospitality and Tourism, 14(2), 116-134.

Hurst, J. L., Niehm, L. S., \& Littrell, M. A. (2009). Retail service dynamics in a rural tourism community. Managing Service Quality: An International Journal, 19(5), 511-540.

Kastenholz, E., Carneiro, M. J., Marques, C. P., \& Loureiro, S. M. C. (2018). The dimensions of rural tourism experience impacts on arousal, memory, and satisfaction. Journal of Travel \& Tourism Marketing, 35(2), 189-201.

Katircioglu, S. T., Mehtap-Smadi, S., Kilinç, C., \& Ünlücan, D. (2012). Service quality and university students' satisfaction on the travel agencies: An empirical investigation from Northern Cyprus. International Journal of Quality and Service Sciences, 4(3), 299-311.

Kim, A. K., \& Brown, G. (2012). Understanding the relationships between perceived travel experiences, overall satisfaction, and destination loyalty. Anatolia, 23(3), 328-347.

Kim-Soon, N., Rahman, A., \& Visvalingam, L. (2014). sE RVQUAL: Can it be used to differentiate guest's perception of service quality of 3 star from a 4 star hotel. International Business Research, 7(7), 37-47.

Ladhari, R. (2009). A review of twenty years of SERVQUAL research. International Journal of Quality and Service Sciences, 1(2), 172-198.

Lewis, B. R., \& Mitchell, V. W. (1990). Defining and measuring the quality of customer service. Marketing Intelligence \& Planning, 8(6), 11-17.

Lin, L., Osman, Z., \& Wang, S. (2018). Indirect effect of trust on customer satisfaction and customer loyalty in Malaysian airline industry. Journal of Economics and Business, 1(2), 134-142.

Loureiro, S. M. C. (2013). The effect of perceived benefits, trust, quality, brand awareness/associations and brand loyalty on internet banking brand equity. International Journal of Electronic Commerce Studies, 4(2), 139-158.

Loureiro, S. M. C., \& González, F. J. M. (2008). The importance of quality, satisfaction, trust, and image in relation to rural tourist loyalty. Journal of Travel \& Tourism Marketing, 25(2), 117-136.

Loureiro, S. M. C., \& Kastenholz, E. (2011). Corporate reputation, satisfaction, delight, and loyalty towards rural lodging units in Portugal. International Journal of Hospitality Management, 30(3), 575-583.

Marković, S., \& Raspor, S. (2010). Measuring perceived service quality using SERVQUAL: A case study of the Croatian hotel industry. Management, 5(3), 195-209.

Marković, S. (2004). Measuring service quality in the Croatian hotel industry: A multivariate statistical analysis. Our Economy, 50(1), 27-35.

Marković, S., \& Raspor Janković, S. (2013). Exploring the relationship between service quality and customer satisfaction in Croatian hotel industry. Tourism and Hospitality Management, 19(2), 149-164.

Marković, S., Raspor, S., \& Šegarić, K. (2010). Does restaurant performance meet customers' expectations? An assessment of restaurant service quality using a modified DINESERV approach. Tourism and Hospitality Management, 16(2), 181-195.

Nam, J. H., \& Lee, T. J. (2011). Foreign travellers' satisfaction with traditional Korean restaurants. International Journal of Hospitality Management, 3o(4), 982-989.

Oh, H., \& Kim, K. (2017). Customer satisfaction, service quality, and customer value: Years 20oo-2015. International Journal of Contemporary Hospitality Management, 29(1), 2-29.

Oliver, R. L. (1999). Whence consumer loyalty? Journal of marketing, 63 (Special issue), 33-44.

Osman, Z., \& Sentosa, I. (2013a). Influence of customer satisfaction on service quality and trust relationship in Malaysian rural tourism. Business and Management Quarterly Review, 4(2), 12-25. 
Osman, Z., \& Sentosa, I. (2013b). Mediating effect of customer satisfaction on service quality and customer loyalty relationship in Malaysian rural tourism. International Journal of Economics Business and Management Studies, 2(1), 25-37.

Ounsri, K., \& Thawesaengskulthai, N. (2019). Hotel service quality factors among different cultures. In 2019 IEEE 6th International Conference on Industrial Engineering and Applications (ICIEA) (pp. 306-312). IEEE.

Parasuraman, A., Zeithaml, V. A., \& Berry, L. (1985). A conceptual model of service quality and its implications for future research. Journal of Marketing, 49(4), 41-50.

Peãa, A. I. P., Jamilena, D. M. F., \& Molina, M. Á. R. (2012). The perceived value of the rural tourism stay and its effect on rural tourist behaviour. Journal of Sustainable Tourism, 20(8), 1045-1065.

Rajaratnam, S. D., Nair, V., Pahlevan Sharif, S., \& Munikrishnan, U. T. (2015). Destination quality and tourists' behavioural intentions: Rural tourist destinations in Malaysia. Worldwide Hospitality and Tourism Themes, $7(5), 463-472$.

Rajesh, R. (2018). Impact of service quality on customer satisfaction of travel agency in Kerala. International Journal of Advances in Scientific Research and Engineering, 4(4), 96-101.

Rozkee, R. M., Jaafar, N., \& Jalal, H. A. (2016). Regression modelling analysis of the relationship between service quality and customer satisfaction: A case of tourist agricultural farm. International Journal of Modelling in Operations Management, 6(1-2), 33-46.

Saneva, D., \& Chortoseva, S. (2018). Service quality in restaurants: Customers' expectation and customers' perception. SAR Journal, 1(2), 47-52.
Setó-Pamies, D. (2012). Customer loyalty to service providers: Examining the role of service quality, customer satisfaction and trust. Total Quality Management \& Business Excellence, 23(11-12), 1257-1271.

Shahin, A., \& Janatyan, N. (2011). Estimation of customer dissatisfaction based on service quality gaps by correlation and regression analysis in a travel agency. International Journal of Business and Management, 6(3), 99-108.

Sirdeshmukh, D., Singh, J., \& Sabol, B. (2002). Consumer trust, value, and loyalty in relational exchanges. Journal of Marketing, 66(1), 15-37.

Su, L., \& Fan, X. (2011, June). A study on the relationships between service quality, satisfaction, trust and loyalty among rural tourism. In Proceedings of the 8th International Conference on Service Systems and Service Management (ICSSSM) (pp. 1-6). IEEE.

Um, S., Chon, K., \& Ro, Y. (2006). Antecedents of revisit intention. Annals of Tourism Research, 33(4), 1141-1158.

Yieh, K., Chiao, Y. C., \& Chiu, Y. K. (2007). Understanding the antecedents to customer loyalty by applying structural equation modeling. Total Quality Management \& Business Excellence, 18(3), 267-284.

Zeithaml, V. A. (200o). Service quality, profitability, and the economic worth of customers: What we know and what we need to learn. Journal of the Academy of Marketing Science, 28(1), 67-85.

Zeithaml, V. A. \& Bitner, M. J. (2003). Services marketing: Integrating customer focus across the firm. McGraw Hill. 



\section{Navidezna resničnost $v$ turizmu: je dovolj »resnična«?}

Marion Rauscher, Andreas Humpe in Lars Brehm

Tehnologija navidezne resničnosti v turističnem sektorju postaja vse bolj priljubljena. Do sedaj se je tehnologija raziskovala predvsem pri uporabi za trženja destinacij. Obratno se navidezna resničnost omenja tudi kot sredstvo za omejevanje ali zmanjševanje števila turistov na določeni znamenitosti ali destinaciji. V tem pogledu se navidezna resničnost obravnava kot nadomestilo dejanskega potovanja in ravno to vprašanje obravnava članek, in sicer vidik možnosti uporabe tehnologije za prenos resničnih življenjskih izkušenj v digitalni svet. S kvalitativno metodo smo raziskovali vedenje in izkustvo uporabnikov ob srečanju s potovanji oz. z obiskom znamenitosti v navidezni resničnosti, da bi bolje razumeli značilnosti, ki vplivajo na sprejemanje tehnologije. Uporabljena je bila strukturna analiza podatkov, kodiranje pa je bilo izvedeno na podlagi t. i. »združene teorije sprejetosti in uporabe tehnologij ( (angl. Unified Theory of Acceptance and Use of Technology - U TAU T). Interpretacija rezultatov poteka v kvalitativnem okviru. Ugotavljamo, da je dojemanje užitka pomemben dejavnik pri sprejemanju tehnologije navidezne resničnosti, medtem ko se zdi, da so olajševalne okoliščine in pričakovani izidi zanjo ovira. Dojeta uporabnost je kot taka ocenjena precej sporno. Čeprav tehnologija ni sprejeta kot nadomestilo za običajno počitniško potovanje, zlasti za popotnike, ki uživajo v aktivnih počitnicah ali cenijo družabne interakcije, pa je bila prepoznana kot alternativa za posebne priložnosti, kot so kratki oddihi od vsakdanjega življenja ali krajši mestni izleti. Na splošno ugotavljamo, da ob ustrezni implementaciji tehnologija ni koristna le za zmanjšanje koncentracije obiskovalcev na turističnih točkah ali za zmanjšanje negativnih vidikov zaradi pogostih potovanj, ampak bi se lahko nadalje uporabila tudi za znamenitosti in kraje, ki jih obiskovalci ne dosežejo oz. obiščejo, ker so predaleč, predragi, nedostopni, nevarni ali preobčutljivi za obisk.

Ključne besede: virtualna resničnost, turizem, nadomestitev potovanj, sprejetje tehnologije, model U TAU T

Academica Turistica, 13(2), 127-138

\section{Učinki imidža destinacije na turistično zadovoljstvo: Primer plavajoče tržnice Don-Wai v mestu Nakhon Pathom na Tajskem}

Napaporn Janchai, Glenn Baxter, and Panarat Srisaeng

Cilj te študije je bil analizirati vpliv imidža plavajoče tržnice kot destinacije na zadovoljstvo turistov. Jedro vprašalnika zaprtega tipa so tvorili atributi, ki so bili identificirani v literaturi o dejavnikih zadovoljstva obiskovalcev turistične destinacije. Vzorec je obsegal 200 turistov, ki so januarja 2018 obiskali plavajočo tržnico Don Wai Nakhon Pathoma. Za empirično preverbo štirih hipotez je bila uporabljena regresijska analiza. Rezultati so pokazali, da so najpomembnejši dejavniki, ki vplivajo na zadovoljstvo turistov: edinstvenost narave, edinstvenost zgodovine in edinstvenost turističnih proizvodov. Arhitekturni dejavnik ni izkazal statistično značilnega vpliva na zadovoljstvo turistov. To je prva študija, ki je empirično obravnavala vplive omenjenih dejavnikov na zadovoljstvo turistov ob obisku plavajoče tržnice kot turistične 
destinacije. Prikazana spoznanja lahko sorodnim destinacijam pridejo prav za boljše razumevanje pomena posameznih dejavnikov zadovoljstva turistov.

Ključne besede: imidž destinacije, plavajoča tržnica, menedžment $\mathrm{v}$ turizmu, zadovoljstvo turistov, Tajska

Academica Turistica, 13(2), 139-151

\section{Ali je mednarodna rast turizma podprta z rastjo turistične potrošnje?} Helena Nemec Rudež

Rast turističnega povpraševanja $\mathrm{v}$ obdobju med letoma 2000 in 2016 je izračunana za 25 evropskih držav ob uporabi različnih kazalcev turizma. Število prihodov turistov in skupna turistična potrošnja se $\mathrm{v}$ tem obdobju povečujeta. Turistični prilivi na prihod turista $\mathrm{v}$ tekočih cenah kažejo na blago rast $\mathrm{v}$ večini preučevanih držav, medtem ko turistični prilivi na prihod turista $\mathrm{v}$ stalnih cenah bolj ali manj stagnirajo $v$ razponu med $-2 \%$ in $+2 \%$ in izkazujejo še močnejši upad v nekaterih državah južne in vzhodne Evrope. Zaključimo, da rast turizma pretežno poganja naraščajoče število prihodov turistov in ne potrošnja na prihod turista.

Ključne besede: mednarodni turizem, rast povpraševanja, evropske države Academica Turistica, 13(2), 153-156

\section{Stebri mestne prostorske občutljivosti in njihova integracija turističnih poti Melita Rozman Cafuta in Boštjan Brumen}

Veliko mest širom sveta ima ustrezne osnovne pogoje za razvoj urbanega turizma. Nekatere lokacije, ki so del standardne ponudbe, so sicer navidezno pomembne za lokalno turistično ponudbo, a niso v skladu s sodobnimi zahtevami sektorja. Zato si turistične organizacije prizadevajo za načrtovanje najboljših možnih turističnih poti z ogledi znamenitosti, ki so tretirane kot najboljše turistične točke. $V$ današnji sodobni turistični industriji uporaba zgolj intuitivnega pristopa ne zadostuje več. V prispevku je predstavljen inovativen pristop, ki omogoča prepoznavanje pomembnih urbanih območij in lokacij, ki jih je smotrno vključiti v turistično ponudbo mesta. Izvedena empirična raziskava je temeljila na analitični metodi mentalnega kartiranja. Vzorec anketiranja je obsegal 200 oseb, za lokacijo raziskave pa je bilo izbrano mesto Maribor (Slovenija, EU). Anketiranci so po spominu risali zemljevid mesta. Zemljevid so risali dvakrat, kot zemljevid mesta podnevi in kot zemljevid mesta ponoči. Pridobljeni grafični rezultati odražajo posameznikovo subjektivno prostorsko predstavo in način mišljenja. Ugotovili smo, da so nekatere točke oz. lokacije v mestu še posebej pomembne in opažene. Te točke smo poimenovali »stebri prostorske občutljivosti« (angl. Pillars of Spatial Sensitivity) - pss-lokacije. Te lokacije so prepoznane kot ustrezne za integracijo $\mathrm{v}$ turistične poti $\mathrm{z}$ ogledi urbanih znamenitosti. Pri obdelavi rezultatov je bilo izpostavljenih 34 bolj ali manj pogosto opaženih Psslokacij. 32 lokacij je imelo različno stopnjo pojavnosti med dnevom in nočjo. Tako se je potrdila domneva, da spreminjanje prostorskih okoliščin vpliva na zaznavanje 
in uporabo mestnega prostora. Rezultati pričujoče raziskave kažejo, da je prostorska občutljivost turistov odvisna od časovne komponente. Turistične oglede urbanih znamenitosti lahko planiramo v skladu s časom.

Ključne besede: urbani turizem, stebri prostorske občutljivosti, mentalni zemljevidi, lokacije turističnih znamenitosti

Academica Turistica, 13(2), 157-166

\section{Duhovna inteligenca in poslovno okolje}

Fadil Mušinović

Prispevek poveže dva razvojno naravnana koncepta, duhovno inteligentnost in poslovne sisteme, ki sta sestavljena iz štirih elementov. Duhovno inteligentnost po Kingu (2008) sestavljajo faktorji kritično eksistenčno razmišljanje, ustvarjanje osebnega pomena, transcendentno zavedanje in širitev stanj zavesti. Poslovni sistemi se po V. Bulc (2006) razvijajo preko štirih stopenj, in sicer od delovnega okolja prek učečega in mislečega okolja do ozaveščenega okolja. Namen raziskave je bil ugotoviti, ali so faktorji duhovne inteligentnosti povezani z razvojnimi stopnjami poslovnih sistemov in ali se $\mathrm{v}$ različnih razvojnih stopnjah poslovnih sistemov faktorji duhovne inteligentnosti razlikujejo. Zbiranje empiričnih podatkov je bilo izvedeno elektronsko, s pomočjo sestavljenega vprašalnika, ki je bil razdeljen $\mathrm{v}$ različna poslovna okolja. Sodeloval je 601 zaposlen posameznik. Rezultati so pokazali pozitivne korelacije med faktorji duhovne inteligentnosti ter učečim, mislečim in ozaveščenim okoljem, ne pa tudi korelacij z delovnim okoljem. V različnih razvojnih stopnjah poslovnih sistemov so se pokazale določene razlike med faktorji duhovne inteligentnosti. Raziskava je še pokazala, da glede duhovne inteligentnosti in poslovnih okolij obstajajo razlike med spoloma, razlike po delovnih izkušnjah in razlike po stopnji izobrazbe.

Ključne besede: duhovna inteligentnost, evolucija, poslovna okolja, posameznik, razvoj

Academica Turistica, 13(2), 167-177

\section{Poklicna in organizacijska pripadnost v sektorju gostoljubnosti}

Marjetka Rangus, Srđan Milošević, Iva Škrbić, Bojana Radenković-Šošić, Jože Hočevar in Mladen Knežević

Namen raziskave je preveriti, ali dva različna profila pripadnosti zaposlenih vplivata na kakovost storitev $\mathrm{v}$ turistični industriji v Sloveniji in v Srbiji ter kako se lahko ugotovljene razlike prenašajo $\mathrm{v}$ delovanje $\mathrm{v}$ sektorju gostoljubja in turizma. Za potrebe študije smo $\mathrm{z}$ uporabo kombinacijo kvalitativnega in kvantitativnega pristopa razvili dva nova instrumenta za merjenje pripadnosti zaposlenih. Prvi instrument smo razvili na podlagi kratkih strukturiranih intervjujev z zaposlenimi v turistični industriji. Na podlagi statistične metode smo določili dva faktorja, ki določata dva različna profila pripadnosti, z metodo grozdenja pa smo ugotovili štiri dimenzije, ki 
vplivajo na oblikovanje profilov pripadnosti. Drugi instrument smo razvili na podlagi obstoječih ocenjevalnih obrazcev za zaposlene v sektorju gostoljubnosti in turizma ter s pomočjo vodilnega in srednjega menedžmenta v hotelih. Ugotovitve raziskave kažejo, da v sektorju gostoljubnosti in turizma obstaja majhen delež poklične pripadnosti med zaposlenimi, razlike med zaposlenimi pa so opazne pri razvrščanju vrednot, povezanih z delom. Ugotovitve lahko pomagajo menedžerjem pri načrtovanju in organiziranju človeških virov ter tudi pri načrtovanju nadaljnjega razvoja politik na področju menedžmenta človeških virov v podjetjih. Izvirni prispevek študije predstavlja novo znanje o razvrščanju vrednot, povezanih z delom, in znanje o percepciji kakovosti dela med zaposlenimi v sektorju gostoljubnosti. Ugotovitve študije so uporabne pri načrtovanju in organiziranju človeških virov in tudi pri načrtovanju nadaljnjega razvoja politik na področju menedžmenta človeških virov v podjetjih. Študija prinaša tudi nova spoznanja o različnih tipih pripadnosti med zaposlenimi.

Ključne besede: turizem, sektor gostoljubnosti, organizacijska pripadnost, poklicna pripadnost, menedžment človeških virov

Academica Turistica, 13(2), 179-191

\section{Analiza uporabe slovenskih hotelskih spletnih strani} Mitja Petelin in Dejan Križaj

Namen raziskave je dobiti vpogled $\mathrm{v}$ opremljenost spletnih mest slovenskih hotelov in na podlagi zastavljenih kriterijev ugotoviti, katera spletna mesta so bolj izpopolnjena kot druga. Določili smo kriterije, pripravili seznam vseh štiri- in petzvezdičnih hotelov v Sloveniji in jih segmentirali s pomočjo multivariantne analize. Spletna mesta hotelov, ki smo jih analizirali leta 2017, se na prvi pogled sicer razlikujejo, s primerjavo njihovih vsebin pa smo prišli do zaključka, da večjih statistično pomembnih razlik ni. Pomembno odkritje raziskave spada na področje varnosti večine analiziranih spletnih mest - le-ta je namreč zelo pomanjkljiva, navedbe o njej pa so včasih tudi zavajajoče. Potencial interaktivnosti in igrifikacije spletnih mest pri veliki večini kljub različnim priporočilom strokovnjakov in znanstvenikov ostaja neizkoriščen.

Ključne besede: spletno mesto, hotel, spletna mesta slovenskih hotelov, varnost Academica Turistica, 13(2), 193-200

\section{Motivacije za potovanje kot merilo v procesu segmentacije trga wellness turizma \\ Ana Težak Damijanić}

Namen prispevka je raziskati potovalne motivacije kot merila v procesu segmentacije wellness turistov. Podatki so bili zbrani prek vprašalnika na vzorcu turistov, ki so se nastanili v enem od 15 wellness hotelov, ki se nahajajo $\mathrm{v}$ štirih regijah wellness turizma Republike Hrvaške. Raziskava je potekala od maja do junija 2013. Podatki so bili obdelani z uporabo enovariatne, bivariatne in multivariatne statistike. Za splošen opis vzorca je bila uporabljena univariatna statistika. Za preučevanje razlik med 
vzorci smo uporabili bivariativno analizo, za določitev dejavnikov, ki temeljijo na konstrukciji motivacije potovanja, in odkrivanje vzorcev pa smo uporabili multivariatno statistiko. Skupno je bilo ugotovljenih devet dejavnikov motivacije potovanja $\mathrm{z}$ uporabo teorije potovalnih motivov push in pull (trije dejavniki motivacije push in šest dejavnikov motivacije pull). Dejavniki motivacije push za potovanja so bili označeni kot zdravstveni trendi, sprostitev in nagrada ter novost; dejavniki motivacije pull, ki so povezani $z$ wellness turističnim produktom, so bili označeni kot osnovni wellness, nematerialni wellness in ekstra wellness, medtem ko so dejavniki motivacije pull, povezani s turistično destinacijo, označeni kot kulturna in naravna dediščina, zabava in rekreacija ter pokrajina. Trije vzorci so se pojavili z uporabo dejavnikov motivacije za potovanja kot meril segmentacije (visoki wellness, nematerialni wellness in manjši wellness vzorci). Sprostitev, infrastruktura wellnessa in naravni viri so pomembni dejavniki pri raziskavah wellness turizma. Kljub temu so dejavniki motivacije push in pull pomembne spremenljivke pri razlikovanju med segmenti.

Ključne besede: motivacija za potovanja, segmentacija trga, wellness turisti, kriteriji za segmentacijo

Academica Turistica, 13(2), 201-213

\section{Merjenje kakovosti storitev $\mathbf{v}$ podeželskem turizmu: uporaba modela RURALQUAL}

Suzana Marković and Jelena Kljaić Šebrek

Namen prispevka je oceniti kakovost storitev in njen vpliv na zadovoljstvo strank, njihovo zaupanje in nakupne namene $\mathrm{v}$ kontekstu podeželskega turizma $\mathrm{z}$ uporabo prilagojenega modela RURALQUAL, ki je bil razvit iz modela SERVQUAL. Raziskava je bila izvedena na vzorcu 307 podeželskih turistov na Hrvaškem. Za analizo razmerij med konstrukti je bil uporabljen model strukturnih enačb $\mathrm{z}$ delnimi najmanjšimi kvadrati (PLS-SEM). Prilagojeni model RURA LQUAL se je izkazal kot zanesljiv in veljaven večdimenzionalen merski instrument, ki vključuje 27 postavk, porazdeljenih v 5 dimenzij. Rezultati kažejo na statistično značilno pozitivno povezanost med kakovostjo storitve in zadovoljstvom kot dejavnikom lojalnosti. Dokazan je tudi šibek pomen zaupanja kot posrednika med zadovoljstvom in lojalnostjo. Rezultati raziskave kažejo, da ponudniki v podeželskem turizmu več pozornosti posvečajo otipljivim elementom kakovosti storitev, $\mathrm{v}$ prihodnje bi pa morali za izboljšanje celotne turistične izkušnje več pozornosti posvetiti tudi nematerialnim elementom kakovosti storitev. Smiselno je, da se prilagojen instrument RURALQUAL občasno uporabi kot orodje za uspešnejši razvoj podeželskega turizma.

Ključne besede: kakovost storitev, zadovoljstvo, zvestoba, podeželski turizem,

RURALQUAL, PLS-SEM

Academica Turistica, 13(2), 215-227 



\section{Instructions for Authors}

\begin{abstract}
Aim and Scope of the Journal
Academica Turistica - Tourism and Innovation Journal (AT-TIJ) is a peer-reviewed journal that provides a forum for the dissemination of knowledge on tourism and innovation from a social sciences perspective. It especially welcomes contributions focusing on innovation in tourism and adaptation of innovations from other fields in tourism settings.

The journal welcomes both theoretical and applicative contributions and encourages authors to use various quantitative and qualitative research methodologies. Besides research articles, the journal also publishes review articles, commentaries, reviews of books and conference reports. Purely descriptive manuscripts which do not contribute to the development of knowledge are not considered suitable.
\end{abstract}

\section{General Guidelines and Policy of the Journal}

Manuscripts are accepted in both American and British English; however, consistency throughout the paper is expected. All manuscripts are subject to an initial editorial screening for adherence to the journal style, for anonymity, and for correct use of English. As a result of this your paper will be either accepted for further consideration or returned for revision. To avoid unnecessary errors you are strongly advised to have your manuscript proofread.

Manuscripts should be organized in the following order: title, abstract, keywords, main text, acknowledgements, references, and appendixes (as appropriate).

Reviewing. Each manuscript, meeting the technical standards and falling within the aims and scope of the journal, will be subject to double-blind review by two reviewers. Authors can propose up to two reviewers for revision of their work and also up to two reviewers they would like to avoid.

The referees are chosen by the Editorial Board. Assessments by the referees will be presented anonymously to the author and, in the case of substantial reservations, the article, with the list of corrections needed, will be returned to the author for correction. The corrected copy of the article with the list of corrections on a separate page should be returned to the Editorial Board.

Permissions. Authors wishing to include figures, tables, or text passages that have already been published elsewhere, are required to obtain permission from the copyright owner(s) and to include evidence that such permission has been granted when submitting their papers. Any material received without such evidence will be assumed to originate from the authors.

Submission declaration. Submission of a manuscript implies that it has not been published previously (except in the form of abstract or as part of a published lecture or academic thesis), that it is not under consideration for publication elsewhere, that its publication is approved by all its authors and tacitly or explicitly by the responsible authorities where the work was carried out. The corresponding author should ensure that all appropriate co-authors and no inappropriate co-authors are included on the paper, and that all coauthors have seen and approved the final version of the paper and have agreed to its submission for publication.

Conflict of interest. All authors are requested to disclose any actual or potential conflict of interest including any financial, personal or other relationships with other people or organizations within three years of beginning the submitted work that could inappropriately influence, or be perceived to influence, their work.

\section{Manuscript Preparation}

Manuscripts should be prepared according to the style prescribed by the Publication Manual of the American Psychological Association (American Psychological Association, 2020; see also http://www.apastyle.org).

Language and style. The first author is fully responsible for the language and style in the context of the instructions. A good scientific standard command of grammar and style is expected.

Text formatting. Please, use the automatic page numbering function to number the pages. Use tab stops or other commands for indents, not the space bar. Use the table function, not spreadsheets, to make tables. Use 
the equation editor or MathType for equations. Whenever possible, use the sI units (Système international d'unités).

The title page should include the title of the article (no more than 85 characters, including spaces), full name of the author(s), affiliation (institution name and address) of each author clearly identified; linked to each author by use of superscript numbers, corresponding author's full name, telephone, and e-mail address.

Abstract. The authors are obliged to prepare two abstracts - one in English and one (translated) in Slovene language. For foreign authors translation of the abstract into Slovene will be provided.

The content of the abstract should be structured into the following sections: purpose, methods, results, and conclusion. It should only contain the information that appears in the text as well. It should contain no reference to figures, tables and citations published in the main text, and should not exceed 250 words.

Beneath the abstract, the authors should supply appropriate keywords (3-6) in English and in Slovene. For foreign authors the translation of the abstract into Slovene will be provided.

The main text should contain a coherent and logical structure preferably following the IMRAD format (Introduction, Methods, Research [and] Discussion). However, other structures are also welcome (e.g. Introduction, Development and Conclusions) as long as the text maintains its logical structure and focus. Acknowledgments are optional.

The length of the articles should not exceed 9,000 words (including tables, figures, and references), double spaced, using Times New Roman font sized 12.

Tables. Each table should be submitted on a separate page in a Word document after References. Each table shall have a brief caption; explanatory matter should be in the footnotes below the table. The table shall contain means and the units of variation (SD, $\mathrm{SE}$, etc.) and must be free of nonsignificant decimal places. Abbreviations used in the tables must be consistent with those used in the text and figures. Definition symbols should be listed in the order of appearance, determined by reading horizontally across the table and should be identified by standard symbols. All tables should be numbered consecutively (Table 1, Table 2 , etc.).

Figures. Captions are required for all Figures and shall appear on a separate manuscript page, beneath table captions. Each figure should be saved as a separate file without captions and named as Figure 1, etc. Files should be submitted in ${ }^{*}$.tiff or ${ }^{*}$.jpeg format. Photographs should be saved at at least 300 dpi. Line art images should be saved at 1200 dpi. Lettering (symbols, letters, and numbers) should be between 8 and 9 points, with consistent spacing and alignment. Font face may be Serif (Minion) or Sans Serif (Myriad). Line width should be 0.5 point or greater. Any extra white or black space surrounding the image should be cropped. Ensure that subject-identifying information (i.e., faces, names, or any other identifying features) is cropped out or opaqued. Prior to publication, the author(s) should obtain all necessary authorizations for the publication of the illustrative matter and submit them to the Editorial Board. All figures should be numbered consecutively (Figure 1, Figure 2, etc.). The journal will be printed in black and white. If the paper contains graphs, we would appreciate that you also e-mail them in a separate Excel file.

\section{References}

References should be formatted according to the $\mathrm{Pu}$ blication Manual of the American Psychological Association (American Psychological Association, 2019).

The list of references should only include works that are cited in the text. Personal communications and unpublished works should only be mentioned in the text. References should be complete and contain all the authors that have been listed in the title of the original publication. If the author is unknown, start with the title of the work. If you are citing a work that is in print but has not yet been published, state all the data and instead of the publication year write 'in print.'

Reference list entries should be alphabetized by the last name of the first author of each work. Do not use footnotes or endnotes as a substitute for a reference list. Full titles of journals are required (not their abbreviations). 


\section{Citing References in Text}

One author. Tourism innovation specific is mentioned (Brooks, 2010). Thomas (1992) had concluded ...

Two authors. This result was later contradicted (Swarbrooke \& Horner, 2007). Price and Murphy (2000) pointed out...

Three or more authors. Wolchik et al. (1999) or (Wolchik et al., 1999).

If two references with three or more authors shorten to the same form, cite the surnames of the first author and of as many of the subsequent authors as necessary to distinguish the two references, followed by a coma and et al.

List several authors for the same thought or idea with separation by using a semicolon: (Kalthof et al., 1999; Biegern \& Roberts, 2005).

\section{Examples of Reference List}

Books

American Psychological Association. (2019). Publication manual of the American Psychological Association (7th ed.).

Swarbrooke, J., \& Horner, S. (2007). Consumer behaviour in tourism. Butterworth-Heinemann.

\section{Journals}

Laroche, M., Bergeron, J., \& Barbaro-Forleo, G. (2001). Targeting consumers who are willing to pay more for environmentally friendly products. Journal of Consumer Marketing, 18(6), 503-520.

Wolchik, S. A., West, S. G., Sandler, I. N., Tein, J.Y., Coatsworth, D., Lengua, L., ... Griffin, W. A. (2000). An experimental evaluation of theorybased mother and mother-child programs for children of divorce. Journal of Consulting and Clinical Psychology, 68, 843-856.

\section{Newspapers}

Brooks, A. (2010, 7 July). Building craze threatens to end Lanzarote's biosphere status. Independent. http://www.independent.co.uk/environment/ nature/building-craze-threatens-to-end -lanzarotes-biosphere-status-2020064.html

\section{Chapters in Books}

Poirier, R. A. (2001). A dynamic tourism development model in Tunisia: Policies and prospects. In Y. Aposotolopoulos, P. Loukissas, \& L. Leontidou (Eds.), Mediterranean tourism (pp. 197-210). Routledge.

\section{Conference Proceedings}

Price, G., \& Murphy, P. (2000). The relationship between ecotourism and sustainable development: A critical examination. In M. Ewen (Ed.), CAUTHE 200o: Peak performance in tourism and hospitality research; Proceedings of the Tenth Australian Tourism and Hospitality Research Conference (pp. 189202). La Trobe University.

\section{Paper Presentation}

Thomas, J. (1992, July). Tourism and the environment: An exploration of the willingness to pay of the average visitor. Paper presented at the conference Tourism in Europe, Durham, England.

\section{Theses and Dissertations}

Sedmak, G. (2006). Pomen avtentičnosti turističnega proizvoda: primer destinacije Piran (Unpublished doctoral dissertation). University of Ljubljana.

\section{Working Papers}

Salamon, L. M., Sokolowski, S. W., Haddock, M. A., \& Tice, H. S. (2013). The state of global civil society volunteering: Latest findings from the implementation of the UN nonprofitt handbook (Comparative Nonprofit Sector Working Paper No. 49). Johns Hopkins University.

\section{Web Pages}

Croatian Bureau of Statistics. (2001). Census of population, households and dwellings. http://www.dzs .hr/Eng/censuses/Census2001/census.htm

\section{Manuscript Submission}

The main manuscript document should be in Microsoft Word document format and the article should be submitted to http://academica.turistica.si/index.php/ AT-TIJ/about/submissions 



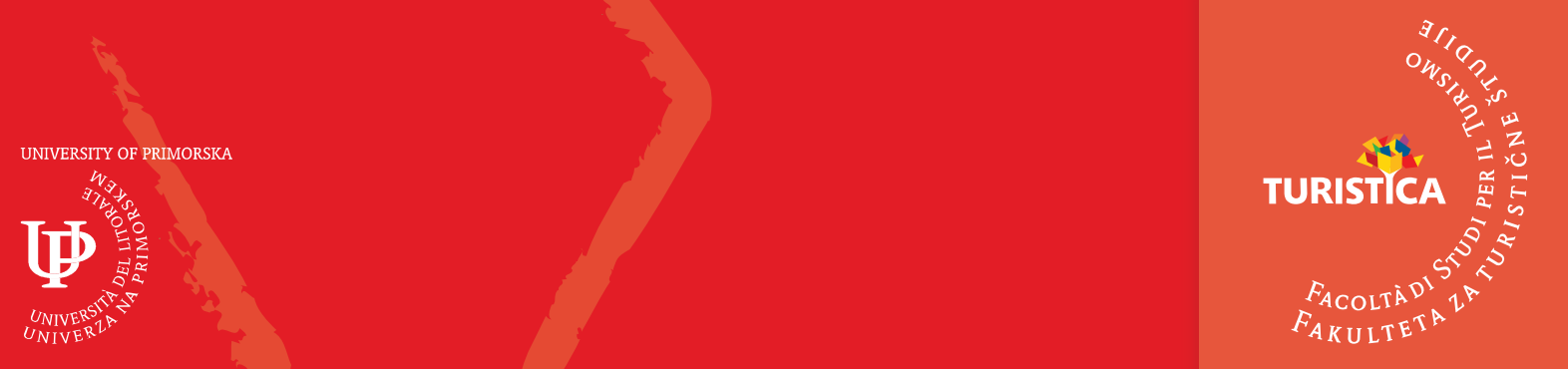